UNIVERSIDADE DE SÃO PAULO

FFCLRP - DEPARTAMENTO DE FÍSICA

RAQUEL PANTOJO DE SOUZA

MEDIDAS ÓPTICAS NÃO INVASIVAS DE TEMPO DE RESPOSTA

DA PERFUSÃO SANGUÍNEA

Ribeirão Preto - SP

2020 
RAQUEL PANTOJO DE SOUZA

\section{MEDIDAS ÓPTICAS NÃO INVASIVAS DE TEMPO DE RESPOSTA DA PERFUSÃO SANGUÍNEA}

Dissertação apresentada ao Departamento de Física da Faculdade de Filosofia, Ciências e Letras de Ribeirão Preto da Universidade de São Paulo, como parte das exigências para a obtenção do título de Mestre em Ciências.

Área de Concentração:

Física Aplicada à Medicina e Biologia.

Orientador:

Prof. Dr. George Cunha Cardoso

Ribeirão Preto - SP 
Autorizo a reprodução e divulgação total ou parcial deste trabalho, por qualquer meio convencional ou eletrônico, para fins de estudo e pesquisa, desde que citada a fonte.

Souza, Raquel Pantojo de

Medidas ópticas não invasivas de tempo de resposta da perfusão sanguínea / Raquel Pantojo de Souza; orientador Prof. Dr. George Cunha Cardoso. Ribeirão Preto - SP, 2020.

121 p. : il.

Dissertação de Mestrado - Programa de Pós-graduação em Física Aplicada à Medicina e Biologia - Faculdade de Filosofia, Ciências e Letras de Ribeirão Preto da Universidade de São Paulo. Área de Concentração: Física Aplicada a Medicina e Biologia

Orientador: George Cunha Cardoso

1 Tempo de Enchimento Capilar; 2 Fotopletismografia; 3 Monitoramento remoto não invasivo; 4 Imageamento óptico 
SOUZA R., P. Medidas ópticas não invasivas de tempo de resposta da perfusão sanguínea. Dissertação apresentada ao Departamento de Física da Faculdade de Filosofia, Ciências e Letras de Ribeirão Preto da Universidade de São Paulo, como parte das exigências para a obtenção do título de Mestre em Ciências.

Aprovado em:

\section{Banca Examinadora}

Prof. Dr. Instituição

Julgamento Assinatura

Prof. Dr. Instituição

Julgamento Assinatura

Prof. Dr. Instituição

Julgamento Assinatura

Prof. Dr. Instituição

Julgamento Assinatura 
Aos meus pais, com muito amor e gratidão, por terem me ensinado o valor da formação escolar, e sempre se empenharam e até se sacrificaram para que eu recebesse educação da melhor qualidade, por vibrarem comigo a cada conquista e por sempre me apoiarem. Se mais uma etapa de minha vida e carreira está se concluindo, devo isso a você 


\section{Agradecimentos}

Toda honra e glórias a Deus, por ter me dado sabedoria e sustento nessa fase. A todos os funcionários do Departamento de Física por me proporcionarem um ambiente de qualidade para que essa pesquisa fosse desenvolvida. Ao prof. George Cunha Cardoso, que me orientou neste trabalho e que sempre foi um exemplo de profissional da ciência e pesquisador por excelência, agradeço pela frase: "Há dois dias sabia que você estava errada mas te deixei errar", sem sua orientação, apoio e amizade nada disso seria possível. Serei eternamente grata por todos voluntários que disponibilizaram seu tempo para que essa pesquisa fosse realizada. Agradeço em especial aos meus pais: Donisete Luís de Souza e Vilma Pantojo de Souza, vó, tias (os) e primas (os) que sempre estiveram presente e me ensinaram o amor da família. A minha irmã Débora Pantojo de Souza que me ensinou a ter coragem para trilhar o caminho da pós graduação. Ao meu amor, Bassam Bachour Júnior, por estar sempre comigo me trazendo paz e motivando nas horas de desânimo. Ao Prof. Luciano Bachmann pelo apoio e orientação. Aos amigos dessa jornada, Jaqueline Fernandes, Luismar Júnior, André Riccieri, Amanda Antunes Fagundes, Dany Maia, Jéssica Lizar, Guilherme Pilotto Fernandes, Matheus Telka Golçalves, Marina Ribeiro Batistuti e Ricardo Estéfani França Rocha que em meio a cafés e conversas a ciência ia sendo desenvolvida. A Beatriz Janke pela ajuda durante as coletas. Aos funcionários do departamento de Física, Nilza Marina Leone Marino e Dona Fátima, e aos técnicos Carlos Renato e Sergio Bueno (Serginho) minha total admiração a vocês. O presente trabalho foi realizado com apoio da Coordenação de Aperfeiçoamento de Pessoal de Nível Superior - Brasil (CAPES) - Código de Financiamento 001. 
'O essencial é invisível aos olhos"

Antoine de Saint-Exupéry 


\section{Resumo}

SOUZA R., P. Medidas ópticas não invasivas de tempo de resposta da perfusão sanguínea. 121 f. Dissertação (Mestrado - Programa de Pós-graduação em Física Aplicada à Medicina e Biologia) - Faculdade de Filosofia, Ciências e Letras de Ribeirão Preto, Universidade de São Paulo, Ribeirão Preto - SP, 2020.

O interesse no uso de métodos ópticos não invasivos para a avaliação da perfusão microvascular da pele, cresceu nos últimos anos. Neste trabalho, estudamos duas técnicas ópticas para avaliação da perfusão. Para isso, utilizamos um oxímetro de dedo para medir as curvas do sinal de fotopletismográficos (sigla PPG do inglês Photoplethysmograph) e simultaneamente avaliamos a perfusão periférica, através do teste do tempo de recarga capilar (sigla CRT do inglês Capillary Refill Time). Trabalhos anteriores relatam limitações quanto a execução do teste de CRT, pois tradicionalmente é realizado de forma visual e suscetível à subjetividade de julgamento, gerando alta variabilidade entre observadores. Para contornar essas e outras limitações, estudos anteriores, realizaram o processamento das imagens durante o teste de CRT, porém não alcançaram resultados satisfatórios. Sendo assim, propomos uma metodologia baseada no uso de imagens de uma câmera digital com luz polarizada. Para isso, utilizamos uma câmera com polarizador, luz polarizada e um dispositivo para aplicar compressão, desenvolvido especificamente para este projeto. Foram recrutados 55 voluntários de 20 a 70 anos, nos quais aplicamos compressão por cerca de $5 \mathrm{~s}$ no antebraço esquerdo e adquirimos vídeos para determinar o CRT (sigla rCRT Reflection Capillary Refill Time). Os vídeos, foram processados em MATLAB. Os resultados indicam que o procedimento desenvolvido requer compressão cerca de 5 vezes menor que o especificado na literatura, além da possibilidade de medição do CRT em todo o espectro de fototipos de pele (escalas Fitzpatrick I a VI), e baixa variabilidade entre medidas repetidas. Em voluntários de pele negra (Tipo V e VI), as medidas de CRT apresentaram incertezas semelhantes às dos participantes de outros fototipos de pele (Tipo I, II, III e IV), diferentes das relatadas em outras pesquisas. Também, essa pesquisa mostrou que os valores de CRT se devem principalmente ao tempo de preenchimento de sangue total, em especial, sangue oxigenado. Observamos que o CRT é proporcional com a ativação do sistema simpático do sistema nervoso através de correlações com a variabilidade da frequência cardíaca (HRV) medida pelo oxímetro digital (PPG). Finalmente, analisamos os dados do PPG a fim de relacionar com a perfusão periférica no dedo com o fluxo sanguíneo na aorta abdominal, usando um modelo de análise de decomposição de pulso (PDA). Determinamos que, no modelo PDA, os pulsos cardíacos são melhor modelados por um conjunto de ondas de função secante hiperbólica do que por funções de onda gaussiana, como proposto na literatura. Em suma, este trabalho permite o desenvolvimento de métricas confiáveis para determinação da perfusão periférica, abrindo caminho para novas possibilidades de desenvolvimentos de equipamentos, visando diagnósticos em pacientes com problemas de perfusão periférica, como por exemplo, em pacientes diabéticos.

Palavras-chave: Tempo de Enchimento capilar; Fotopletismografia; Monitoramento remoto não invasivo; Imageamento óptico. 


\section{Abstract}

SOUZA R., P. Non-invasive optical measurements of blood perfusion response times.

121 f. Dissertação (Mestrado - Programa de Pós-graduação em Física Aplicada à Medicina e Biologia) - Faculdade de Filosofia, Ciências e Letras de Ribeirão Preto, Universidade de São Paulo, Ribeirão Preto - SP, 2020.

The interest in the use of non-invasive methods for the hemodynamic evaluation of microvascular perfusion of the skin has increased in recent years. A clinically well-established technique is the measurement of Capillary Refill Time (CRT). The limitations of CRT, which were performed only visually, include being susceptible to the subjectivity of visual judgment, which was highly variable among different evaluators, incorrect results for dark-skinned people, irritation, or sensitive skin. Previous studies to overcome these limitations with the use of cameras haven't achieved the desired results. Seeking to overcome such limitations, we propose the used methodology based on the use of images from a digital camera and, as an innovation in CRT measurements, the use of polarized light. We use a webcam with polarizers, polarized light, and a device to apply compression, developed specifically for this project. 55 volunteers from 20 to 70 years old were recruited, on whose left forearms we applied compression for about $5 \mathrm{~s}$ and acquired footage of the process, which was then processed through MATLAB scripts. The results have shown that the procedure requires compression about 5 times lower than that specified in the literature, measurement of CRT in the entire spectrum of skin colors (Fitzpatrick scales 1 to 6), and low variability in repeated measurements. In dark-skinned volunteers, CRT measurements have shown uncertainties similar to those of participants of other skin colors, unlike what is presented by other studies. We have also found that CRT is primarily determined by the time necessary to fill whole blood, mainly oxygenated blood. Also, it was observed that CRT proportional to the activation of the sympathetic system of the nervous system through correlations with heart rate variability (HRV) measured by digital plethysmograph (PPG). Finally, we analyzed the PPG data to relate peripheral perfusion in the finger to blood flow in the abdominal aorta, using a pulse decomposition analysis (PDA) model. We show that, in the PDA model, cardiac pulses are better modeled by a wave function Hyperbolic Secant than by Gaussian pulses, as proposed in the literature. In short, this work allows the development of solid metrics to determine peripheral perfusion, paving the way for new possibilities for developments aimed at diagnosing patients with peripheral diseases, such as sedentary people and people with diabetics.

Keywords: Capillary refill time; Photoplethysmography; non-invasive remote monitoring; Optical imaging 


\section{LISTA DE FIGURAS}

FIGURA 1. DIAGRAMA ILUSTRATIVO DA ESTRUTURA DA PELE HUMANA. FONTE: ADAPTADO DE BARANOSKI \& KRISHNASWAKY 2010

FIGURA 2. ILUSTRAÇÃO DA PROPAGAÇÃO DA LUZ NAS CAMADAS DA PELE. ESQUEMA UTILIZADO COMO METODOLOGIA DESSE TRABALHO. FONTE: ADAPTADO (ANDERSON; PARRISH, 1981).

FIGURA 3. DEMONSTRAÇÃO DA TÉCNICA PARA A MEDIDA DO TEMPO DE ENCHIMENTO CAPILAR NO ANTEBRAÇO DE UM PARTICIPANTE ADULTO. A) A PRESSÃO É APLICADA NO ANTEBRAÇO POR 5 - 6S PARA CAUSAR BRANQUEAMENTO. B) MUDANÇA NA COR DA PELE NA REGIÃO ONDE FOI APLICADA A PRESSÃO.

(C) RETORNO DA COR DA PELE AO NORMAL.

FIGURA 4. ESCALA DE COR CLASSIFICADA POR NÚMEROS DE 1 A 36 DA ESCALA DE VON LUSCHAN. AO LADO IMAGEM DO POSICIONAMENTO DO ANTEBRAÇO DE UM PARTICIPANTE.

FIGURA 5. A) DISPOSITIVO DESENVOLVIDO PARA A REALIZAÇÃO DO TESTE. B) APARATO CRIADO PARA POSICIONAMENTO DO PARTICIPANTE, COM FONTE DE ILUMINAÇÃO, SUPORTE PARA O INSTRUMENTO DE PRESSÃO E CÂMERA. C) FOTOGRAFIA DO POSICIONAMENTO DO VOLUNTÁRIO. LEGENDA: (1) FONTE DE ILUMINAÇÃO; (2) CÂMERA; (3) INSTRUMENTO DE PRESSÃO; (4) PONTEIRA; (5) APOIO PARA O BRAÇO.

FIGURA 6. A) POSICIONAMENTO DO PARTICIPANTE. B) ESQUEMA ILUSTRATIVO. 40

FIGURA 7. MODELO ESQUEMÁTICO DO EXPERIMENTO. APÓS 10 S DO INÍCIO DE CADA VÍDEO, FOI EXERCIDO COMPRESSÃO NO ANTEBRAÇO DO VOLUNTÁRIO POR CERCA DE 5 S. APÓS ESSE TEMPO ERA REALIZADO A LIBERAÇÃO DO INSTRUMENTO DE PRESSÃO DA SUPERFÍCIE DA PELE. O VÍDEO FOI REGISTRADO EM TODO O TEMPO, AO TÉRMINO DE 35 S SE INICIAVA OUTRA RODADA.

FIGURA 8. ESPECTRO RELATIVO DA SENSIBILIDADE DA CÂMERA (R-VERMELHO G-VERDE B-AZUL). EM CONJUNTO COM O GRÁFICO DOS COEFICIENTES DE EXTINÇÃO MOLAR DAS HEMOGLOBINAS OXIGENADAS $\left(\mathrm{HBO}_{2}\right)$ E DESOXIGENADAS (HB). INSET IMAGEM DE CADA FRAME DO VÍDEO.

FIGURA 9. A) POSICIONAMENTO DO MATERIAL BRANCO PADRÃO (MOSTRADO NA SETA) AO LADO ANTEBRAÇO DE UM PARTICIPANTE. O CÍRCULO, DELIMITA A REGIÃO DE INTERESSE (ROI) NO MOMENTO DE MÁXIMO BRANQUEAMENTO. B) RESPOSTA DA INTENSIDADE (RGB) DA REGIÃO DO BRANCO EM TODO O MOMENTO DO VÍDEO

FIGURA 10. IMAGEM DO ANTEBRAÇO DE UM PARTICIPANTE COM REGIÃO DEMARCADA DA ROI ESCOLHIDA PARA O PROCESSAMENTO DA IMAGEM. A) DURANTE O INSTANTE QUE O INSTRUMENTO DE PRESSÃO ESTÁ EM CONTATO COM A PELE; B) MUDANÇA DA COR DA PELE APÓS A RETIRADA DO INSTRUMENTO DE PRESSÃO.

FIGURA 11. IMAGEM DO ANTEBRAÇO DE UM PARTICIPANTE EM ESCALA DE CINZA COM AS CONTRIBUIÇÕES RGB DA ESQUERDA PARA DIREITA. A) COM OS POLARIZADORES PERPENDICULARES NAS POSIÇÕES: (L) E (R) E B) COM OS POLARIZADORES NAS POSIÇÕES PARALELAS (R) E (R) 
FIGURA 12- CONTRIBUIÇÃO DE CADA CANAL DURANTE 35 S DO TESTE DO RCRT ANTES, DURANTE E APÓS A COMPRESSÃO APLICADA. GRÁFICO DE UM VOLUNTÁRIO, PADRÃO SEMELHANTE FOI OBTIDO NOS DEMAIS VOLUNTÁRIOS. R- CANAL VERMELHO, G- CANAL VERDE, B- CANAL AZUL.

FIGURA 13. CURVA DO CANAL VERDE APÓS A RETIDA DO INSTRUMENTO DE PRESSÃO DE UM VOLUNTÁRIO. APÓS APROXIMADAMENTE 23 S TEM-SE UMA REGIÃO RUIDOSA 49

FIGURA 14. CURVA DO CANAL VERDE, MOSTRA O CRITÉRIO DE CORTE. A) AJUSTE POLINOMIAL DE SEXTA ORDEM (LINHA CONTÍNUA) E A FUNÇÃO EXPONENCIAL (LINHA PONTILHADA). INSET MOSTRA AJUSTE EXPONENCIAL SIMPLES ATÉ O PONTO CRÍTICO $(t c)$.

FIGURA 15. RESPOSTA DAS CONTRIBUIÇÕES: A) OXI-HEMOGLOBINA E B) DESOXI-HEMOGLOBINA DURANTE O TESTE DE ENCHIMENTO CAPILAR DE UM VOLUNTÁRIO. INSET AJUSTE COM A EQUAÇÃO 2.8. 51

FIGURA 16. CORRELAÇÃO DO TEMPO DE DECAIMENTO (110 PONTOS - CINCO REPETIÇÕES DE 22 VOLUNTÁRIOS) DA CURVA HBO ${ }_{2(C R T)}$ E RCRT. A) AJUSTE LINEAR COM R² $=0.66$ E CORRELAÇÃO DE PEARSON=0.81. ÁREA DEMARCADA REPRESENTA BANDA DE CONFIANÇA DE 95\%. B) ANÁLISE BLANDALTMAN, LINHA CHEIA SIMBOLIZA A MÉDIA DA DIFERENÇA E LINHA PONTILHADA SÃO OS LIMITES: SUPERIOR E INFERIOR IGUAIS 1, 96.SD. TESTE T IGUAL $P=0.05$.

FIGURA 17. CORRELAÇÃO DO TEMPO DE DECAIMENTO (110 PONTOS - CINCO REPETIÇÕES DE 22 VOLUNTÁRIOS) DA CURVA DO HBR(CRT) E RCRT. A) AJUSTE LINEAR COM R² $=0.61$ E CORRELAÇÃO DE PEARSON=0.78. ÁREA DEMARCADA REPRESENTA BANDA DE CONFIANÇA DE 95\%. B) ANÁLISE BLANDALTMAN, LINHA CHEIA SIMBOLIZA A MÉDIA DA DIFERENÇA E LINHA PONTILHADA SÃO OS LIMITES: SUPERIOR E INFERIOR IGUAIS 1, 96.SD. TESTE T IGUAL P=0.14

FIGURA 18. CORRELAÇÃO DO TEMPO DE DECAIMENTO (110 PONTOS - CINCO REPETIÇÕES DE 22 VOLUNTÁRIOS) DA CURVA DO HBT(CRT) E RCRT. A) AJUSTE LINEAR COM R² $=0.58$ E CORRELAÇÃO DE PEARSON $=0.76$. ÁREA DEMARCADA REPRESENTA BANDA DE CONFIANÇA DE 95\%. B) ANÁLISE BLANDALTMAN, LINHA CHEIA SIMBOLIZA A MÉDIA DA DIFERENÇA E LINHA PONTILHADA SÃO OS LIMITES: SUPERIOR E INFERIOR IGUAIS 1, 96.SD. TESTE T IGUAL P=0.08.

FIGURA 19. A) VALORES MÉDIOS DE RCRT COM DOIS INSTRUMENTOS DE COMPRESSÃO: 7 KPA E 24 KPA. PARA 14 VOLUNTÁRIOS. A REGIÃO DEMARCADA PELA LINHA TRACEJADA VERTICAL, SEPARA O GRUPO DE VOLUNTÁRIOS DO SEXO FEMININO (P1 Á P10), DO GRUPO DE VOLUNTÁRIOS DO SEXO MASCULINO (P11 A P14). OS VALORES DE RCRT E A INCERTEZA FORAM OBTIDOS A PARTIR DO AJUSTE DA CURVA EXPONENCIAL. B) DECAIMENTO DA INTENSIDADE DO CANAL VERDE PARA O PARTICIPANTE P14 EM CADA COMPRESSÃO. .55

FIGURA 20. VALORES DE RCRT PARA AS COMPRESSÕES DE 7 KPA E 24 KPA. AJUSTE LINEAR RCRT 24 KPA $=0,63+$ $0,75 *$ RCRT 7 KPA COM CORRELAÇÃO DE PEARSON R = 0,69 E BANDA DE CONFIANÇA DE 95\%. .56

FIGURA 21. IMAGEM DO ANTEBRAÇO DO PARTICIPANTE \#P14 APÓS A RETIRADA DO INSTRUMENTO DE PRESSÃO DA PELE A) 7 KPA E B) 24 KPA.

FIGURA 22. IMAGEM DO ANTEBRAÇO DE DOIS PARTICIPANTES COM CORES DE PELE DIFERENTE A) TIPO I E B) TIPO V. REGIÃO DEMARCADA NA PELE, MOSTRA A COR DO BRAÇO ANTES DA COMPRESSÃO APLICADA E 
ABAIXO, (CE D) APÓS A LIBERAÇÃO DO INSTRUMENTO DE PRESSÃO. CURVA DO CANAL VERDE COM AJUSTE EXPONENCIAL, ATÉ O PONTO CRÍTICO $(t c)$.

FIGURA 23. BOXPLOT DA DISTRIBUIÇÃO DOS VALORES MÉDIOS DE RCRT (S) SEPARADOS POR SEXO, NA FAIXA ETÁRIA DE 20 Á 49 ANOS. RESULTADO DE TESTE ANOVA DE VARIÂNCIA DE KRUSKAL-WALLIS, NÃO APRESENTOU SIGNIFICÂNCIA, $P=0,5575$.

FIGURA 24. TENDÊNCIA DO RCRT MÉDIO COM A IDADE. AJUSTE LINEAR (LINHA CONTINUA) COM R=0.48 E P $<0.05$. BARRA DE ERRO DE CADA PONTO EXPERIMENTAL REPRESENTA O DESVIO PADRÃO DE CINCO MEDIDAS. A REGIÃO CINZA REPRESENTA O INTERVALO DE CONFIANÇA DE 95\%, DA DISTRIBUIÇÃO DOS PONTOS EM TORNO DO AJUSTE LINEAR.

FIGURA 25. TEMPO DE ENCHIMENTO CAPILAR REALIZADO PELO TESTE VISUAL POR DOIS OBSERVADORES DIFERENTES (OBSERVADOR 1 E OBSERVADOR 2) A) DISTRIBUIÇÃO DOS DADOS OBTIDOS PELO TESTE VISUAL, $\mathrm{R}^{2}=51$ B) ANÁLISE BLAND-ALTMAN, LINHA CHEIA SIMBOLIZA A MÉDIA DA DIFERENÇA E LINHA PONTILHADA SÃO OS LIMITES: SUPERIOR E INFERIOR IGUAIS 1,96.SD.

FIGURA 26. MEDIDAS DO TEMPO DE ENCHIMENTO CAPILAR REALIZADO PELO TESTE VISUAL POR DOIS OBSERVADORES DIFERENTES (OBSERVADOR 2 E OBSERVADOR 3) A) DISTRIBUIÇÃO DOS DADOS B) ANÁLISE BLAND-ALTMAN, LINHA CHEIA SIMBOLIZA A MÉDIA DA DIFERENÇA E LINHA PONTILHADA SÃO OS LIMITES: SUPERIOR E INFERIOR IGUAIS 1,96.SD.

FIGURA 27. MEDIDAS DO TEMPO DE ENCHIMENTO CAPILAR REALIZADO PELO TESTE VISUAL POR DOIS OBSERVADORES DIFERENTES (OBSERVADOR 1 E OBSERVADOR 3). A) DISTRIBUIÇÃO DOS DADOS. B) ANÁLISE BLAND-ALTMAN, LINHA CHEIA SIMBOLIZA A MÉDIA DA DIFERENÇA E LINHA PONTILHADA SÃO OS LIMITES: SUPERIOR E INFERIOR IGUAIS 1, 96.SD

FIGURA 28. DISTRIBUIÇÃO DE 110 VALORES DE RCRT (5 REPETIÇÕES DE 22 PARTICIPANTES). A TENDÊNCIA DOS PONTOS SEGUE UMA DISTRIBUIÇÃO NORMAL (LINHA EM VERMELHO). B) HISTOGRAMA DA RESPOSTA DO COEFICIENTE DE VARIAÇÃO DAS MEDIDAS, CALCULADO PELA RAZÃO ENTRE A INCERTEZA DO AJUSTE DA CURVA $\left(\Sigma_{1}\right)$ E O VALOR DE RCRT DADO: $\Sigma_{1} /$ RCRT1, PARA CADA UMA DAS 110 MEDIDAS.

FIGURA 29. VALORES DO TESTE DO TEMPO DE ENCHIMENTO CAPILAR PELO MODO DE REFLEXÃO (RCRT) EM RELAÇÃO AO COEFICIENTE DE VARIAÇÃO. INSET MOSTRA ZOOM DO INTERVALO DO COEFICIENTE DE VARIAÇÃO ( 0-20 \%), NESTE, LINHA PONTILHADA DELIMITA A POSIÇÃO DE 10\% PONTO ESCOLHIDO PARA O CRITERIO DE REJEIÇÃO. OS PONTOS MOSTRAM PARTICIPANTES DE DIFERENTES FOTOTIPOS 65

FIGURA 30. DISTRIBUIÇÃO DO CV EM RELAÇÃO AO RCRT PONDERADO PELA MÉDIA DE CADA VOLUNTÁRIO. QUADRADO PONTOS ANTES DA EXCLUSÃO DO CRITÉRIO DE REJEIÇÃO E CÍRCULO APÓS A ANÁLISE DE REJEIÇÃO (REJEITADO 24 PONTOS). $\triangle$ É INTERVALO DE INCERTEZA A SER CONSIDERADO NESSE ESTUDO. NOTAR QUE OS PONTOS EXPERIMENTAIS ESTÃO DISPOSTOS EM POSIÇÕES ALEATÓRIAS DIFERENTES NO EIXO HORIZONTAL EM CADA BOXPLOT (ORIGIN 9.0 TRIAL VERSION).

FIGURA 31. INTENSIDADE NO TEMPO DOS CANAIS RGB COM OBSTRUÇÃO DE CERCA DE $40 \mathrm{~S}$, COM OBSTRUÇÃO: A) 20 MMHG E B) 40 MMHG. A SETA MOSTRA MOMENTO DE LIBERAÇÃO DA OBSTRUÇÃO. 
FIGURA 32. PROTOCOLO USADO PARA O TESTE DA OBSTRUÇÃO.

FIGURA 33. VALORES MÉDIOS DO ÍNDICE DE ERITEMA (EI) ADQUIRIDO A PARTIR DO VÍDEO DO ANTEBRAÇO DE 7 VOLUNTÁRIOS SEM OBSTRUÇÃO(ESTADO NORMAL), COM OBSTRUÇÃO DE 20 MMHG E 40 MMHG, COM DURAÇÃO DE $30 \mathrm{~S}$.

FIGURA 34. VALORES MÉDIOS DO ÍNDICE DE ERITEMA (EI) ADQUIRIDO A PARTIR DO VÍDEO DO ANTEBRAÇO DE 7 VOLUNTÁRIOS SEM OBSTRUÇÃO (ESTADO NORMAL), COM OBSTRUÇÃO DE 20 MMHG E 40 MMHG, COM DURAÇÃO DE $60 \mathrm{~S}$.

FIGURA 35. RCRT EM RESPOSTA COM O AUMENTO DA OCLUSÃO COM DURAÇÃO DE 60 S EM 6 PARTICIPANTES.

FIGURA 36. CONTORNO DO PULSO DE PRESSÃO QUE SE PROPAGA NO SISTEMA CIRCULATÓRIO. AORTA PROXIMAL, ARTÉRIAS FEMORAL E RADIAL, ARTERÍOLA E CAPILAR. FONTE: ADAPTADO (HALL; GUYTON, 2011).

FIGURA 37. MODELO DA FORMAÇÃO DO SINAL DE PPG. ARCO AÓRTICO COM AS ARTÉRIAS PRINCIPAIS E SENTIDO DA ONDA TRANSMITIDA (T), ONDA REFLETIDA (R) DEVIDO AOS SÍTIOS DE BIFURCAÇÃO. FONTE: ADAPTADO (MILLASSEAU ET AL., 2002; ELGENDI, 2012).

FIGURA 38. MODELO ESQUEMÁTICO DA VARIAÇÃO DA ATENUAÇÃO DA LUZ NO TECIDO SEPARADO PELAS COMPONENTES AC E DC. A) INTERAÇÃO DA LUZ EM CADA CAMADA E GRÁFICO DA TRANSMISSÃO APRESENTA AUMENTO NA DIÁSTOLE E DIMINUIÇÃO NA SÍSTOLE. B) GRÁFICO DE ABSORÇÃO DO SINAL DE FOTOPLETISMOGRAFIA NO TEMPO DO SINAL OBTIDO PELO OXÍMETRO NO DEDO ESQUERDO DE UM VOLUNTÁRIO DA PESQUISA, PICOS MÁXIMOS DE ABSORÇÃO NA SÍSTOLE E MÍNIMO NA DIÁSTOLE. FONTE: ADAPTADO (TAMURA ET AL., 2014)

FIGURA 39. A INTENSIDADE DE LUZ INCIDENTE IO QUE SE PROPAGA A UMA DISTÂNCIA (A) ATÉ ATINGIR O MEIO (D), A PARTIR DESSE PONTO, A INTENSIDADE DECAI EXPONENCIALMENTE COM A DISTÂNCIA DE PENETRAÇÃO DEVIDO A ABSORÇÃO DO MEIO. A INTENSIDADE DE LUZ (I) É DETERMINADA PELA LEI DE BEER-LAMBERT A PARTIR DESSE PONTO, SE MANTÉM CONSTANTE ATÉ ATINGIR O FOTODETECTOR. FONTE: ADAPTADA (WEBSTER, 1997).

FIGURA 40. MODELO ESQUEMÁTICO DE UM DISPOSITIVO OXÍMETRO MEDIDO NA PONTA DO DEDO A) TIPO DE TRANSMISSÃO E B) MODO REFLEXIVO. 80

FIGURA 41. ESBOÇO DO SISTEMA ARTERIAL E SEU EFEITO NA FORMA DO PULSO DE PRESSÃO NA ARTÉRIA RADIAL. LEGENDA: (1) ARCO AÓRTICO (2) AORTA TORÁCICA (3) ARTÉRIA RENAL (4) AORTA ABDOMINAL (5) ARTÉRIA ILÍACA (6) ARTÉRIA BRAQUIAL. DOIS LOCAIS DE REFLEXÃO NAS ARTÉRIAS RENAIS (3), OUTRO NA VIZINHANÇA DA BIFURCAÇÃO ILÍACA (5), DÃO ORIGEM AOS PULSOS REFLETIDOS (P1 E P2) QUE ACOMPANHAM A EJEÇÃO PRIMÁRIA DO VENTRÍCULO ESQUERDO. FONTE: ADAPTADA (LATHAM ET AL., 1985; BARUCH ET AL., 2011).

FIGURA 42. A) CURVA DO PPG DE UM VOLUNTÁRIO, B) DETALHE DE (A), PARA CADA PULSO FORAM AJUSTADAS TRÊS ONDAS COM GAUSSIANAS, E DEPOIS TRÊS ONDAS SECANTE HIPERBÓLICA. C) AJUSTES DE UM PULSO DE PPG E TEMPOS DE ATRASO $(\Delta t 0,1 \mathrm{E} \Delta t 0,2)$ ENTRE OS PICOS DAS ONDAS. .86 
FIGURA 43. MÉDIA DOS TEMPOS DE ATRASOS $\Delta t 0,1 \mathrm{E} \Delta t 0,2$ DE VINTE PULSOS SUBSEQUENTES PARA 42 PARTICIPANTES. VALORES OBTIDOS POR DOIS AJUSTES, SECANTE HIPERBÓLICO E GAUSSIANO. A) $\Delta t 0,1$ B) $\Delta t 0,2$.

FIGURA 44. VARIABILIDADE ENTRE OS TEMPOS: A) $\triangle T 0,1 \mathrm{E}$ B) $\triangle T 0,2$. CADA PONTO SIMBOLIZA A MÉDIA DOS 20 VALORES DA DIFERENÇA ENTRE CADA TEMPO DE ATRASO DE 42 PARTICIPANTES. 90 FIGURA 45. CURVAS DE PPG PARA TRÊS PARTICIPANTES DO SEXO FEMININO, COM ASPECTOS TÍPICOS PARA AS IDADES MOSTRADAS.

FIGURA 46. DISTRIBUIÇÃO DOS VALORES DO TEMPO DE ATRASO $(\Delta$ T0,2) COM A IDADE, OBTIDOS PELAS FUNÇÕES: A) GAUSSIANA E B) SECANTE HIPERBÓLICA DE 42 PARTICIPANTES DO SEXO FEMININO (DIAMANTE VERMELHO) E MASCULINO (QUADRADO EM PRETO) DISTRIBUÍDOS EM DIFERENTES FAIXAS ETÁRIAS: 20 A 30 , 30 A 50 E 50 A 70 ANOS. CADA PONTO REPRESENTA A MÉDIA DO TEMPO DE ATRASO $\Delta$ T0,2 DE 20 PULSOS SUBSEQUENTES.

FIGURA 47. AJUSTE LINEAR DA RELAÇÃO FUNCIONAL DO RMSSD COM RCRT CORRIGIDO PELO HR (EQ.4.1). RESPOSTA PARA 22 VOLUNTÁRIOS. 97

FIGURA 48. AJUSTE LINEAR DA RELAÇÃO FUNCIONAL DO SDNN COM RCRT CORRIGIDO PELO HR (EQ.4.1).......98 FIGURA 49. A) IMAGEM DA ESPECIFICAÇÃO DA FONTE CALIBRADA MERCÚRIO/ARGÔNIO OCEAN OPTICS COM RAIAS ENTRE 253-922 NM. B) ESPECTRO. 110

FIGURA 50. ESPECTRO DA LÂMPADA LED SEM (LINHA CONTÍNUA) E COM (LINHA PONTILHADA) POLARIZADOR CIRCULAR.

FIGURA 51. TRANSMISSÃO DA LUZ NA CONFIGURAÇÃO DO POLARIZADOR CIRCULAR. 111

FIGURA 52. ESQUEMA DO POLARIZADOR CIRCULAR UTILIZADO NOS EXPERIMENTOS. EM UMA DAS FACES POSSUI POLARIZAÇÃO LINEAR E NA OUTRA FACE UM MATERIAL RETARDADOR DE QUARTO DE ONDA. ESSA CONFIGURAÇÃO VISA TRANSFORMAR A LUZ POLARIZADA LINEARMENTE EM LUZ POLARIZADA CIRCULARMENTE E VICE-VERSA.

FIGURA 53. MONTAGEM EXPERIMENTAL PARA VERIFICAR POSICIONAMENTO DOS POLARIZADORES. TESTE DE MODO DE TRANSMISSÃO. A) ESQUEMA DO POSICIONAMENTO DOS POLARIZADORES B) IMAGEM DO EXPERIMENTO.

FIGURA 54. MONTAGEM EXPERIMENTAL PARA VERIFICAR O POSICIONAMENTO DOS POLARIZADORES, POSICIONAMENTO MODO DE REFLEXÃO. A) ESQUEMA DO POSICIONAMENTO DOS POLARIZADORES B) IMAGEM DO EXPERIMENTO.

FIGURA 55. ESPECTRO DA LÂMPADA LED OBTIDO PELO ESPECTRÔMETRO, REALIZANDO MONTAGEM DO TESTE DO MODO DE TRANSMISSÃO.

FIGURA 56. ESPECTRO DA LÂMPADA LED OBTIDO PELO ESPECTRÔMETRO, REALIZANDO A MONTAGEM DO TESTE DO MODO DE TRANSMISSÃO VARIAÇÃO DE ÂNGULOS PEQUENOS 115

FIGURA 57. ESPECTRO DA LÂMPADA LED OBTIDO PELO ESPECTRÔMETRO, REALIZANDO O EXPERIMENTO DO TESTE DE MODO DE REFLEXÃO. 
FIGURA 58. ESPECTRO DA LÂMPADA DE XENÔNIO UTILIZADA NA ENTRADA DO MONOCROMADOR NESTE É POSSÍVEL OBSERVAR UM PICO CARACTERÍSTICO DE ALTA INTENSIDADE NA FAIXA DE 450-550 NM. ......117 


\section{LISTA DE TABELAS}

TABELA 1- CARACTERÍSTICA DOS 42 PARTICIPANTES. F-FEMININO, M-MASCULINO, IMC-ÍNDICE DE MASSA CORPÓREA, SBP-PRESSÃO SISTÓLICA, DBP-PRESSÃO DIASTÓLICA, HR-FREQUÊNCIA CARDÍACA. ................36 TABELA 2. CLASSIFICAÇÃO DOS FOTOTIPOS DA PELE COM A ESCALA DE FITZPATRICK E VON LUSCHAN EM RELAÇÃO A QUEIMADURA E BRONZEAMENTO DA PELE. FONTE: ADAPTADO PATHAK, 2004 E SACHDEVA, 2009 (PATHAK, 2004; SACHDEVA, 2009).

TABELA 3. COEFICIENTES DE EXTINÇÃO PARA OS TRÊS CROMÓFOROS DA PELE NOS TRÊS COMPRIMENTOS DE44 TABELA 4. VALORES MÉDIOS DE RCRT OBTIDOS PELO AJUSTE EXPONENCIAL DA CURVA DO CANAL VERDE UTILIZANDO OS INSTRUMENTOS DE COMPRESSÃO DE 7 KPA E 24 KPA PARA 14 VOLUNTÁRIOS E OS VALORES DA PRESSÃO ARTERIAL SISTÓLICA E DIASTÓLICA......

TABELA 5. VALORES DE CRT OBTIDOS PELO MÉTODO CONVENCIONAL 61

TABELA 6. RESULTADO DOS INTERVALOS DE INCERTEZA ( $\triangle$ ) PARA 86 PONTOS APÓS A EXCLUSÃO DOS VALORES DE COEFICIENTE DE VARIAÇÃO - $\Sigma_{1} /$ RCRTI >10\%. .67

TABELA 7. ALGUNS DOS FATORES QUE AFETAM A AMPLITUDE DO PULSO DE PPG .80

TABELA 8. CARACTERÍSTICA DOS 42 PARTICIPANTES. F-FEMININO, M-MASCULINO, IMC-ÍNDICE DE MASSA CORPÓREA, SBP-PRESSÃO SISTÓLICA, DBP-PRESSÃO DIASTÓLICA, HR-FREQUÊNCIA CARDÍACA. 84 TABELA 9. VALORES MÉDIOS DA VARIABILIDADE $\delta \triangle T 0$, I ONDE I=1,2. MEDIDOS EM 40 PARTICIPANTES. 'SE: ERRO PADRÃO.

TABELA 10. ESPECIFICAÇÕES CONFORME FORNECEDOR DO POLARIZADOR. 112

TABELA 11. MAPA DE CORRELAÇÃO DOS VALORES ADQUIRIDOS NO EXPERIMENTO. DADOS DE 22 PARTICIPANTES 


\section{Sumário}

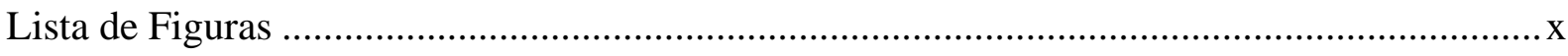

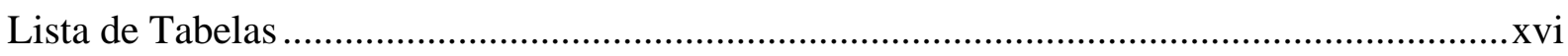

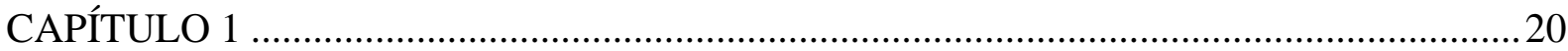

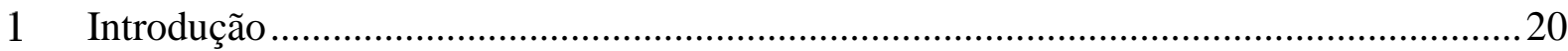

$1.1 \quad$ A pele

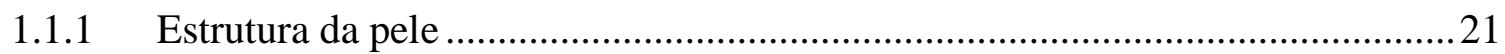

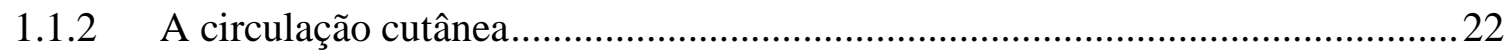

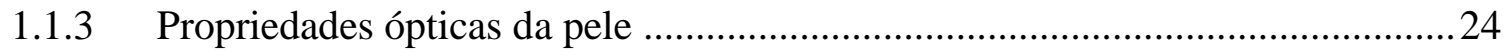

1.2 Técnicas de avaliação da perfusão periférica ......................................................2

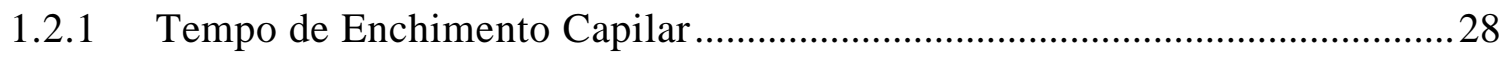

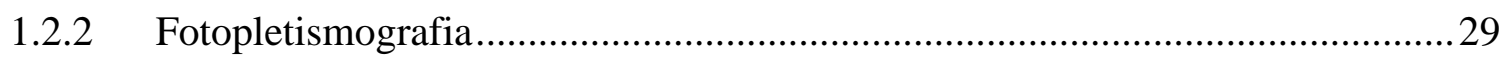

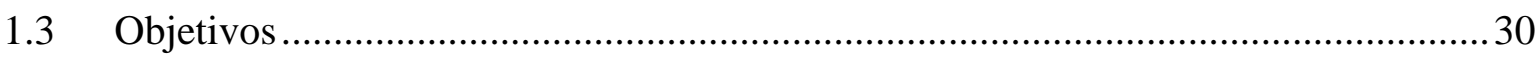

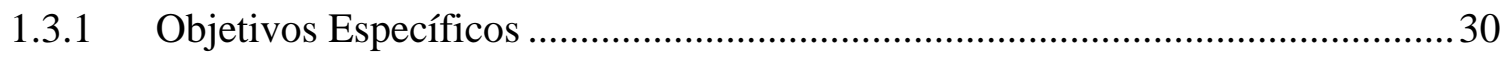

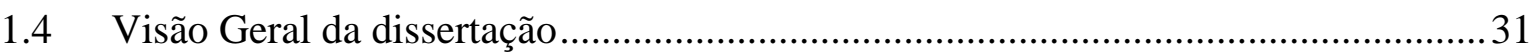

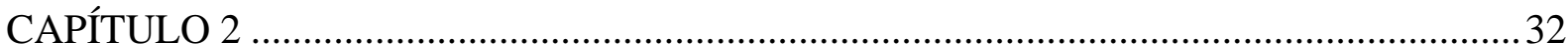

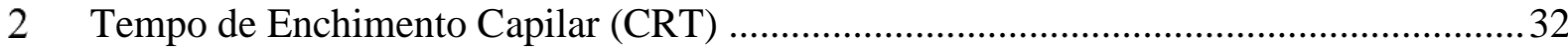

2.1 Fatores limitantes no teste do Tempo de enchimento capilar ..................................33

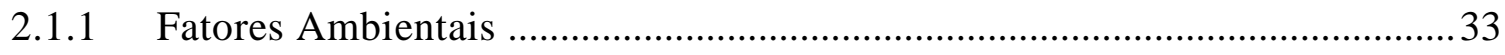

2.1.2 Intensidade e região de aplicação .................................................................... 34

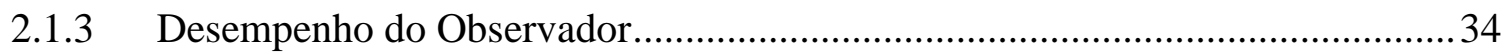

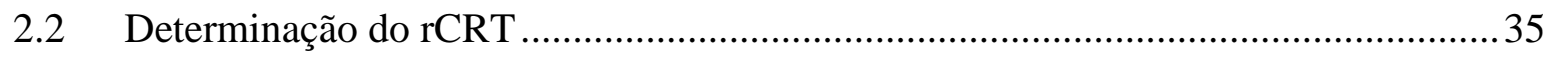

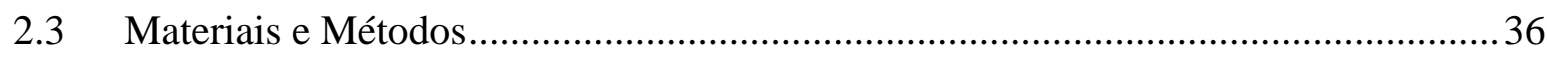

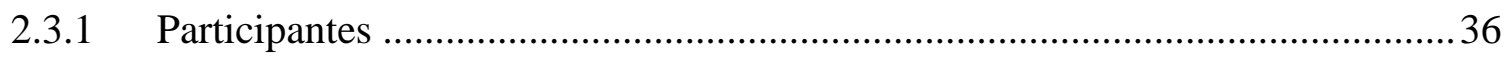

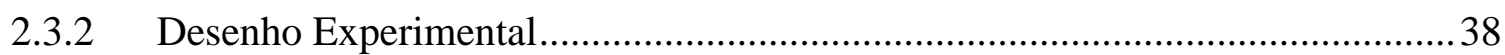




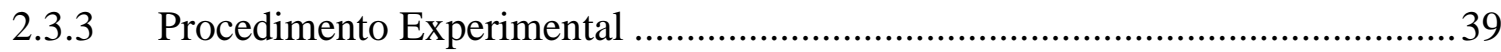

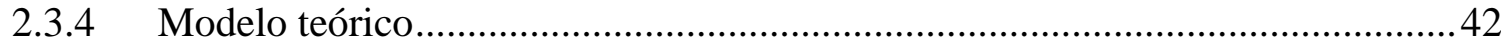

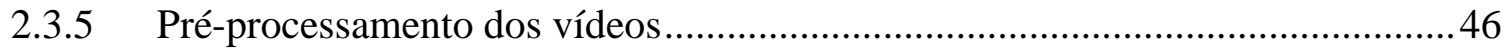

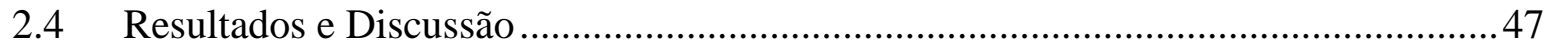

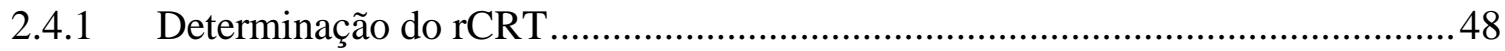

2.4.2 Investigação: $\mathrm{rCRT}$ versus $\mathrm{HbO}_{2}$, $\mathrm{Hbr}$ e $\mathrm{Hbt}$....................................................50

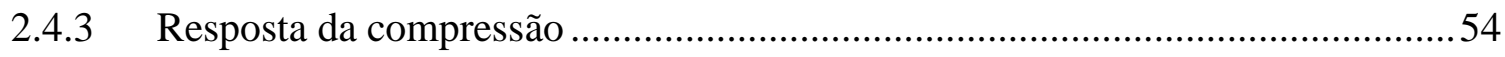

2.4.4 rCRT com diferentes fototipos de pele ........................................................... 58

2.4.5 Dependência do rCRT com sexo e idade.....................................................59

2.4.6 Relação do teste de rCRT na avaliação inter-observadores ...............................62

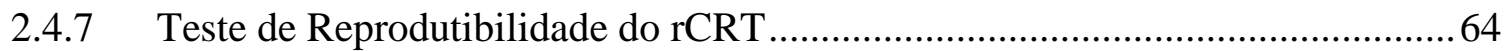

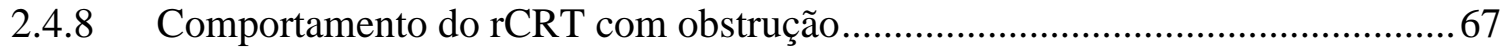

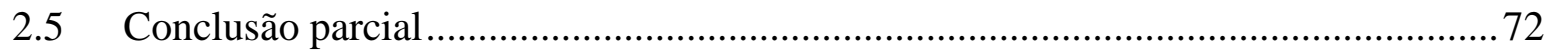

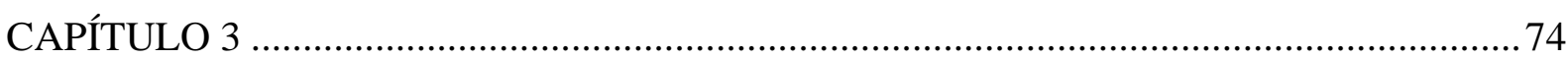

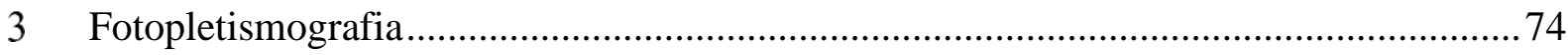

3.1 Fisiologia do Sinal fotopletismográfico......................................................... 74

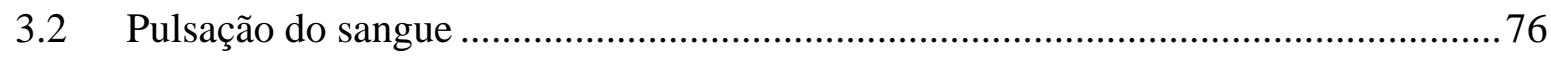

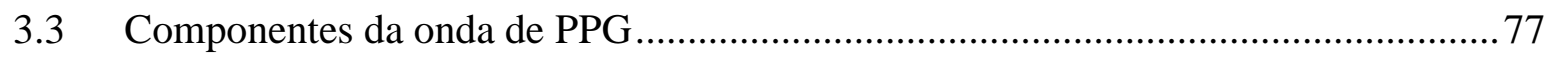

3.4 Modos de operação da fotopletismografia ......................................................... 78

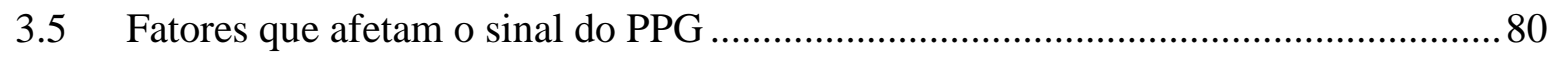

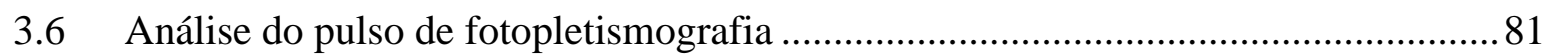

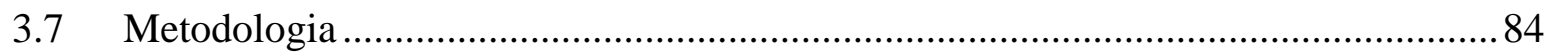

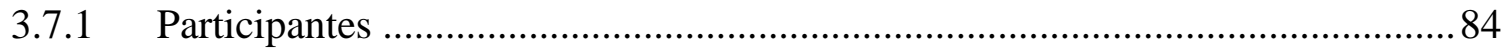

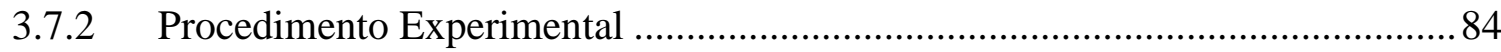

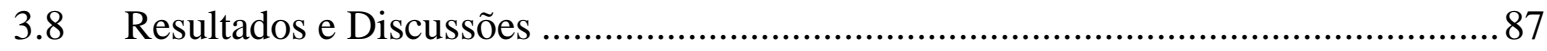

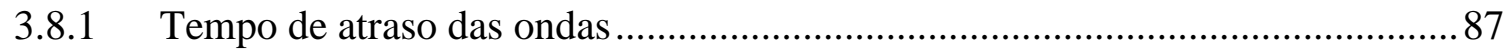


3.8.2 Variabilidade das medidas dos tempos de atraso.

3.8.3 Análise do tempo de atraso $(\Delta \mathbf{t 0}, 2)$ com a idade .......................................... 91

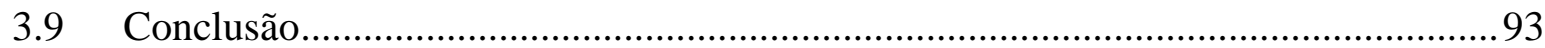

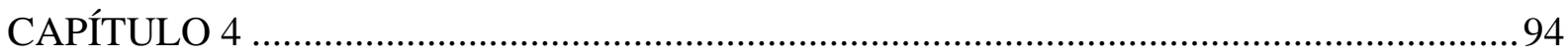

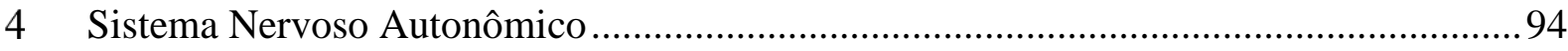

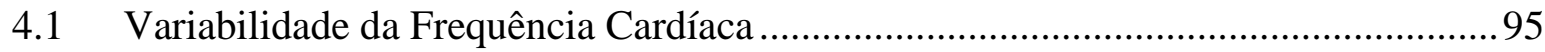

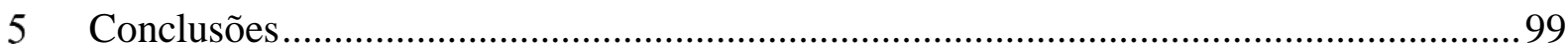

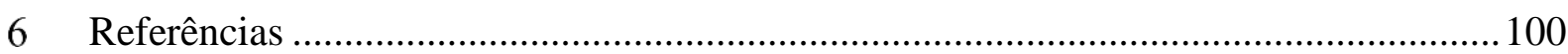

7 Apêndice A - Caracterização dos Equipamentos ......................................................... 110

7.1 Metodologia para caracterização da Fonte de iluminação ........................................110

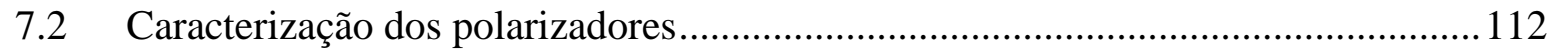

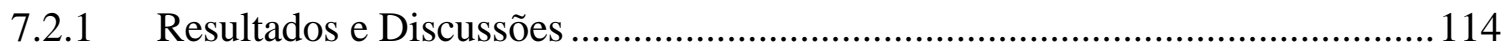

7.3 Metodologia para determinação da Curva de Sensibilidade da Câmera ..................116

Apêndice B -Resultado da Correlação ................................................................................ 118

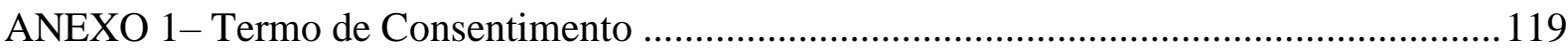

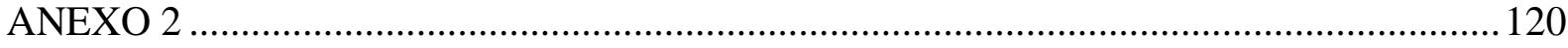

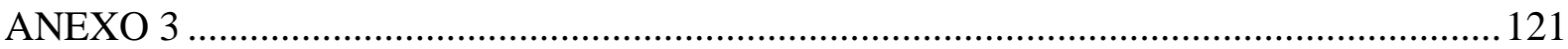




\section{CAPÍTULO 1}

A investigação das mudanças nas propriedades ópticas da cor da pele tem sido analisado por anos como complemento subjetivo na detecção e diagnóstico de doenças (IGARASHI; NISHINO; NAYAR, 2007; EVERETT; BUDESCU; SOMMERS, 2012). No entanto o sucesso desses trabalhos depende do conhecimento adequado do comportamento da luz no tecido. Neste capítulo serão apresentados os conceitos sobre a estrutura da pele, suas características e funcionalidades. A partir desses conceitos, é possível entender algumas técnicas ópticas utilizadas nesse estudo para avaliação da perfusão da periférica.

\section{Introdução}

\subsection{A pele}

A pele é o maior órgão do corpo humano e o tecido mais externo, representa cerca de $8 \%$ do peso corporal. Mudanças na cor da pele, por serem de fácil observação visual, possuem alto impacto em diversos campos da ciência e tecnologia, em particular, pesquisas nas áreas de computação gráfica, cosméticas e na medicina (IGARASHI; NISHINO; NAYAR, 2007; EVERETT; BUDESCU; SOMMERS, 2012).

$\mathrm{Na}$ área médica, pesquisas sobre a pele tem sido proposto na área vascular na abordagem de novas metodologias de quantificação da função microcirculatória, associada a diversas doenças, como, por exemplo: Diabetes Mellitus Tipo 2 (STEWART et al., 2004; SOKOLNICKI et al., 2007); esclerose sistêmica (BOIGNARD et al., 2005); envelhecimento primário (SCHRIGER; BARAFF, 1988; HOLOWATZ; THOMPSON-TORGERSON; KENNEY, 2008) doença renal (STEWART et al., 2004) e cardiovascular (STEWART et al., 2004).

A pele desempenha várias funções, essas variam de acordo com o indivíduo, como: idade, sexo e fototipo. Como, por exemplo, a quantidade de melanina presente na estrutura da pele em diferentes indivíduos é um fator modificador da capacidade de absorção de luz ultravioleta. Pessoas idosas perdem flexibilidade e resistência da pele devido à desnaturação da 
estrutura. A principal função da pele é atuar como barreira para o meio externo. Dessa forma, protege o corpo contra feridas (causadas por atrito e impacto), bactérias, vírus e luz ultravioleta. Também evita perda de água e regula a temperatura do corpo pelo fluxo sanguíneo por meio da evaporação do suor. Além disso, a pele possui muitas fibras e terminações nervosas que permitem atuar como órgão sensorial (IGARASHI; NISHINO; NAYAR, 2007).

\subsubsection{Estrutura da pele}

Como mostra a Figura 1, a pele apresenta uma estrutura complexa, composta por várias camadas com: células, fibras, veias, capilares e nervos que formam redes, e também possui pelos sobre a superfície. O padrão histológico da pele pode ser definido a partir das três camadas que a compõem: epiderme, derme e hipoderme. A epiderme é um epitélio de revestimento e encontra-se firmemente acoplada ao tecido conjuntivo do qual recebe suporte, a derme. Abaixo da derme reside outro tecido conjuntivo, a hipoderme, que contém gordura (Figura 1).

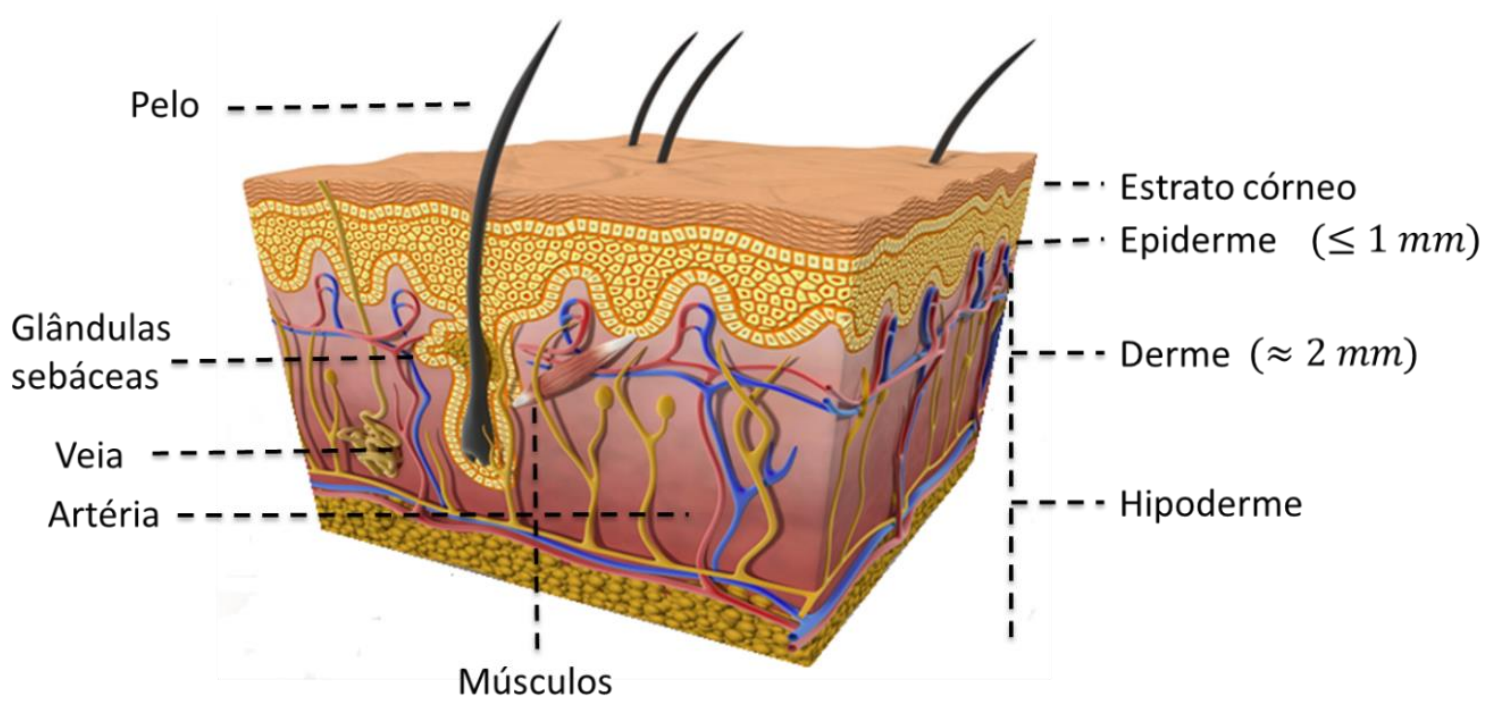

Figura 1. Diagrama ilustrativo da estrutura da pele humana. Fonte: adaptado de Baranoski \& Krishnaswaky 2010.

A epiderme é formada por camadas de células compactadas. Sua espessura varia de 0.027-0.15 mm (WELLER; HUNTER; MANN, 2015). Essa não contém vasos sanguíneos e recebe os nutrientes da derme (WELLER; HUNTER; MANN, 2015). Histologicamente, a epiderme consiste em quatro tipos de células: queratinócitos, melanócitos, células de Merkel e 
Células de Langerhans. Essas estão dispostas em quatro estratos: córneo, granuloso, espinhoso e basal.

O estrato córneo é a camada mais superficial, e tem como função atuar como barreira contra substâncias químicas e microrganismos, sua estrutura é repleta de queratina. O estrato granuloso localiza-se entre as camadas: córnea e espinhosa. E o estrato basal contém: as célulastronco da epiderme, células de Merkel que são células especializadas com função neuroendócrina, responsáveis pela sensação tátil e os melanócitos responsáveis pela produção de melanina (WELLER; HUNTER; MANN, 2015).

Os melanócitos são células que podem sintetizar melanina, para isso, oxidam a tirosina em 3,4-di-hidroxifenilalanina (DOPA) através da enzima tirosinase e transformam a DOPA em melanina (do grego melas, negro), um pigmento pardo-amarelado a marrom-escuro. A melanina concentra-se sobre o núcleo, protegendo o material genético da radiação ultravioleta (WELLER; HUNTER; MANN, 2015).

A derme $(0,6-3 \mathrm{~mm})$ é a parte interna formada pela camada de tecido conjuntivo. $\mathrm{Na}$ qual se encontra os anexos da pele, os vasos sanguíneos, linfáticos e os nervos, conforme observado na Figura 1. Sua função é representada pela flexibilidade e elasticidade. A superfície externa da derme é irregular. Essas saliências são conhecidas como papilas dérmicas que aumentam a área de contato derme-epiderme, fazendo com que a pele tenha maior resistência (BARANOSKI; KRISHNASWAMY, 2010).

As camadas da pele têm estruturas, constituições e características fisiológicas diferentes. Por exemplo, a epiderme é uma camada muito fina $(<1 \mathrm{~mm}$ em média) que consiste principalmente de células. Por outro lado, a derme é uma camada espessa ( $2 \mathrm{~mm}$ em média) composta por mais fibras em comparação com a epiderme (IGARASHI; NISHINO; NAYAR, 2007).

\subsubsection{A circulação cutânea}

Nos últimos anos houve aumento representativo no estudo da circulação cutânea a fim de examinar os mecanismos da função e disfunção microcirculatória (EVERETT; BUDESCU; SOMMERS, 2012). A camada dérmica da pele apresenta, rica rede vascular, com alto nível de perfusão. Muitas vezes o fluxo sanguíneo médio na pele é maior que o mínimo do fluxo necessário para a nutrição das células, pois esse é regulador de calor de todo o organismo. A 
circulação cutânea é o principal órgão efetor da termorregulação humana e possui alta capacidade de reserva vasodilatadora em resposta a estímulos metabólicos, térmicos e farmacológicos (HOLOWATZ; THOMPSON-TORGERSON; KENNEY, 2008).

$\mathrm{Na}$ circulação da pele, o fluxo sanguíneo oscila de $8 \mathrm{~L} / \mathrm{min}$ (ou $\pm 60 \%$ do débito cardíaco) em condições de estresse térmico intenso a quase zero em ambientes frios (CHARKOUDIAN, 2010). Esse fato evidencia a plasticidade do controle regulatório no leito vascular (STEWART et al., 2004). O nível de fluxo sanguíneo em uma dada condição ambiental ou de exercício é controlado por uma complexa interação de reflexos e mecanismos de controle local que influenciam o fluxo sanguíneo da pele (HOLOWATZ; THOMPSON-TORGERSON; KENNEY, 2008; CHARKOUDIAN, 2010).

A fração de volume de sangue no tecido humano pode variar aproximadamente entre 0,2\% e 7\% (BARANOSKI; KRISHNASWAMY, 2010). O aumento do fluxo sanguíneo leva ao aumento do volume sanguíneo da pele, devido à disposição de dois plexos venosos próximos à superfície da pele. Os vasos sanguíneos da pele estão dispostos em dois plexos: camada superficial, e profunda, paralelos à superfície da pele. A maioria dos vasos se situam no plexo superficial dentro de 1 a $2 \mathrm{~mm}$ da superfície e consiste em arteríolas de alta resistência, capilares e vênulas. O fluxo sanguíneo através dos capilares é controlado por arteríolas altamente inervadas. As arteríolas consistem em um revestimento de células endoteliais e são cercadas por duas camadas de células do músculo liso. A camada interna das células do músculo liso vascular é arranjada longitudinalmente dentro da arteríola, enquanto a camada externa é arranjada como uma espiral. O segundo plexo está localizado na interface das camadas dermehipoderme. Em geral, os vasos desse plexo são de maior diâmetro que os do plexo superior e contêm quatro ou cinco camadas de músculo liso vascular. O plexo inferior é formado por vasos perfurantes dos tecidos mais profundos e dá origem a arteríolas ascendentes que se conectam ao plexo superior e a vasos laterais aos folículos capilares e glândulas sudoríparas (JOHNSON; MINSON; KELLOGG, 2014).

O sangue é um tecido conjuntivo em forma líquida no corpo humano e compõe cerca de $8 \%$ do peso corporal total. O sangue é composto por aproximadamente: $55 \%$ de plasma, menos que $1 \%$ de glóbulos brancos e plaquetas, e 44-45\% de eritrócitos (ou glóbulos vermelhos). Os glóbulos brancos fornecem proteção e imunidade contra infecções e doenças, as plaquetas impedem a perda de sangue reparando lesões (coagulação) e os glóbulos vermelhos transportam nutrientes e resíduos do metabolismo (TORTORA; DERRICKSON, 2014). 
Os glóbulos vermelhos possuem formato bicôncavo que garante grande área de superfície usada na difusão de moléculas e gases, em sua estrutura possui uma proteína chamada hemoglobina (SCANLON; SANDERS, 2007; TORTORA; DERRICKSON, 2014). Cada glóbulo vermelho contêm aproximadamente 300 milhões de moléculas de hemoglobinas (SCANLON; SANDERS, 2007; TORTORA; DERRICKSON, 2014).

A hemoglobina é uma proteína presente na maioria dos vertebrados, que dá aos glóbulos vermelhos a capacidade de transportar oxigênio (SCANLON; SANDERS, 2007). A molécula de hemoglobina consiste em uma proteína com estrutura globular chamada globina, que compreende quatro cadeias polipeptídicas (duas cadeias $\alpha$ e duas cadeias $\beta$ ) e um pigmento não proteico em forma de anel chamado heme ligado a cada das quatro cadeias. No centro de cada heme, há um íon de ferro $\left(\mathrm{Fe}^{+2}\right)$ que pode combinar reversivelmente com uma molécula de oxigênio, permitindo que cada molécula de hemoglobina se ligue a quatro moléculas de oxigênio (KIM et al., 2010). A hemoglobina possui diferentes formas, definidas como derivados da hemoglobina. Os derivados mais comuns da hemoglobina são: hemoglobina oxigenada $\left(\mathrm{HbO}_{2}\right)$ e a hemoglobina desoxigenada $(\mathrm{Hb})$. A hemoglobina oxigenada é uma molécula de hemoglobina ligada ao oxigênio, enquanto a hemoglobina desoxigenada não está ligada ao oxigênio. Geralmente, na veia, mais de $47 \%$ da hemoglobina é oxigenada, já nas artérias, 90-95\% da hemoglobina é oxigenada (ANGELOPOULOU, 1999; KIM et al., 2010). $\mathrm{A} \mathrm{HbO}_{2}$ e a $\mathrm{Hb}$, serão estudados a seguir pois são moléculas absorvedores de luz e partir da sua concentração na pele permitem inferir informações sobre o nível de oxigenação do tecido.

\subsubsection{Propriedades ópticas da pele}

As diferenças fisioanatômicas das camadas da pele, geram grandes influências na propagação da luz nessas camadas e levam a efeitos ópticos diferentes. Essas diferenças permitem visualizar as camadas (epiderme e derme) como a principal via óptica para descrever as propriedades ópticas dos componentes presentes (IGARASHI; NISHINO; NAYAR, 2007).

A propagação da luz em tecidos biológicos é influenciada por múltiplos processos fotobiofísicos. Em cada camada da pele, as propriedades ópticas e visuais diferem significativamente, pois dependem das características fisiológicas. O feixe de luz ao entrar em contato com a pele é refletido diretamente (reflexão especular), ou absorvido e espalhado. Por exemplo, o comportamento do espalhamento da luz nas células e fibras depende do tamanho e 
forma de cada estrutura. A propagação de luz nas camadas epiderme e derme são diferentes, pois suas estruturas, densidades e espessuras apresentam alta diferença. A reflexão na superfície da pele é influenciada pelas características morfológicas, como rugas e cor da pele que variam de pessoa a pessoa (IGARASHI; NISHINO; NAYAR, 2007; BARANOSKI; KRISHNASWAMY, 2010).

O princípio físico do método utilizado neste projeto se baseia na forma a qual a luz interage com a pele (Figura 2). A imagem adquirida pela câmera é uma combinação dos espectros de absorção do sangue arterial oxigenado e desoxigenado; do leito do tecido microvascular e de outros parâmetros externos (movimentação do antebraço do participante) e depende principalmente do comprimento de onda da luz incidente (MOÇO; STUIJK; DE HAAN, 2016). Supondo um simples feixe incidente na superfície da pele, há reflexão em sua superfície e a penetração da luz é retro espalhada após espalhamento. O retorno da luz após espalhamento interno ocorre quando o feixe de luz já atravessou a epiderme e parte da derme. O feixe de luz que penetra na pele é espalhado múltiplas vezes, despolarizado-se.

Quando o feixe de luz alcança a superfície de pele (estrato córneo), cerca de 4\% da luz incidente é refletida, causada pela diferença do índice de refração entre o ar $(n=1,0)$ e a superfície da pele (estrato córneo $\mathrm{n}=1,55$ ) (ANDERSON; PARRISH, 1981; KOLLIAS; STAMATAS, 2002), essa reflexão não se dá como um espelho perfeito, devido à rugosidade da camada. Sendo assim, a luz incidente reflete em uma série de ângulos diferentes ao ângulo de entrada (Figura 2). Esse fenômeno é responsável pelo brilho observado na pele humana. A maior parte da luz incidente penetra as primeiras camadas e é absorvida ou espalhada de forma aleatória.

Durante a penetração, a luz pode interagir com os constituintes da pele de maneira a alterar sua direção (KOLLIAS; STAMATAS, 2002). A pele possui compostos químicos absorvedores de luz, chamados cromóforos (ANDERSON; PARRISH, 1981; KOLLIAS; STAMATAS, 2002; STAMATAS et al., 2004; IGARASHI; NISHINO; NAYAR, 2007). Os cromóforos são moléculas que absorvem energia eletromagnética com eficiência característica dada pelo coeficiente de extinção $(\varepsilon)$ da molécula em função do comprimento de onda $(\lambda)$ (STAMATAS et al., 2004). A pele, possui três cromóforos primários: melanina (mel); hemoglobina oxigenada $\left(\mathrm{HbO}_{2}\right)$ e Hemoglobina desoxigenada $(\mathrm{Hb})$, os dois últimos permitem inferir informações sobre o nível de oxigenação do tecido (ANDERSON; PARRISH, 1981; STAMATAS et al., 2004). A melanina e a hemoglobina são especialmente importantes para entender a aparência da pele normal, uma vez que absorvem a luz particularmente na faixa 
visível do espectro eletromagnético (YOON et al., 1987). Cada um deles possuem espectros de absorção específicos (ANDERSON; PARRISH, 1981; BARANOSKI; KRISHNASWAMY, 2010).

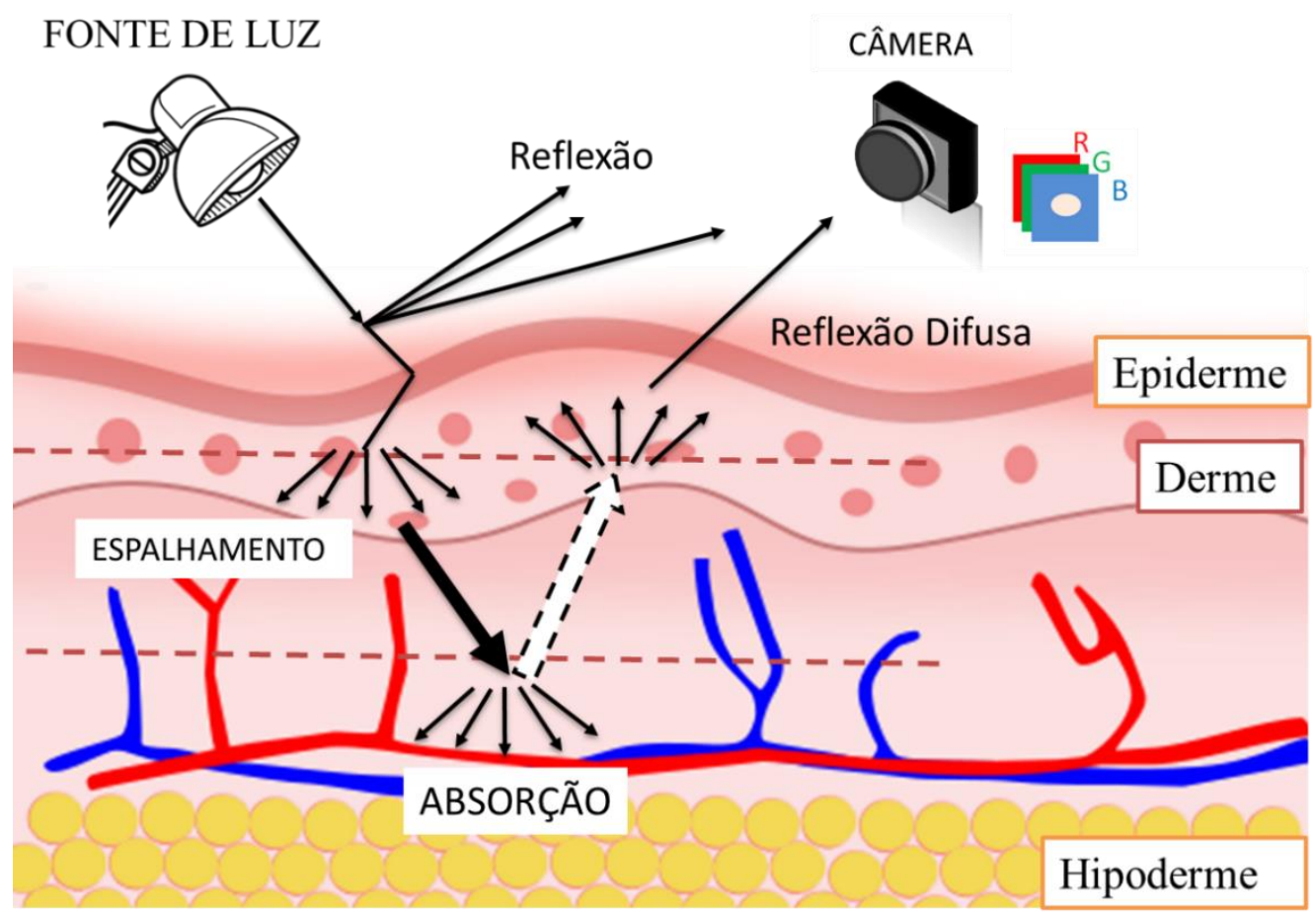

Figura 2. Ilustração da propagação da luz nas camadas da pele. Esquema utilizado como metodologia desse trabalho. Fonte: adaptado (ANDERSON; PARRISH, 1981).

A hemoglobina, discutida na seção anterior, absorve luz e dá ao sangue sua cor avermelhada. Mapas de distribuição dos cromóforos da pele podem fornecer informações qualitativas e quantitativas sobre a gravidade da patologia (ANDERSON; PARRISH, 1981).

A melanina apresenta alta absorção na luz visível e na radiação ultravioleta (UV) (ANDERSON; PARRISH, 1981). A melanina tem dois subtipos: eumelanina e a feomelanina; a eumelanina apresenta uma cor marrom-escura, geralmente encontrada no cabelo preto e nos olhos; enquanto a feomelanina apresenta uma coloração vermelho-amarelada encontrada no cabelo vermelho varia significativamente de indivíduo para indivíduo (ANDERSON; PARRISH, 1981; CHO et al., 2014) (THODY et al., 1991; IGARASHI; NISHINO; NAYAR, 2007; CHO et al., 2014).

$\mathrm{O}$ aumento da mudança no escurecimento da pele é relacionado com a distribuição e concentração de melanina na epiderme (STAMATAS; KOLLIAS, 2004). Em indivíduos de 
pele branca a fração de volume da melanossomas (organelas especializadas na síntese de melanina) na epiderme é entre $1 \%$ e $3 \%$ já em indivíduos de pele negra é maior que $43 \%$ (IGARASHI; NISHINO; NAYAR, 2007). Embora a melanina seja responsável pela cor da pele e é facilmente caracterizada por seus máximos de absorção mesmo o olho treinado possui limitações na detecção de mudanças sutis da pele, pois o olho apresenta resposta logarítmica à intensidade da luz e possui melhor desempenho quando se tem regiões de alto contraste, por exemplo, uma lesão eritematosa ou pigmentada próximo de uma região normal (KOLLIAS; STAMATAS, 2002).

\subsection{Técnicas de avaliação da perfusão periférica}

Conforme descrito na Seção anterior, o sangue transporta oxigênio e nutrientes para os tecidos, garantindo boa oxigenação dos mesmos. Entretanto, alterações no sistema circulatório que cursam vasoconstrição, geram redução na quantidade de sangue nos tecidos supridos por tal artéria, levando a diminuição da perfusão local.

A avaliação da perfusão periférica é muito importante uma vez que fornece informações para a avaliação da circulação sanguínea local, como no caso do choque (LIMA; BAKKER, 2012; SANTOS et al., 2019). Sendo assim, a avaliação da perfusão é indissociável da avaliação hemodinâmica (RÉA-NETO et al., 2006). A avaliação pode ser realizada por métodos não invasivos e aplicada rapidamente em todo hospital. Como exemplos, indicador de instabilidade hemodinâmica em procedimentos cirúrgicos e salas de emergência (VAN GENDEREN; VAN BOMMEL; LIMA, 2012). Assim, o monitoramento da perfusão é de vital importância na prática clínica e, nas últimas décadas, várias técnicas foram desenvolvidas para a avaliação não invasiva desses parâmetros (VAN GENDEREN; VAN BOMMEL; LIMA, 2012).

Dentre as técnicas conhecidas, há um destaque no uso de métodos ópticos para essas aplicações. Neste caso, aplica-se luz em diferentes comprimentos de onda no tecido, usando as características do tecido para avaliação (PINSKY et al., 2006). Existem diferentes métodos ópticos comumente usados para monitoração da perfusão. Nesta dissertação, daremos enfoque para duas técnicas: i) Teste do Tempo de Enchimento Capilar e a ii) Técnica de oximetria, descritas a seguir. 


\subsubsection{Tempo de Enchimento Capilar}

Sinais de má perfusão periférica são respostas indicadores preliminares de instabilidade hemodinâmica ecomplicações tardias que podem levar ao óbito (LIMA et al., 2009; VALENZUELA ESPINOZA; WELSH; DUBIN, 2014a). A perfusão periférica pode ser avaliada de diversas formas, sendo a mais comum o teste do Tempo de Enchimento Capilar ou também conhecido como o Tempo de Recarga (sigla CRT, do inglês Capillary Refill Time) (VALENZUELA ESPINOZA; WELSH; DUBIN, 2014a).

O CRT foi introduzido pela primeira vez por Beecheret al. em 1947, os valores temporais foram classificados em três categorias: normal, lento e prolongado (muito lento). Em 1980, Champion (CHAMPION et al., 1980) incluiu o teste no escore de trauma projetado para avaliar a gravidade da lesão no primeiro contato com o atendimento médico (PICKARD; KARLEN; ANSERMINO, 2011).

O teste é definido como o tempo que a pele leva para recuperar a cor após uma compressão aplicada (Figura 3). O teste tradicionalmente é realizado da seguinte forma: o profissional da saúde (ou observador), aplica leve compressão com o dedo indicador na superfície da pele. A compressão deve ser suficiente para causar o clareamento ou branqueamento da pele (PICKARD; KARLEN; ANSERMINO, 2011; VALENZUELA ESPINOZA; WELSH; DUBIN, 2014b; NICKEL et al., 2018), por cerca de 5 segundos, após retirar a compressão o observador cronometra o tempo de retorno da cor da pele da região comprimida.O valor normal do tempo de recarga não é definido em adultos, alguns autores consideram valores menores que 2 segundos um tempo normal.

Geralmente o CRT é utilizado como medida na monitoração hemodinâmica, por ser um método rápido e de fácil execução na avaliação do estado circulatório (TIBBY; HATHERILL; MURDOCH, 1999). A diminuição da elasticidade da pele; o atraso no retorno da pele ao seu estado original (após de uma leve compressão); e a perda de turgor cutâneo $^{1}$ ou aumento CRT (lentidão no retorno da cor da pele aos valores originais após a

\footnotetext{
${ }^{1}$ Turgor é um conceito de avaliação do nível de hidratação cutânea. O teste é realizado, pinçando com o polegar e o indicador uma prega de pele, incluindo tecido subcutâneo. Espera-se que a prega se desfaça rapidamente, quando a prega continua elevada depois de ser puxada é um sinal de desidratação (MARIA et al., 2016).
} 
compressão) podem ser indicadores não só de desidratação (FLEMING et al., 2015), mas também de estado de choque (CHAMPION et al., 1980).
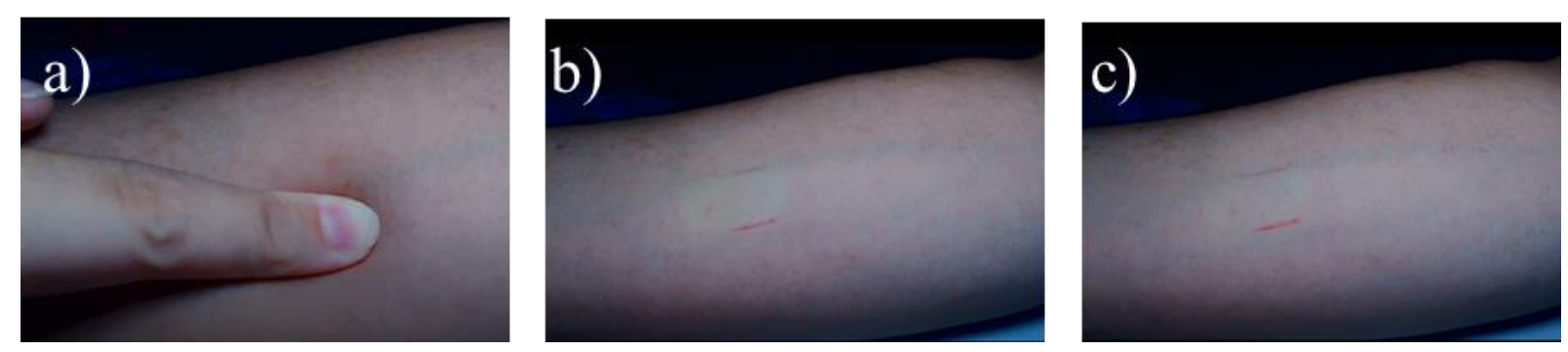

Figura 3. Demonstração da técnica para a medida do tempo de enchimento capilar no antebraço de um participante adulto. a) A pressão é aplicada no antebraço por 5 - 6s para causar branqueamento. b) mudança na cor da pele na região onde foi aplicada a pressão. (c) Retorno da cor da pele ao normal.

\subsubsection{Fotopletismografia}

A palavra pletismografia é uma combinação de duas palavras gregas 'pletismo', que significa aumento (SHELLEY, 2007) e 'grafia' que significa escrita. A fotopletismografia (PPG do inglês ) se trata da pletismografia fotoelétrica e foi originalmente introduzida na década de 1930 por Hertzman et. al (HERTZMAN; SPEALMAN, 1937). A PPG requer basicamente dois componentes optoeletrônicos, uma fonte de luz para iluminar o tecido e um fotodetector que mede pequenas variações da intensidade da luz transmitida ou refletida (depende da forma de medição), associadas a alterações na perfusão do tecido (ALLEN, 2007). A intensidade de luz varia de acordo com as mudanças de volume do fluxo de sangue tanto venoso quanto arterial, possibilitando a monitorização da saturação de oxigênio.

Esta técnica óptica permite detectar alterações no volume sanguíneo no leito microvascular dos tecidos (ELGENDI, 2012). O método é utilizado em dispositivos médicos disponíveis comercialmente, como o oxímetro de pulso (ALLEN, 2007). Os sinais vitais obtidos a partir do PPG incluem a determinação da saturação arterial de oxigênio no sangue (SpO2) (LAZARO et al., 2018); frequência cardíaca e respiratória (JOHANSSON, 2003). Além disso, possibilita o monitoramento contínuo e instantâneo destes parâmetros. Essas características permitem 
acompanhar os pacientes em estado crítico como cirurgia e em terapias intensivas com o intuito de verificar a atividade mecânica cardíaca e a saturação de oxigênio, antes que possa haver algum dano como: taquicardia, bradicardia ou cianose (coloração púrpura da pele e membranas mucosas devido a um aumento na quantidade de hemoglobina desoxigenada no sangue ou defeito estrutural na molécula de hemoglobina) (WEI et al., 2011).

No oxímetro as alterações no volume de sangue são expressas na extremidade do dedo (LAZARO et al., 2018) como uma onda de pulso, providenciando informações sobre: o batimento de origem aórtica, as características do sistema vascular, as propriedades dos vasos periféricos e o estado do fluxo sanguíneo. Assim, mudanças no formato do pulso podem estar associadas com doenças cardiovasculares (MILLASSEAU et al., 2000).

\subsection{Objetivos}

Este trabalho teve como objetivo a investigação utilizando dois métodos ópticos para avaliação da perfusão. O primeiro tem como foco principal desenvolver uma metodologia de aquisição de imagens para obtenção do CRT. No segundo, com o uso de um oxímetro de dedo convencional, foi realizado a análise de decomposição do pulso (sigla PDA, do inglês Pulse Decomposition Analysis). Aqui, nosso objetivo é o estudo da resposta pletismográfica da perfusão periférica como função da propagação do pulso cardíaco na aorta e artérias centrais.

\subsubsection{Objetivos Específicos}

- Desenvolver metodologia para quantificar do tempo de enchimento capilar com o uso de imagens digitais.

- Analisar os efeitos de compressão no antebraço.

- Investigar os efeitos do Teste de CRT em resposta da concentração da hemoglobina oxigenada e hemoglobina desoxigenada.

- Desenvolvimento de uma técnica que possibilite o estudo em diferentes fototipos de pele.

- Estudar os efeitos da obstrução no antebraço em resposta com o CRT.

- Implementar nova função de ajuste, diferente da mostrada na literatura para análise da decomposição do pulso do PPG. 
- Encontrar correlação das mudanças no sinal do PPG em resposta com o CRT.

\subsection{Visão Geral da dissertação}

Esta dissertação foi dividida em cinco capítulos e dois apêndices, aqui será apresentado uma breve descrição de cada um. O capítulo 1 aborda conceitos teóricos sobre a estrutura da pele, suas características e funcionalidades. O Capítulo 2 aborda o teste de enchimento capilar (CRT), com uma revisão sobre o teste CRT e as principais limitações. Esse capítulo também mostra a metodologia realizada para a determinação do CRT de forma reprodutível e os resultados obtidos. O Capítulo 3 aborda a técnica de fotopletismografia com a análise de decomposição de pulso (PDA). No início do capítulo é realizada uma revisão da técnica e a suas principais limitações; esse capítulo mostra ainda a metodologia e os resultados obtidos. O Capítulo 4 desenvolve buscando correlação entre mudanças na resposta da variabilidade da frequência cardíaca (HRV) e o CRT (como descrito no Capítulo 2). As conclusões finais desta dissertação são apresentadas no Capítulo 5. O Apêndice A mostra a metodologia e os resultados da calibração dos instrumentos utilizados, e o Apêndice B mostra os resultados do teste de correlação dos parâmetros estudados nessa dissertação. 


\section{CAPÍTULO 2}

A dinâmica do fornecimento de oxigênio na microcirculação da pele assume papel importante no diagnóstico de diversas doenças. Essas doenças estão relacionadas com a mudança do estado perfusional da pele, como a úlcera venosa (MATAS et al., 2001) e a neuropatia diabética (LANTING et al., 2017). No entanto, medidas absolutas da saturação de oxigênio na microcirculação da pele não são de fácil acesso (RADY; RIVERS; NOWAK, 1996; LIMA; BAKKER, 2012). Existe o crescente interesse na análise do fluxo sanguíneo e nas medidas quantitativas da microcirculação na obtenção de resultados confiáveis e reprodutíveis (VALENZUELA ESPINOZA; WELSH; DUBIN, 2014b; SHINOZAKI et al., 2019a). Neste capítulo será introduzido uma curta revisão bibliográfica da técnica utilizada na avaliação da perfusão periférica, o teste do Tempo de Enchimento Capilar.

\section{Tempo de Enchimento Capilar (CRT)}

Recentemente, o CRT tem sido sugerido como um parâmetro de perfusão sanguíneo importante na triagem de adultos (SANSONE et al., 2017). No Brasil o teste é feito em caráter mandatório em todos os casos de suspeita de dengue, e também na avaliação do estado de hidratação em crianças com diarreia (BRASIL. MINISTÉRIO DA SAÚDE., 2007; BRANDT; DE CASTRO ANTUNES; DA SILVA, 2015). Entretanto, existe a necessidade de novos estudos que relacionem o CRT com outros prognósticos. De maneira geral, o tempo de enchimento capilar pode ser indicador na avaliação do grau de urgência dos pacientes. Sansone et al. relataram associação entre CRT prolongado ( $>2$ segundos) em idosos sob condições de sepse, resultados similares foram mostrados em casos de hiperglicemia, hipertensão e alterações na quantidade de alanina e ureia (POSTELNICU; EVANS, 2017; SANSONE et al., 2017).

O grau de branqueamento causado na pele após compressão exercida possui relação direta com a perfusão do leito capilar, dependendo de fatores tais como (CLOUGH, 1999):

i. Fluxo sanguíneo capilar;

ii. Tônus arteriolar; 
iii. Propriedades do fluxo do sangue e seus elementos de plasma e células;

iv. Obstrução capilar como função da densidade capilar funcional (número de capilares que são preenchidos por glóbulos vermelhos circulantes em uma determinada área);

v. Viscosidade do sangue;

vi. Nível de Oxido Nítrico (NO) no sangue.

A compressão modifica as propriedades ópticas do tecido, causando branqueamento da pele. O tempo de recuperação das propriedades ópticas originais depende dos fatores listados acima, que por sua vez se relacionam com a saúde cardiovascular. Pelo método visual, alguns fatores são limitantes para a garantia da reprodutibilidade do teste, a seguir será mostrado alguns desses fatores.

\subsection{Fatores limitantes no teste do Tempo de enchimento capilar}

Nos últimos anos, alguns estudos vêm observando fatores que afetam a confiabilidade do teste do CRT do modo visual (TIBBY; HATHERILL; MURDOCH, 1999; PICKARD; KARLEN; ANSERMINO, 2011; SHINOZAKI et al., 2019a). O CRT pode ser medido por diferentes técnicas, porém é suscetível a fatores que podem interferir nos resultados, entretanto, essas limitações são raramente consideradas pelos profissionais que realizam o teste (VALENZUELA ESPINOZA; WELSH; DUBIN, 2014b). Os principais fatores que podem causar alta variabilidade nas medidas de CRT, são:

i. Fatores ambientais, como temperatura (GORELICK et al., 1993; SHINOZAKI et al., 2019b) e iluminação do ambiente;

ii. Fototipo de pele (BOURCIER et al., 2016);

iii. Intensidade e região de aplicação (PICKARD; KARLEN; ANSERMINO, 2011);

iv. Desempenho do observador e no cuidado na realização da medição.

\subsubsection{Fatores Ambientais}

A temperatura ambiente afeta a medição do CRT tanto em adultos como em crianças, interferindo na avaliação da perfusão sanguínea periférica (GORELICK et al., 1993; HARIRI et al., 2019). Gorelick et al. relataram CRT prolongado em crianças quando permaneceram num ambiente frio por 15 minutos (GORELICK et al., 1993). Esses resultados corroboram com o 
mostrado por Shinozaki et al., através de um dispositivo mecânico realizaram a compressão e liberação da ponta do dedo. Shinozaki et al. analisaram os resultados do CRT em três configurações de temperatura, ambiente $\left(25^{\circ} \mathrm{C}\right)$, frio $\left(15^{\circ} \mathrm{C}\right)$ e quente $\left(38^{\circ} \mathrm{C}\right)$, os resultados mostraram que no grupo em temperatura fria, houve aumento no CRT (SHINOZAKI et al., 2019b). Outro trabalho, mostrou a diminuição no CRT com o aumento da temperatura (ANDERSON et al., 2008a). Consequentemente, mudanças na temperatura ambiente, podem aumentar a variabilidade nas medidas, com isso se faz necessário a padronização da temperatura durante o teste, a fim de garantir a reprodutibilidade do teste de CRT.

\subsubsection{Intensidade e região de aplicação}

A duração ideal e a quantidade de compressão aplicada na superfície da pele para se fazer o teste de CRT são pouco padronizadas (PICKARD; KARLEN; ANSERMINO, 2011). Alguns autores sugerem a aplicação de compressão moderada por $3 \mathrm{~s}, 5 \mathrm{~s}$ ou até o branqueamento do leito capilar (GORELICK et al., 1993; VALENZUELA ESPINOZA; WELSH; DUBIN, 2014b; FLEMING et al., 2016). Strozik et al. estudaram aspectos do CRT em relação a duração da pressão aplicada, os resultados mostraram ausência de estatística significante no teste com duração entre 3 e 7 s (STROZIK; PIEPER; ROLLER, 1997). Para o presente estudo utilizamos o tempo de compressão de $5 \mathrm{~s}$, como sugerido por diversos autores (GORELICK et al., 1993; VALENZUELA ESPINOZA; WELSH; DUBIN, 2014b; FLEMING et al., 2016).

\subsubsection{Desempenho do Observador}

O teste de CRT, quando realizado pelo método convencional, possui dependência não só com diversos parâmetros citados anteriormente mas também com o olho clinico do profissional da saúde (ANDERSON et al., 2008b; VALENZUELA ESPINOZA; WELSH; DUBIN, 2014a; MARIA et al., 2016; SHINOZAKI et al., 2019a). Shinozaki et al. mostraram que o nível de treinamento do profissional é um fator importante que afeta a confiabilidade da medida (SHINOZAKI et al., 2019a). As diferenças intra-observadores podem ser afetadas pela intensidade da luz ambiente. Champion et al. já haviam relatado a dificuldade em se medir o CRT a noite. Brown et al. relataram a diferença estatística 
significante nas avaliações do CRT em ambientes escuros quando comparados com ambientes claros. Sendo assim, o teste do CRT apresenta um desafio em condições de pouca iluminação (CHAMPION et al., 1980; BROWN; PRASAD; WHITLEY, 1994).

\subsection{Determinação do rCRT}

A cor da pele pode fornecer informação sobre a oxigenação tecidual, o estado nutricional, perfusão tecidual, e muda com lesões e processos de cicatrização (EVERETT; BUDESCU; SOMMERS, 2012). Entretanto, medidas feitas a partir de julgamentos visuais apresentam incertezas, inconsistências na avaliação da cor e falta de concordância entre observadores pois adiciona fator do erro humano nas avaliações (SHINOZAKI et al., 2019a), especialmente em casos onde há uma grande concentração de melanina (MATAS et al., 2001).

O olho humano possui resposta logarítmica à diferentes níveis de intensidades de luz e é incapaz de distinguir dois cromóforos coexistindo, como por exemplo, a pigmentação da melanina sobrepondo a resposta da hemoglobina. Visualmente é impossível distinguir a contribuição de cada elemento, e, da mesma forma, quantificar a oxi-hemoglobina e desoxihemoglobina (KOLLIAS; STAMATAS, 2002; TOYODA, 2017). A fim de diminuir a subjetividade das medidas de CRT em 2020, Shinozaki et al. mostrou a possibilidade de se medir o CRT com processamento de video (RGB) da ponta do dedo indicador de pacientes, no momento da liberação da compressão da pele, a intensidade dos pixels (em escala de cinza) no tempo apresenta um decaimento. Essa queda é gradual até que em um dado ponto ocorre retorno da intensidade que se tinha antes da compressão (SHINOZAKI et al., 2020).

O uso de métodos ópticos por meio de processamento de vídeo possibilita a quantificação dos principais cromóforos e com isso, estimar as mudanças temporais nos valores de oxigenação periférica. Dessa forma, o uso de imagens por câmeras para estudo da quantificação da microcirculação periférica é bastante promissor. Neste projeto, foi investigado o tempo de enchimento capilar de imagens do antebraço de participantes com diferentes fototipos de pele e idade.

O objetivo deste trabalho é desenvolver uma metodologia para a avaliação do teste de CRT a partir da imagem de reflexão da pele, adquiridas pela câmera de vídeo, método chamado de rCRT, que será descrito a seguir, e assim, estabelecer um sistema para avaliação do CRT 
com o objetivo de minimizar as limitações apresentadas pelo teste tradicional (mostrados na seção anterior), a partir do julgamento do observador.

\subsection{Materiais e Métodos}

\subsubsection{Participantes}

Foram recrutados 42 voluntários saudáveis, 23 mulheres e 19 homens, com faixa etária de 20 a 70 anos (Tabela 1). Todos os participantes foram instruídos sobre o método e objetivos abordados e assinaram o Termo Livre Esclarecido. O Projeto foi submetido e aprovado pelo Comitê de Ética (Protocolo $n^{\circ}$ 2.926.258 da FFCLRP/USP - Anexo 1) elaborado segundo a declaração de Helsinque e aprovado pelo Comitê de ética em Pesquisa (Resolução 196/96 do Ministério da Saúde, CONSELHO NACIONAL DE SAÚDE, 1996).

Tabela 1- Característica dos 42 participantes. f-feminino, m-masculino, IMC-índice de massa corpórea, SBP-Pressão Sistólica, DBP-Pressão Diastólica, HR-Frequência Cardíaca.

\begin{tabular}{|c|c|c|}
\hline $\mathrm{N}=42$ Participantes $(23 \mathrm{f}, 19 \mathrm{~m})$ & Média & $\pm \mathrm{SD}^{*}$ \\
\hline Idade & 38 & 16 \\
\hline Altura (m) & 1.68 & 0.10 \\
\hline Peso (kg) & 71 & 15 \\
\hline $\mathrm{IMC}\left(\mathrm{kg} / \mathrm{m}^{2}\right)$ & 25 & 4 \\
\hline $\mathrm{SBP}(\mathrm{mmHg})$ & 118 & 17 \\
\hline DBP (mmHg) & 75 & 11 \\
\hline HR (BPM) & 77 & 10 \\
\hline
\end{tabular}

*SD - Desvio Padrão

Os participantes foram classificados conforme o fototipo, com a escala Von Luschan (Figura 4). Escalas que avaliam a cor de pele apresentam uma classificação subjetiva, entretanto, são utilizadas como auxilio no diagnóstico em numerosos tratamentos (SACHDEVA, 2009). Cada participante foi classificado após consenso por dois pesquisadores e separados em 6 grupos correspondentes a Escala Fitzpatrick (Tabela 2), para isso, essa 
classificação foi realizada com a observação da imagem do antebraço de duas fotos, com as luzes da sala acesas e com apenas a lâmpada de luz polarizada acesa.

\begin{tabular}{|l|l|l|l|l|l|l|l|}
\hline & 1 & 10 & & & 19 & 28 \\
\hline & 2 & 11 & & & 20 & 29 \\
\hline & 3 & 12 & & & 21 & 30 \\
\hline & 4 & 13 & & & 22 & 31 \\
\hline & 5 & 14 & & & 23 & 32 \\
\hline & 6 & 15 & & & 24 & 33 \\
\hline & 7 & 16 & & & 25 & 34 \\
\hline & 8 & 17 & & & 26 & 35 \\
\hline & 9 & 18 & & & 27 & 36 \\
\hline
\end{tabular}

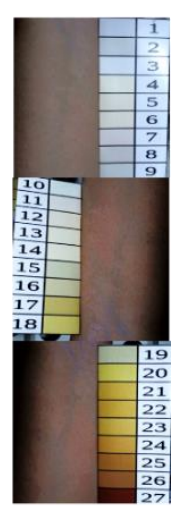

Figura 4. Escala de cor classificada por números de 1 a 36 da Escala de Von Luschan. Ao lado imagem do posicionamento do antebraço de um participante.

Tabela 2. Classificação dos fototipos da pele com a escala de Fitzpatrick e Von Luschan em relação a queimadura e bronzeamento da pele. Fonte: adaptado Pathak, 2004 e Sachdeva, 2009 (PATHAK, 2004; SACHDEVA, 2009).

\begin{tabular}{ccc}
\hline Escala Fitzpatrick & $\begin{array}{c}\text { Escala de von } \\
\text { Luschan }\end{array}$ & Queimaduras e bronzeamento \\
\hline I & $0-6$ & $\begin{array}{c}\text { Queima facilmente, mas nunca se } \\
\text { bronzeia }\end{array}$ \\
& II & Queima facilmente, se bronzeia com \\
dificuldade
\end{tabular}




\subsubsection{Desenho Experimental}

Para a realização da compressão, foi desenvolvido um dispositivo (Figura 5) em colaboração com a Oficina Mecânica do Departamento de Física. O dispositivo é composto por uma estrutura com: dois suportes posicionados em lados opostos; um cilindro oco de acrílico no centro e um apoio para o braço Figura 5(a). Nos suportes, foram acoplados a câmera (Logitech HD Pro-C910) e a fonte de iluminação (Figura 5(b)). A câmera foi posicionada para fazer imagens da região do antebraço, situada cerca de $9 \mathrm{~cm}$ da primeira linha (linha divisória da mão-antebraço) do pulso. Tanto a câmera quanto a fonte de luz são acopladas a um polarizador linear, a fim de eliminar a componente de reflexão especular da pele (GRONER et al., 1999). O cilindro de acrílico permite introduzir um instrumento de pressão com massa variada. Os instrumentos de pressão possuem um ponto de apoio para sua retirada e uma ponteira na extremidade (de Teflon) com área de contato circular de $4 \mathrm{~cm}^{2}$ para simular a pressão criada pela ponta de um dedo, como realizado no método convencional. A extremidade de Teflon com espessura de cerca de $1 \mathrm{~cm}$ serve como isolante térmico para evitar resfriamento da pele em contato com o metal a $21^{\circ} \mathrm{C}$.
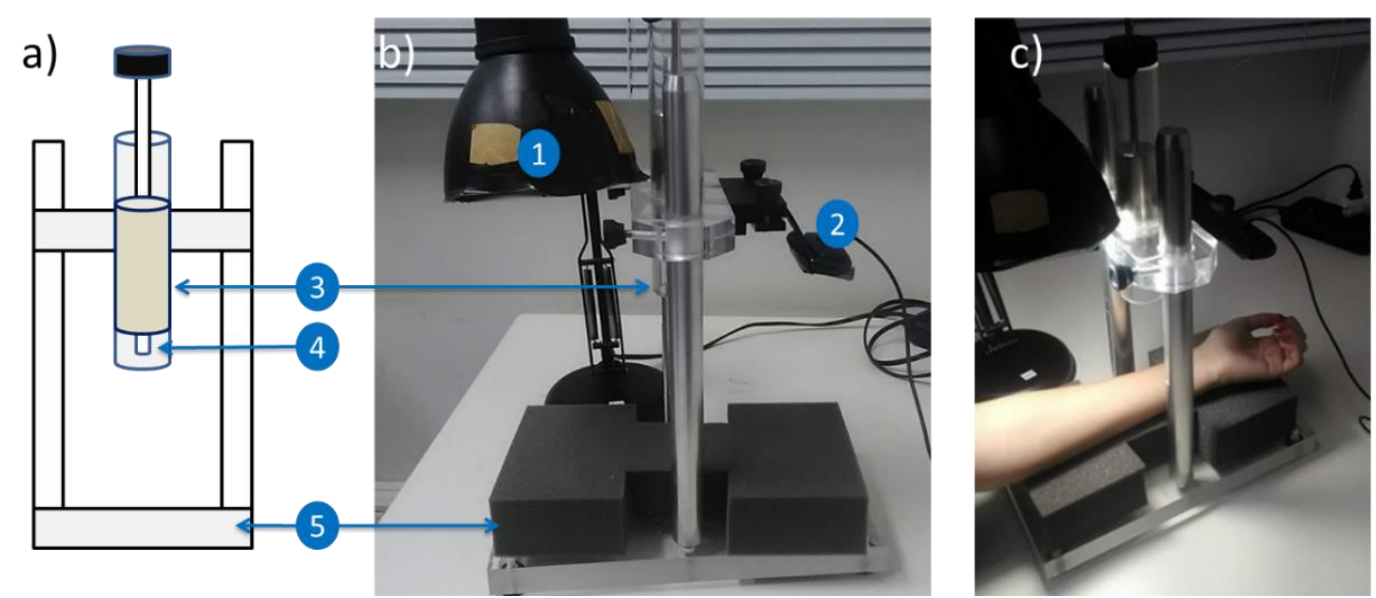

Figura 5. a) Dispositivo desenvolvido para a realização do teste. b) Aparato criado para posicionamento do participante, com fonte de iluminação, suporte para o instrumento de pressão e câmera. c) Fotografia do posicionamento do voluntário. Legenda: (1) Fonte de iluminação; (2) Câmera; (3) Instrumento de pressão; (4) Ponteira; (5) Apoio para o braço.

Os experimentos foram realizados em uma sala escura, para minimizar interferência de outras fontes de luz não polarizada. A fonte de luz escolhida para a realização dos experimentos 
foi uma lâmpada LED (Taschibra TKL 90) emitindo comprimento de onda entre 400-700 nm. A potência de saída do feixe foi de $14 \mathrm{~W}$. A fonte de luz foi ligada aproximadamente 15 minutos antes do início de cada aquisição para estabilização. A temperatura ambiente da sala foi mantida em torno de $21^{\circ} \mathrm{C}$ em todos os dias da coleta, em concordância com Pickard et al.(PICKARD; KARLEN; ANSERMINO, 2011).

Os voluntários permaneceram sentados por cerca de $10 \mathrm{~min}$, monitorados por um Oxímetro (Modelo CMS50D com saída USB) no dedo indicador esquerdo, com o braço no nível do coração. Os resultados do sinal do oxímetro serão tratados no Capítulo 3.

\subsubsection{Procedimento Experimental}

Para as medidas de rCRT, foi solicitado que o participante permanecesse sentado em posição confortável em uma cadeira com altura regulada de forma que seus pés ficassem apoiados no chão, o braço esquerdo permanecia posicionado no dispositivo criado, e a mão direita apoiada sob na coxa direita. A Figura 6(a), mostra uma fotografia do posicionamento do braço e a Figura 6(b) ilustra a configuração do posicionamento dos participantes.

Foi escolhida a região de interesse (sigla ROI do inglês Region of Interest) desse trabalho. Para isso, utilizamos uma região do antebraço esquerdo, a cerca de $9 \mathrm{~cm}$ da primeira linha do pulso, para realizar o teste.

Nosso objetivo é a avaliação da perfusão empregando dois métodos ópticos simultaneamente, o Teste do Tempo de Enchimento Capilar e o sinal de Fotopletismografia (descrito no Capítulo 3) . Para isso, foi registrado o sinal com um oxímetro de dedo na ponta do dedo indicador esquerdo. Estudos mostram menor ruído no sinal de PPG proveniente do braço esquerdo em relação com o braço direito (HICKEY; PHILLIPS; KYRIACOU, 2016). Dessa forma, a ROI escolhida garante não só alta estabilidade (menor movimentação) dos voluntários quando posicionados com o braço apoiado, mas também possibilita correlacionar os dados do teste de CRT com o sinal de PPG.

Os vídeos foram adquiridos, operando em 24 frames por segundo, armazenado em 8 bits. O processamento dos vídeos foi realizado em linguagem MATLAB (MATLAB R2015a, The MathWorks, Inc., Natick, Massachusetts, United States). Os programas escritos nessa dissertação estão disponíveis no ANEXO 3. Foram excluídos alguns vídeos onde houve movimentação significativa do antebraço do participante durante a aquisição das imagens. Após 
a obtenção das imagens, foram medidas a circunferência do antebraço, a pressão arterial e a taxa de frequência cardíaca dos participantes. Os participantes responderam um formulário de perguntas sobre a altura, pressão arterial normal, consumo de cafeína e a regularidade na realização de exercícios físicos (ANEXO 2).
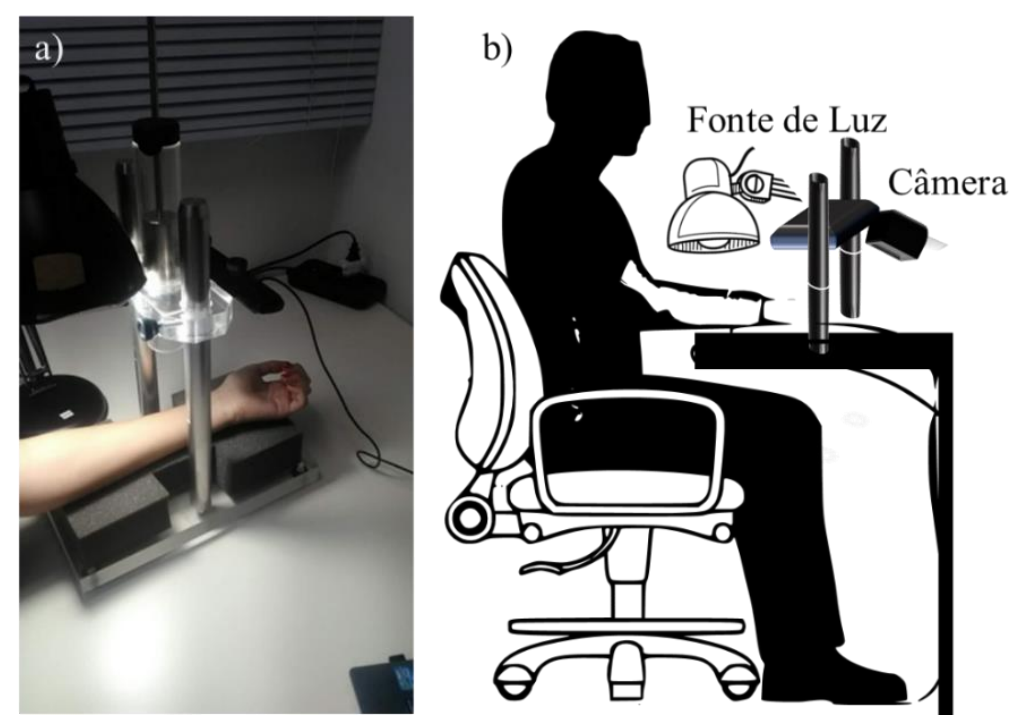

Figura 6. a) Posicionamento do participante. b) Esquema ilustrativo.

\subsubsection{Variação da compressão aplicada}

Alguns estudos mostram alta correlaçao entre a quantidade de compressão aplicada e o tempo do CRT. Savedra et al, mostraram que a compressão mais leve resultou em um CRT mais curto em criancas de 6 a 14 meses de idade (SAAVEDRA et al., 1991). Entretanto, esses exibem dados em recem nascidos ou crianças e não em adultos, como é o nosso objetivo.

Sendo assim, investigamos o comportamento do aumento da compressão durante o teste do CRT em 14 voluntários adultos. Inicialmente verificamos a quantidade de compressão aplicada pelo método tradicional do teste do CRT. Com uma balança calibrada, calculamos a compressão média exercida pela ponta do dedo. Esse teste mostrou que a compressão exercida com a ponta do dedo na superficie da pele é da ordem de $10 \mathrm{kPa}$. Com isso, desenvolvemos dois instrumentos para compressão com massas diferentes e área de contato iguais $\left(4 \mathrm{~cm}^{2}\right)$. Cada um deles exerciciam compressões no antebraço de aproximadamente $7 \mathrm{kPa}$ e $24 \mathrm{kPa}$.

As compressões foram realizadas na ROI inicialmente demarcada, após um período de espera de 10 segundos. A compressão foi aplicada de forma suave, controlada e reprodutível, 
com duração de cerca de $5 \mathrm{~s}$, tempo padronizado por outros estudos (PICKARD; KARLEN; ANSERMINO, 2011; LIMA; BAKKER, 2012). Após liberação do instrumento de pressão, registrou-se a mudança da cor da pele por $20 \mathrm{~s}$. Todo o procedimento foi realizado em duplicata em cada voluntário para cada instrumento de compressão. Entre uma medida e outra foram aguardados 2 minutos. Nesse período o voluntário permanecia com o braço abaixado paralelo ao corpo. Os resultados deste experimento serão mostrados na Seção 2.4.3.

\subsubsection{Teste de reprodutibilidade}

O teste de reprodutibilidade foi realizado em duas etapas:

Na primeira, foram adquiridos cinco vídeos sequenciais (intervalo de cerca de $30 \mathrm{~s}$ entre cada vídeo) do antebraço de cada voluntário (Figura 7). Após um período de observação de 10 s foi exercida uma compressão local de aproximadamente $7 \mathrm{kPa}$ ( instrumento com massa de 0,3kg (Figura 6), em área de $4 \mathrm{~cm}^{2}$ ) no antebraço dos voluntários de forma controlada e reprodutível, com duração de cerca de 5 s (PICKARD; KARLEN; ANSERMINO, 2011; LIMA; BAKKER, 2012). Após liberação do aparato de pressão, registrou-se a mudança da cor da pele por $20 \mathrm{~s}$. Durante todo o teste, foi armazenado o sinal gerado pelo oxímetro de dedo, posicionado no dedo indicador esquerdo dos voluntários, o resultado das curvas do sinal de fotopletismografia serão mostrados no Capítulo 3.

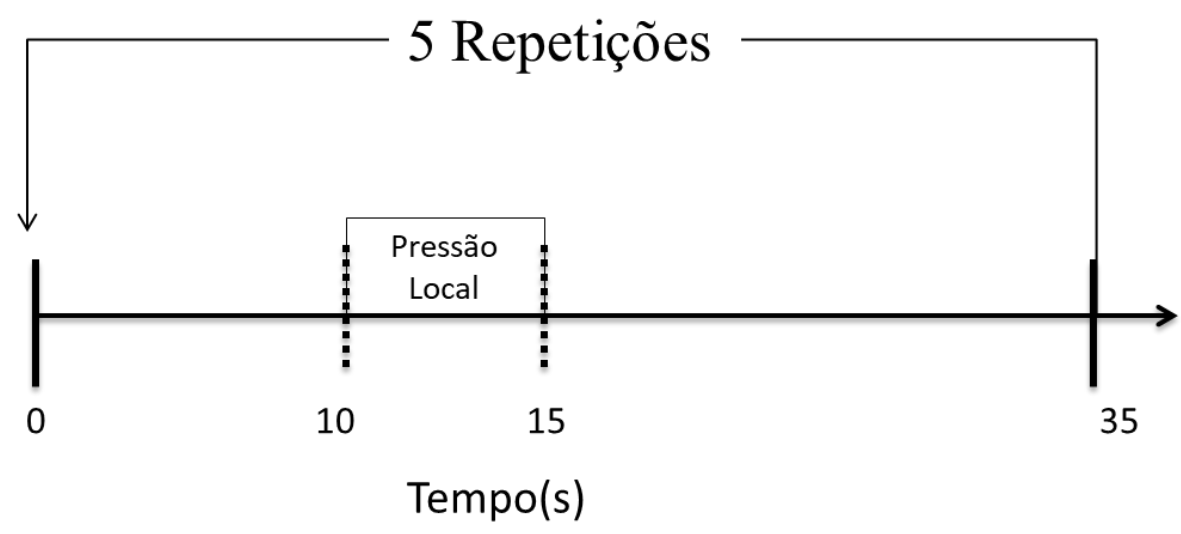

Figura 7. Modelo esquemático do Experimento. Após 10 s do início de cada vídeo, foi exercido compressão no antebraço do voluntário por cerca de 5 s. Após esse tempo era realizado a liberação do instrumento de pressão da superfície da pele. O vídeo foi registrado por $35 \mathrm{~s}$. Ao término de 35 s se iniciava outra rodada. 
A segunda etapa do teste de reprodutibilidade, foi realizado para estudar o tempo de CRT de forma visual. Para isso, três pesquisadores assistiram cada vídeo independentemente e cronometraram o tempo de retorno da cor da pele de forma visual observando os vídeos. Cada pesquisador cronometrou cada vídeo 3 vezes para análise estatística. Foi padronizado a posição em que todos os observadores fixavam o olho.

\subsubsection{Modelo teórico}

O método utilizado para a investigação do comportamento da resposta das curvas de hemoglobina oxigenada e desoxigenada em resposta com os valores do tempo de enchimento capilar, assume que a pele é constituída pelos cromóforos principais: hemoglobina oxigenada $\left(\mathrm{HbO}_{2}\right)$, desoxigenada $(\mathrm{Hb})$, e melanina (Mel). A absorção de luz pelos cromóforos leva a mudança na cor da pele (TSUMURA; HANEISHI; MIYAKE, 1998; GONG; DESVIGNES, 2012). Assim, o modelo que melhor descreve esse processo, é dado pela Lei de BeerLambert:

$$
\mathrm{I}(\lambda)=\mathrm{I}_{\mathrm{o}} 10^{-\varepsilon(\lambda) \cdot l \cdot \mathrm{C},}
$$

onde $I$ é dada pela intensidade de luz refletida no tecido, $I_{o}$ a quantidade de luz incidente, $l$ o comprimento $(\mathrm{cm})$ de interação luz-cromóforos; $C$ é a concentração molar do cromóforo $\left(\mathrm{mol} / \mathrm{cm}^{3}\right)$ e $\varepsilon$ é o coeficiente de extinção molar tabelados de cada cromóforo $\left(\mathrm{Lmol}^{-1} \mathrm{~cm}^{-1}\right)$. Os valores da intensidade da luz refletida $(I)$ de cada pixel da ROI pode ser escrito pelo modelo de absorção dos três principais de cromóforos pela lei de Beer-Lambert:

$-\log \left(\frac{\mathrm{I}(\lambda)}{\mathrm{I}_{\mathrm{ref}}(\lambda)}\right)=\varepsilon_{\mathrm{Hb}}(\lambda) l_{\mathrm{Hb}} c_{\mathrm{Hb}}+\varepsilon_{\mathrm{HbO}_{2}}(\lambda) l_{\mathrm{HbO}_{2}} c_{\mathrm{HbO}_{2}}+\varepsilon_{\mathrm{Mel}}(\lambda) l_{\mathrm{Mel}} c_{M e l}$,

onde $\left(I_{r e f}\right)$ é a intensidade de referência (Seção a seguir), e $\varepsilon_{H b}, \varepsilon_{H_{b O}}$ e $\varepsilon_{\text {Mel }}$ são os coeficientes de extinção molar (SIGEL, 1977; PRAHL'S S., 2011). Assim, as variações de cada contribuição podem ser estimadas medindo a intensidade de luz refletida da região. Em uma imagem produzida por câmera de três canais em cada pixel RGB teremos um sistema de três equações (SPIGULIS et al., 2017): 


$$
\left(\begin{array}{c}
-\log \left(\frac{I\left(\lambda_{\mathrm{R}}\right)}{I_{\text {refR }}}\right) \\
-\log \left(\frac{I_{\left(\lambda_{\mathrm{G}}\right)}}{I_{\text {refG }}}\right) \\
-\log \left(\frac{I_{\left(\lambda_{\mathrm{B}}\right)}}{I_{\text {ref } B}}\right)
\end{array}\right)=\left(\begin{array}{lll}
\varepsilon_{\mathrm{HbO}_{2}}\left(\lambda_{\mathrm{R}}\right) & \varepsilon_{\mathrm{Hb}}\left(\lambda_{R}\right) & \varepsilon_{\mathrm{Mel}}\left(\lambda_{\mathrm{R}}\right) \\
\varepsilon_{\mathrm{HbO}_{2}}\left(\lambda_{\mathrm{G}}\right) & \varepsilon_{\mathrm{Hb}}\left(\lambda_{\mathrm{G}}\right) & \varepsilon_{\mathrm{Mel}}\left(\lambda_{\mathrm{G}}\right) \\
\varepsilon_{\mathrm{HbO}_{2}}\left(\lambda_{\mathrm{B}}\right) & \varepsilon_{\mathrm{Hb}}\left(\lambda_{\mathrm{B}}\right) & \varepsilon_{\mathrm{Mel}}\left(\lambda_{\mathrm{B}}\right)
\end{array}\right)\left(\begin{array}{c}
\mathrm{C}_{\mathrm{HbO}_{2}} \\
\mathrm{C}_{\mathrm{Hb}} \\
\mathrm{C}_{\mathrm{Mel}}
\end{array}\right),
$$

onde $I_{i}$ são as intensidades normalizadas de refletância nos comprimentos de onda característicos dos canais (RGB), $\varepsilon_{\mathrm{HbO}_{2}}\left(\lambda_{\mathrm{i}}\right), \varepsilon_{\mathrm{Hb}}\left(\lambda_{\mathrm{i}}\right)$ e $\varepsilon_{\mathrm{Mel}}\left(\lambda_{\mathrm{i}}\right),(\mathrm{i}=\mathrm{R}, \mathrm{G}, \mathrm{B})$ os coeficientes de extinção da hemoglobina oxigenada e desoxigenada, da melanina para cada um dos canais. $\mathrm{C}_{\mathrm{HbO} 2}, \mathrm{C}_{\mathrm{Hb}}$ e $\mathrm{C}_{\mathrm{Mel}}$ denotam as distribuições de concentração média de uma ROI por unidade de tempo. Aqui consideramos $l_{\mathrm{i}}(\lambda)$ idêntico para os três comprimentos de onda, o que é uma aproximação. Tal aproximação permitiu embutir $l$ nas concentrações $C_{j}$ (mol/área) removendo uma variável do problema.

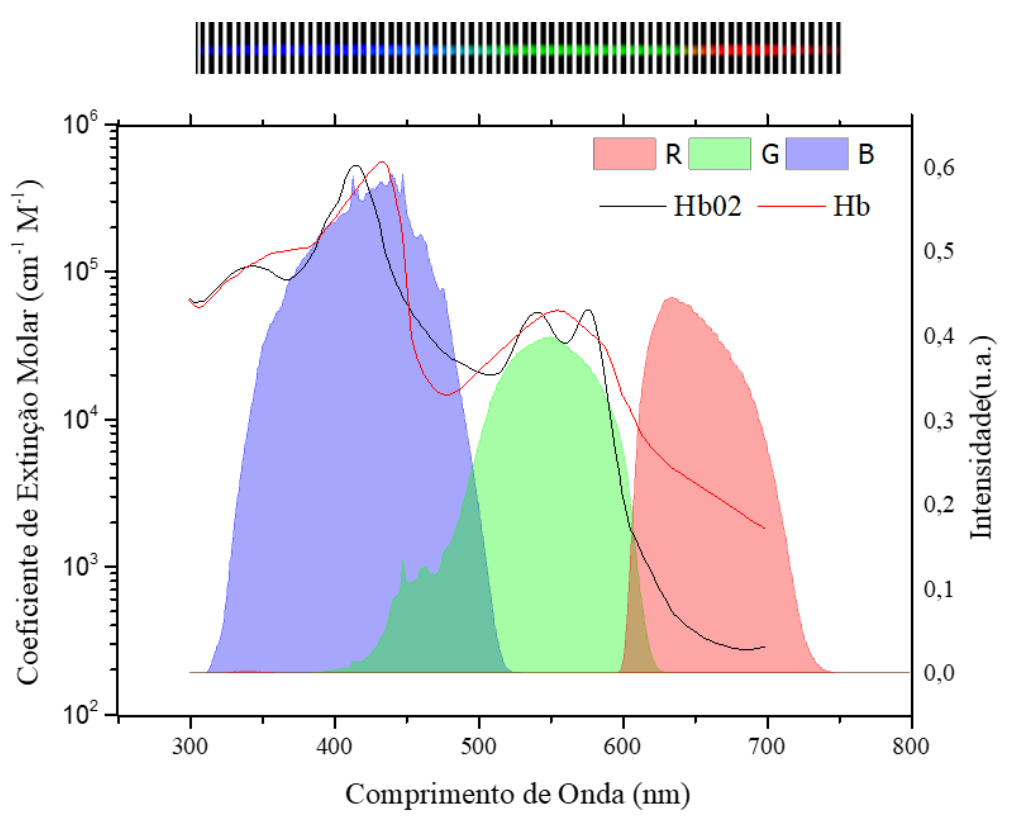

Figura 8. Espectro relativo da sensibilidade da câmera (R-vermelho G-verde B-azul). Em conjunto com o gráfico dos coeficientes de extinção molar das hemoglobinas oxigenadas $\left(\mathrm{HbO}_{2}\right)$ e desoxigenadas $(\mathrm{Hb})$. Inset (acima do gráfico) mostra imagem de cada frame do vídeo durante a rotação do monocromador.

Os coeficientes de extinção tabelados (Tabela 3) (SIGEL, 1977; PRAHL’ S S., 2011) dos três cromóforos de interesse foram selecionados a partir da curva de sensibilidade da câmera 
utilizada (Figura 8) (Mais informações, Apêndice A) apresentou picos de absorção de cada canal: $\lambda_{R}=632 \mathrm{~nm}, \lambda_{G}=550 \mathrm{~nm}$ e $\lambda_{B}=432 \mathrm{~nm}$.

Tabela 3. Coeficientes de extinção para os três cromóforos da pele nos três comprimentos de onda (RGB) (SIGEL, 1977; PRAHL'S S., 2011).

\begin{tabular}{lccc}
\hline \multirow{2}{*}{ Cromóforo } & $\boldsymbol{\varepsilon ( 6 3 2 \mathbf { n m } )}$ & $\boldsymbol{\varepsilon ( 5 5 0 ~ \mathbf { ~ m } )}$ & $\boldsymbol{\varepsilon}(\mathbf{4 3 2} \mathbf{~ n m})$ \\
\cline { 2 - 4 } & \multicolumn{3}{c}{$(\mathbf{1} / \mathbf{m o l . c m})$} \\
\hline Melanina & 709,86 & 1024,9 & 2125 \\
Oxi-hemoglobina & 561,2 & 43016 & 214120 \\
Desoxi-hemoglobina & 4930,8 & 53412 & 552160 \\
\hline
\end{tabular}

Como utilizamos os valores médios da ROI, para cada frame, podemos reescrever a Eq. (2.3) como:

$$
-\log \vec{I}(x, t)=M \vec{C}(x, t),
$$

onde $\overrightarrow{\mathrm{I}}(\mathrm{x}, \mathrm{t})$ é um vetor cujas entradas são as intensidades relativas retroespalhadas e medidas pelos canais R G e B da câmera e dependem do frame (x,t), M é uma matriz constante com os coeficientes de extinção $(\varepsilon)$ e $\vec{C}(x, t)$ são as concentrações médias por unidade de área de cada um dos três cromóforos no pontos $(\mathrm{x}, \mathrm{t})$ da imagem. Resolvendo o sistema acima é possível obter as concentrações $\mathrm{C}_{\mathrm{HbO} 2}, \mathrm{C}_{\mathrm{Hb}}$ e $\mathrm{C}_{\mathrm{Mel}}$ durante todos os frames do vídeo. Dessa maneira é possivel calcular a contribuição de hemoglobina total, esse formalismo, será usado nas análises da Seção 2.4.2.

$$
C_{\mathrm{Hbt}}=C_{\mathrm{Hb}}+C_{\mathrm{HbO}_{2}} \text {. }
$$

\subsubsection{Intensidade de referência}

O modelo físico sugere que a contribuição de cada cromóforo está relacionada com o comprimento de onda RGB, relacionado com os picos de absorção de cada cromóforo. Para se fazer a correta extração do sinal, é necessário a correção da intensidade de cada canal pela quantidade de luz que atinge a superfície da pele. Para essa investigação foram realizados dois processamentos diferentes: 
i) Correção por um papel branco, como é possível ver na Figura 9(a) (Sinalizado pela seta) e;

ii) Correção pela intensidades no momento de máximo branqueamento como mostra a Figura 9(a) delimitado pelo círculo.

a)

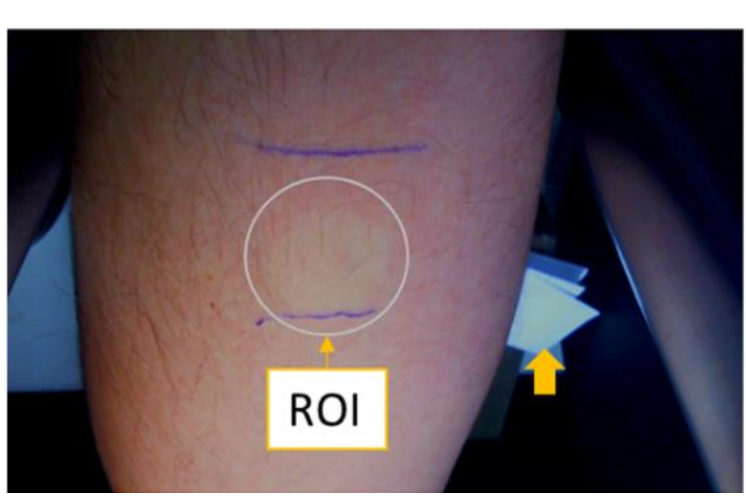

b)

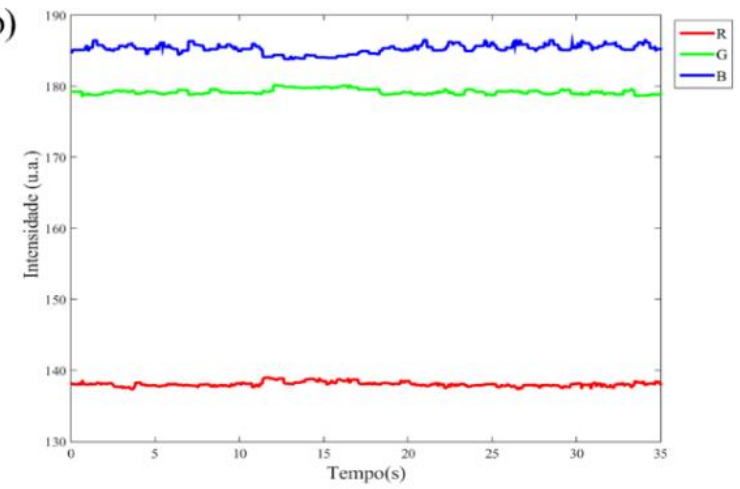

Figura 9. a) Posicionamento do material branco padrão (mostrado na seta) ao lado antebraço de um participante. $\mathrm{O}$ círculo delimita a região de interesse (ROI) no momento de máximo branqueamento. b) Resposta da intensidade (RGB) da região do branco em todo o momento do vídeo.

O material branco padrão foi posicionado ao lado do antebraço do participante. Com isso, a correção realizada por esse método modifica a intensidade de referência, de forma que:

$$
I_{\text {ref }\left(\lambda_{R G B}\right)}=I_{\text {Branco }(R G B),}
$$

onde $I_{\text {Branco }(R G B)}$ é a intensidade média dos canais RGB adquiridos no processamento das imagens com a ROI no papel.

A Figura 9(b) mostra a curva da intensidade de cada canal de uma pequena área da região do papel (material branco padrão), como é possível ver, no momento que o instrumento de pressão atinge a superfície da pele (10 - $16 \mathrm{~s})$ a intensidade do canal azul apresenta uma pequena queda, em contrapartida, os canais verde e vermelho aumentam. Isso se deve devido ao design utilizado, a referência branca ficou em regiões de penumbra do braço. O uso dos polarizadores na fonte de luz e na câmera fazem com que a imagem adquira uma coloração azulada. Esse fato explica o alto valor do canal azul na Figura 9(b) uma vez que o papel deveria refletir de igual forma para todos os três canais (RGB), entretanto, isso não ocorreu.

Para realizar o teste de forma correta, deve-se posicionar o papel ao lado da ROI e garantir as mesmas condições de iluminação. Entretanto, como durante o experimento o posicionamento foi realizado erroneamente, tomamos como referência a intensidade máxima 
de cada canal $I_{\max (\text { pele })}(R), I_{\max (\text { pele })}(G), I_{\max (\text { pele })}(B)$, no momento de máximo branqueamento (no ponto de máximo de cada canal) logo após a retirada do instrumento de pressão. Dessa forma, a intensidade de referência (Eq.2.2) é escrita como:

$$
I_{\text {ref }\left(\lambda_{R G B}\right)}=I_{\max (P E L E)(R G B)} \text {. }
$$

Utilizamos essa normalização nos resultados obtidos na Seção 2.4.2.

\subsubsection{Pré-processamento dos vídeos}

Os arquivos de vídeo foram transferidos a um computador para serem processados em MATLAB escrito especificamente para essa tarefa. Ao iniciar o programa, a primeira etapa é a detecção da ROI. Para isso, foi utilizado a função imfreehand.

A ROI escolhida foi a região do antebraço onde o instrumento de pressão tocava a superfície da pele (Figura 10). Desta forma foi criado uma máscara com a função poly2mask com o tamanho da ROI escolhida. Após é realizado a separação dos canais RGB (Red, Blue, Green) utilizando a função $\mathrm{im} 2 \mathrm{col}$ a qual faz o rearranjo da matriz em colunas. Para cada canal (RGB) foi calculado a média (mean) de intensidade de cor dos pixels de cada frame. O resultado é armazenado em uma array. Essas médias correspondem à intensidade de cor de cada canal no frame. Com isso, foi criado um vetor que converteu o número de frames em escala de tempo.
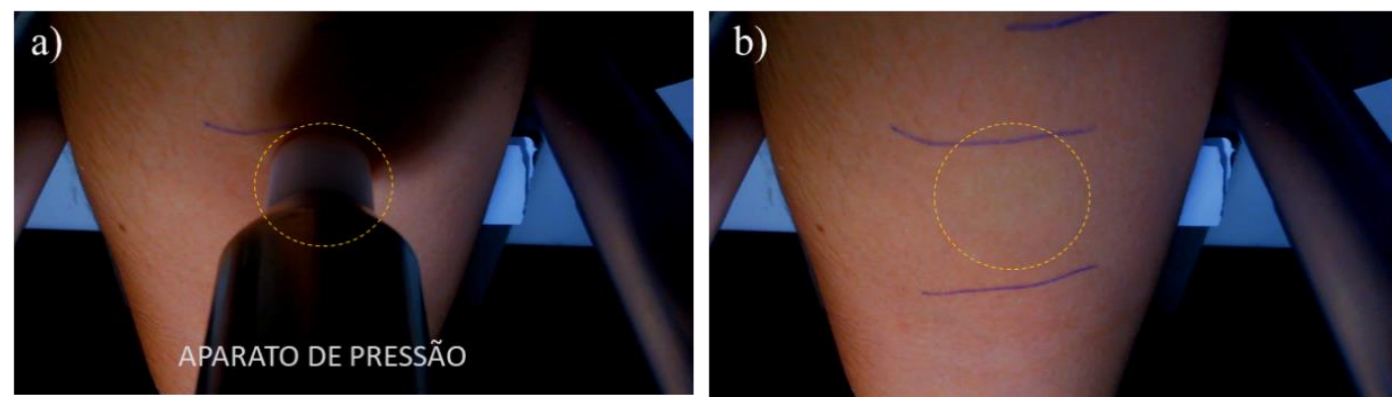

Figura 10. Imagem do antebraço de um participante com região demarcada da ROI escolhida para o processamento da imagem. a) Durante o instante que o instrumento de pressão está em contato com a pele; b) Mudança da cor da pele após a retirada do instrumento de pressão. 


\subsection{Resultados e Discussão}

O uso de polarizadores (mais detalhes no Apêndice A) permite melhor visualizar perfusão sanguínea abaixo da superfície externa da pele. A Figura 11 mostra como o uso do polarizador interfere nas imagens adquiridas pela câmera. As imagens foram adquiridas com polarizador linear tipo R (circular a direita) na lâmpada e tipo L (circular a esquerda) na câmera. Nessa configuração os polarizadores estão alinhados (não perpendiculares) e a imagem formada na câmera contém reflexão da primeira superfície da pele e informação das estruturas internas da pele. É possível ver que as imagens adquiridas dessa forma apresentam uma característica granulosa.

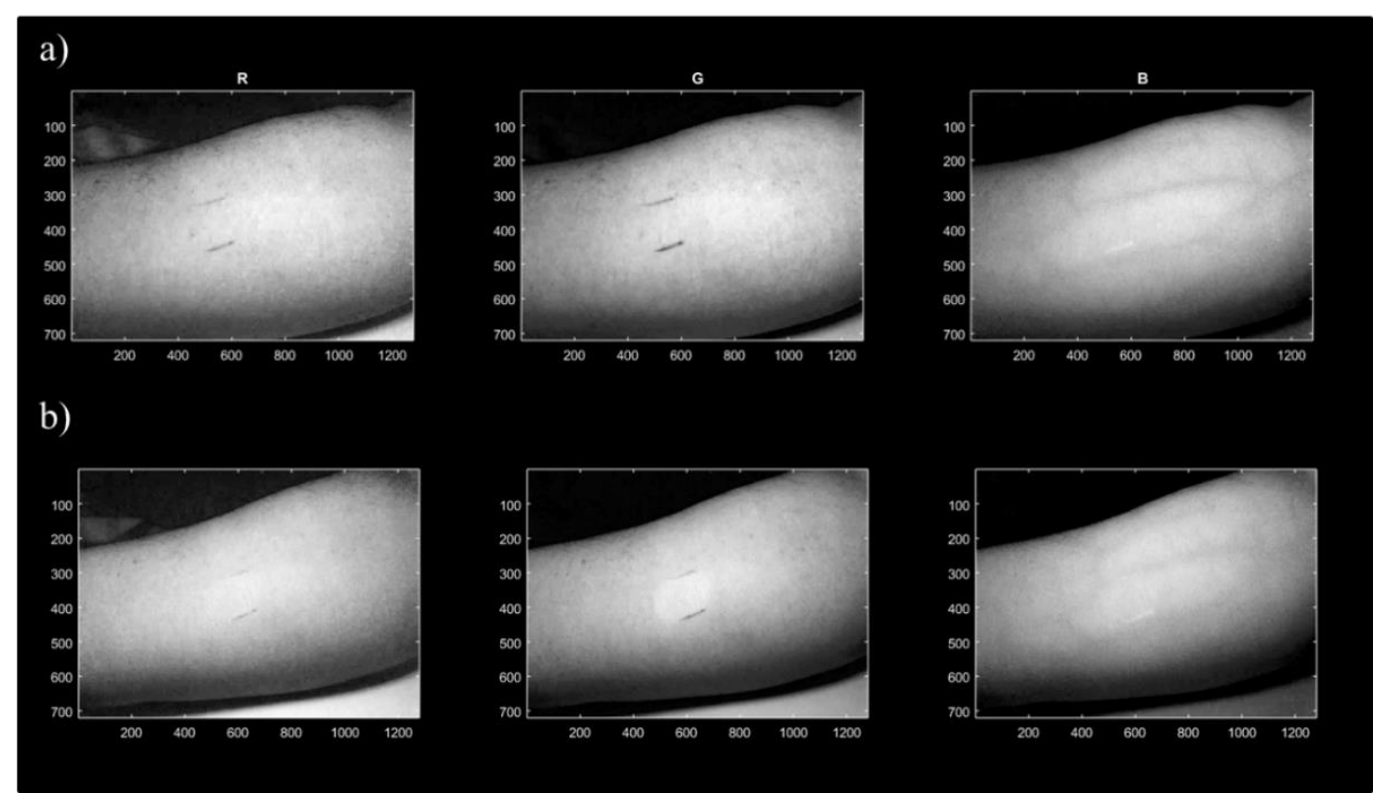

Figura 11. Imagem do antebraço de um participante em escala de cinza com as contribuições RGB da esquerda para direita. a) com os polarizadores perpendiculares nas posições: (L) e (R) e b) com os polarizadores nas posições paralelas (R) e (R).

Na Figura 11(b) os polarizadores estão "cruzados". Foram utilizados polarizadores lineares tipo $\mathrm{R}$ tanto na câmera quanto no iluminador. A polarização da luz muda de $\mathrm{R}$ para $\mathrm{L}$ quando reflete (inverte direção de propagação). Nessa configuração de polarizadores cruzados é possível ver nitidamente a mudança de cor após a liberação da compressão, pois com a configuração dos polarizadores, a reflexão especular na superfície da pele é suprimida, permitindo melhor visualizar a recapilarização da microcirculação da pele. Essa configuração foi utilizada em todos os experimentos nessa dissertação. 


\subsubsection{Determinação do rCRT}

O teste piloto realizado em voluntários saudáveis mostra que após a retirada do instrumento de pressão da superfície da pele ocorre mudança significativa na intensidade da cor dos canais RGB. A Figura 12 apresenta a curva da contribuição média de cada canal: vermelho, verde e azul obtidos de uma sequência de 35 segundos. As curvas de cada canal foram separadas em três regiões: anterior, durante e após a compressão. A região de compressão apresenta queda brusca. Essa queda se dá devido ao fato que durante a compressão, o instrumento de pressão permanece na frente da câmera.

Para obter o rCRT, é necessário calcular o tempo de retorno da cor da pele a partir do processamento das imagens. A curva da contribuição da intensidade de cada canal (Figura 12), sugere que após a compressão (retirada do instrumento de pressão) da superfície da pele ocorre uma leve mudança na intensidade de cada canal até o total reestabelecimento da cor da pele $(\approx$ 35 s). É notável, no canal verde, a presença de um pico expressivo seguido de um decaimento. Esse padrão se mantem para todos os voluntários. Dessa forma, realizamos uma investigação para estudo do comportamento da curva do canal verde.

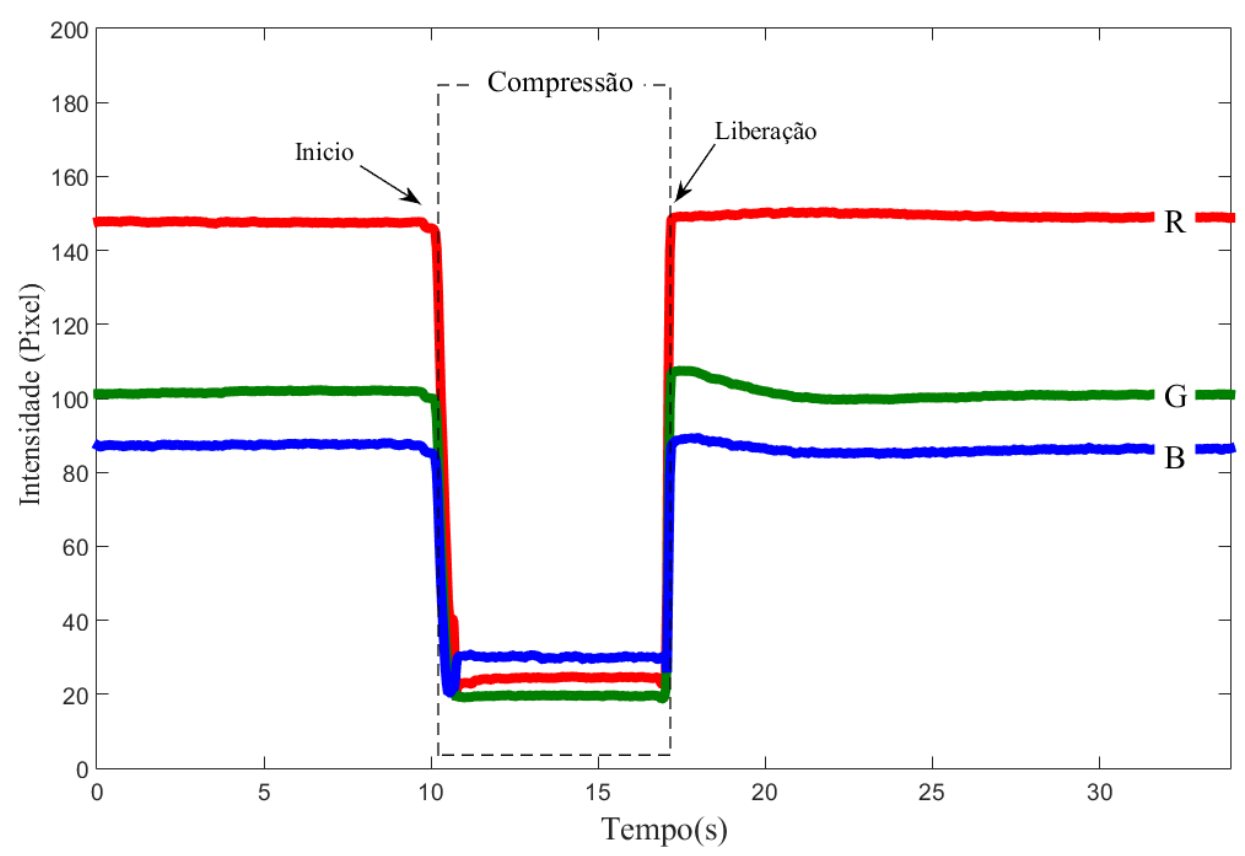

Figura 12. Contribuição de cada canal durante 35 s do teste do rCRT antes, durante e após a compressão aplicada. Gráfico de um voluntário, padrão semelhante foi obtido nos demais voluntários. R- Canal Vermelho, G- Canal Verde, B- Canal Azul. 
Como mostrado na Figura 13 o decaimento do canal verde não possui um modelo para tempos longos, a região onde a função é válida varia entre os participantes. Em alguns casos a resposta da intensidade do pixel após a liberação do aparato foi turbulenta, tendo como resultado a presença de uma curva ruidosa, principalmente na parte mais lenta do decaimento (após cerca de 6 segundos), dificultando a realização de um ajuste funcional de decaimento.

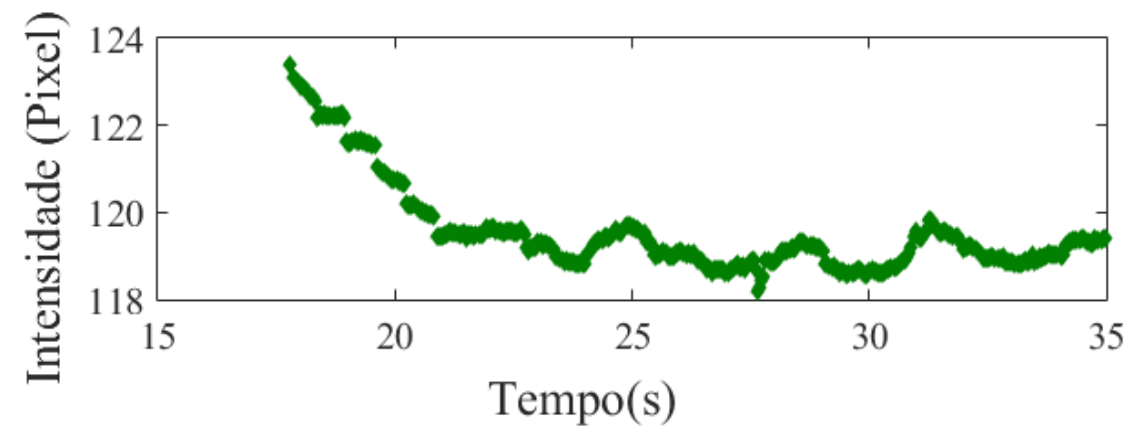

Figura 13. Curva do canal verde após a retida do instrumento de pressão de um voluntário. Após aproximadamente $23 \mathrm{~s}$ tem-se uma região ruidosa.

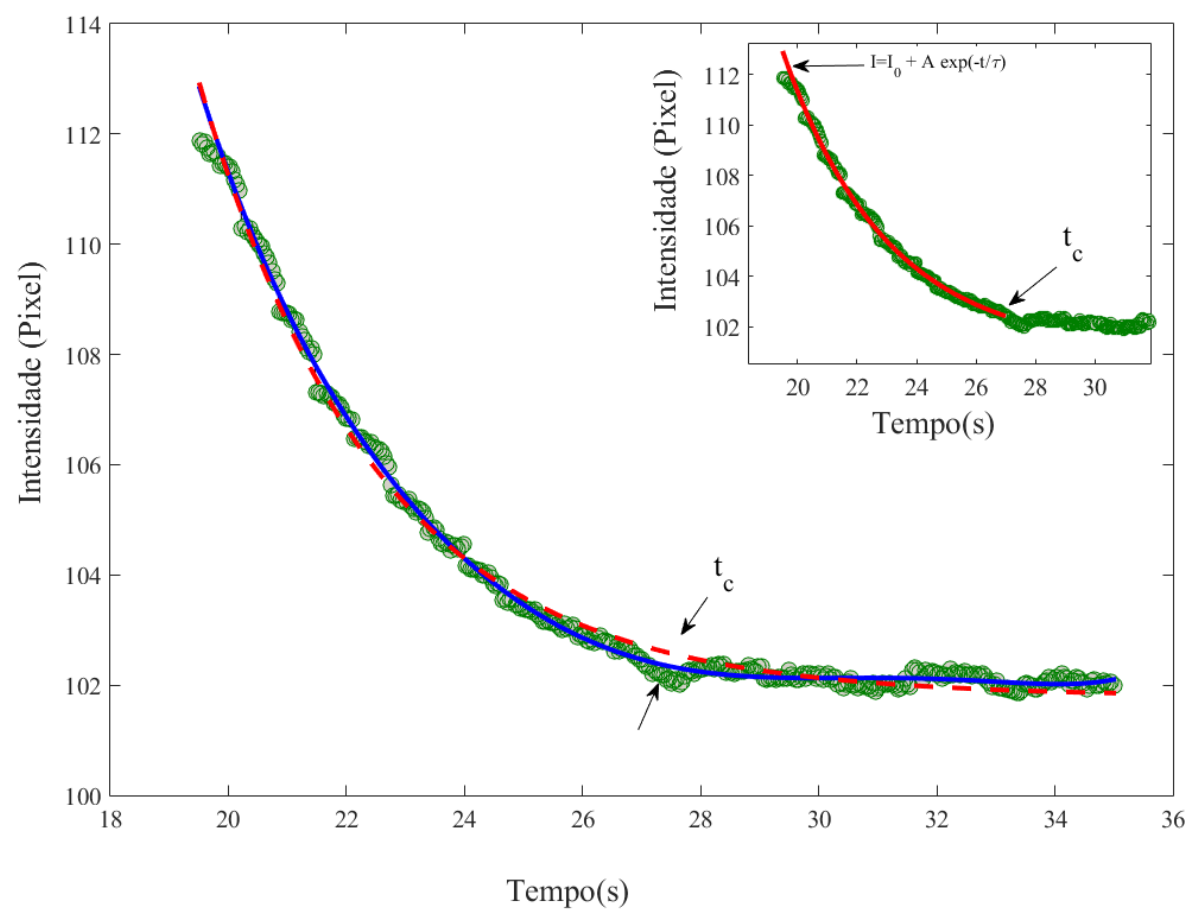

Figura 14. Curva do canal verde, mostra o critério de corte. a) Ajuste polinomial de sexta ordem (linha contínua) e a função exponencial (linha pontilhada). Inset mostra ajuste exponencial simples até o ponto crítico $\left(t_{c}\right)$. 
Sendo assim, desenvolvemos um critério de corte, escrito em MATLAB, para estabelecer o ponto de término da região na qual o ajuste exponencial é válido. Dessa forma, o programa obtém a curva temporal do canal verde durante todo experimento de cada vídeo e separa somente a terceira região (após a retirada do instrumento de pressão).

Em seguida, foi aplicado dois filtros no sinal do canal verde (Figura 14). Primeiramente avaliamos o uso de uma função polinomial, sendo o polinômio de $6^{\circ}$ ordem escolhido pois foi o de menor ordem que apresentou o melhor ajuste em todos os dados experimentais. Também foi utilizado uma função exponencial. Esses ajustes auxiliaram na padronização da escolha do ponto de máxima divergência (chamado de tempo crítico $\left(t_{c}\right)$ ), isso quer dizer: o tempo crítico é o ponto de máxima variação do ajuste exponencial em relação ao ajuste polinomial, como indicado pela seta na Figura 14

Após essas etapas, foi ajustado uma segunda exponencial até o $t_{c}$. O tempo de decaimento dessa segunda exponencial chamamos de rCRT. Acreditamos que o rCRT do ajuste exponencial das curvas esteja intrinsecamente relacionado com o CRT obtido pelo teste convencional, porém não sendo o mesmo valor encontrado pela técnica visual, dada a sensibilidade aumentada das câmeras RGB em relação ao olho humano.

\subsubsection{Investigação: rCRT versus $\mathrm{HbO}_{2}$, $\mathrm{Hbr}$ e $\mathrm{Hbt}$}

Levantamos a hipótese de que o comportamento do canal verde apresenta boa resposta para o CRT porque possui alta correlação com as mudanças na concentração de hemoglobina oxigenada e desoxigenada durante a compressão. Durante a compressão da pele com um material translúcido, é possível visualizar a mudança de cor da pele, nesse momento, o sangue é temporariamente bloqueado fazendo com que a pele apresente uma cor 'branqueada' (em alguns casos, amarelada) em vez de rosa (coloração normal). Neste trabalho, é possível visualizar esse resultado poucos segundos após liberação da compressão (retirada do instrumento de pressão).

Em um tecido bem oxigenado, o espectro da $\mathrm{HbO}_{2}$ produz dois picos: $540 \mathrm{~nm}$ e $577 \mathrm{~nm}$. Durante a compressão, ocorre diminuição da concentração de $\mathrm{HbO}_{2}$ no tecido epidérmico e o canal verde por ter alta sensibilidade na faixa de 532 - $550 \mathrm{~nm}$ é o mais afetado. Segundo Matas et al. o nível de oxigenação no sangue pode alterar em resposta a compressão aplicada (MATAS et al., 2001). A partir das Equações 2.3 à 2.5 obtemos as contribuições da concentração de 
hemoglobina oxigenada (Figura 15(a)) e desoxigenada (Figura 15(b)). Não analisamos o contribuição da melanina, pois permanece constante durante o experimento.

Durante a obstrução ocorre conversão da $\mathrm{HbO}_{2}$ para $\mathrm{Hb}$ devido ao consumo, uma vez que o fluxo está bloqueado. Após a liberação do instrumento de compressão na superfície da pele, na microcirculação tem-se baixa concentração de $\mathrm{HbO}_{2}$ (assinalado pela seta da Figura 15(a)) e alta concentração de $\mathrm{Hb}$ (assinalado pela seta da Figura 15(b)). Em seguida ocorre o reestabelecimento na concentração de hemoglobina na forma oxigenada e desoxigenada de forma gradual por alguns segundos até sua total recuperação.
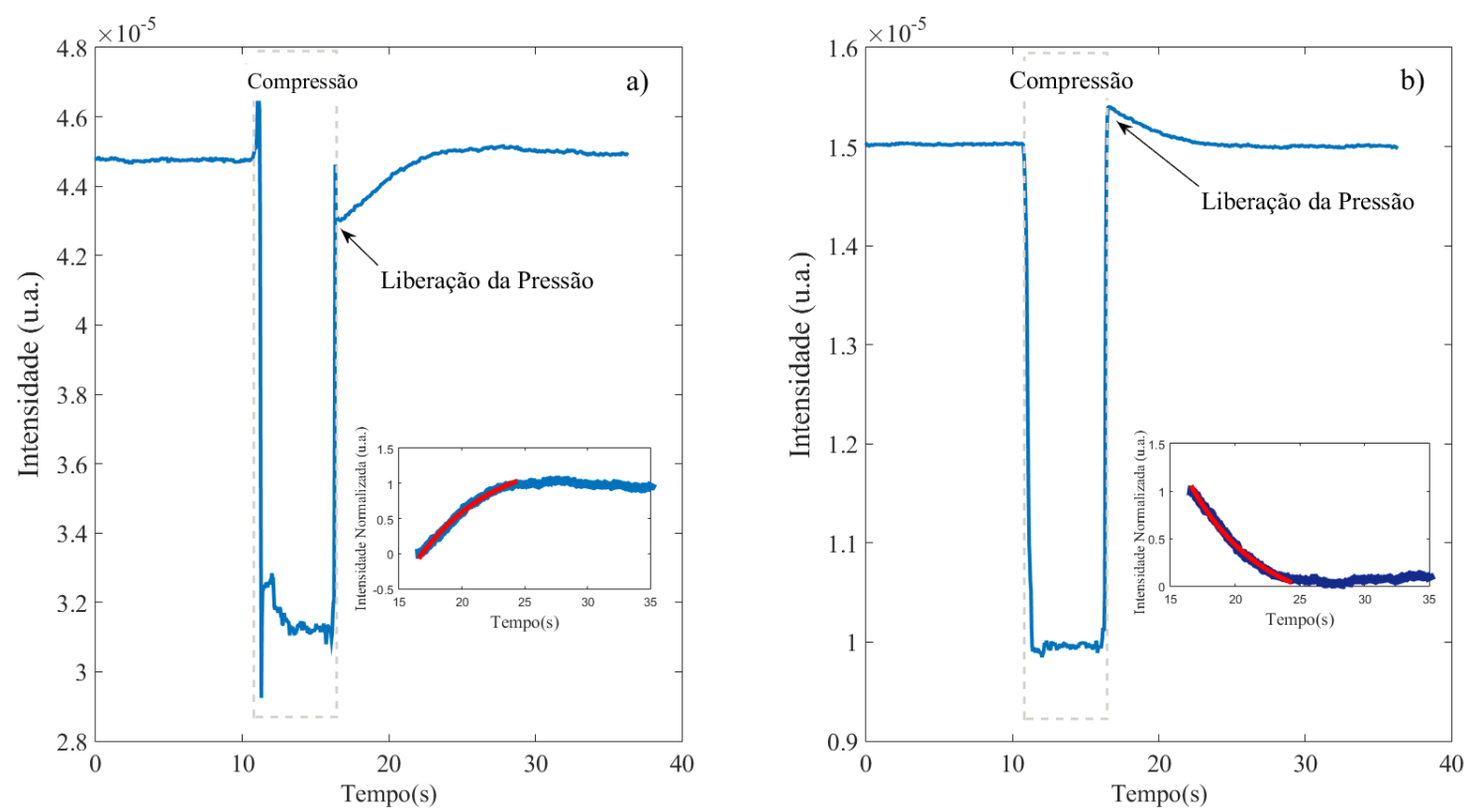

Figura 15. Resposta das contribuições: a) oxi-hemoglobina e b) desoxi-hemoglobina durante o teste de enchimento capilar de um voluntário. Inset ajuste com a Equação 2.8.

Os valores provenientes das intensidades dos canais RBG $\left(I\left(\lambda_{R}\right), I\left(\lambda_{G}\right), I\left(\lambda_{B}\right)\right)$, da Equação 2.3, possuem baixa incerteza original do sistema, pois derivam da média adquirida da ROI temporalmente. A Figura 15 mostra que as mudanças são suaves e continuas em função dos parâmetros de perfusão no tempo.

O método baseado na lei de Beer-Lambert (Equação 2.4) emprega um modelo de resolução matricial, com base no conhecimento espectral da hemoglobina oxigenada, desoxigenada e melanina, para os comprimentos de onda da faixa espectral correspondente aos canais RGB da câmera. Uma preocupação nesse tipo de sistema está no bom condicionamento da matriz M. Em matrizes mal condicionadas, pequenas perturbações nos coeficientes do 
sistema resultam em grandes modificações na solução, o que é indesejado. Na matriz, $\mathbf{M}$ da Equação 2.4, temos um número de condicionamento $k(\boldsymbol{M}) \approx 700$, o que gera uma perda de até dois algarismos significativos $(\log (700))$ nos vetores resposta do sistema em relação a incerteza dos parâmetros de entrada do problema. Não obstante, observamos na Figura 15 que ocorre continuidade dos valores de concentrações dos cromóforos (hemoglobina oxigenada e desoxigenada) de um frame para outro. Assim, o condicionamento da matriz $\mathbf{M}$ não é limitante para a solução do sistema em nossas condições experimentais.

Para verificação do rCRT através de uma metodologia alternativa, comparamos o tempo de retorno da cor da pele pelo canal verde (rCRT), com o tempo de recarga das contribuições: oxi-hemoglobina $\left(\mathrm{HbO}_{2}\right)$ e desoxi-hemoglobina (Hbr). Para isso, é possível ajustar uma função de carga de capacitor (Equação 2.8). Essa função teve ajuste positivo para a curva de $\mathrm{HbO}_{2} \mathrm{Hbt}$ e negativo para a curva da Hbr:

$$
I=I_{O}+A\left(1-\exp \left(-\frac{t}{\tau}\right)\right)
$$

onde, $I_{O} \approx 0$ e $A$ são parâmetros arbitrários para o ajuste.

As curvas obtidas, foram corrigidas pela intensidade do pixel nos $5 \mathrm{~s}$ iniciais do vídeo (Eq.2.7). A Eq.2.8 foi ajustada até o ponto critico $\left(t_{c}\right)$, como relatado na Seção anterior (Inset da Figura 15(a e b)). Com isso a constante de tempo $(\tau)$ em cada uma das curvas foi interpretada como o tempo de reoxigenação $\left(\mathrm{HbO}_{2(\mathrm{CRT})}, \mathrm{Hbt}_{(\mathrm{CRT})}\right)$ e desoxigenação $\left(\mathrm{Hbr}_{(\mathrm{CRT})}\right)$ provinda de cada uma das contribuições.

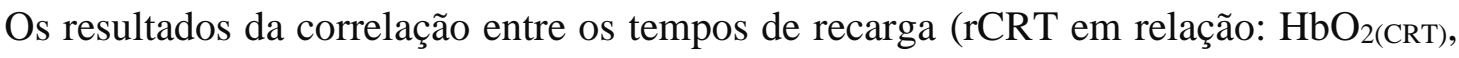
$\left.\operatorname{Hbr}_{(\mathrm{CRT})}, \mathrm{Hbt}_{(\mathrm{CRT})}\right)$ estão mostrados nas Figura 16 a 18, para isso, utilizamos a avaliação pelo método de Bland-Altman. O método Bland-Altman foi desenvolvido em 1986 por Martin Bland e Douglas Altman com o intuito de avaliar a associação entre duas variáveis, a partir de um gráfico de dispersão entre a diferença média das variáveis. Neste gráfico é possível visualizar o viés (o quando as diferenças se afastam do valor zero), gerando como resposta o erro a partir da dispersões dos pontos ao redor da média, os limites de concordância são da ordem de 1,96.SD (MARTIN BLAND; ALTMAN, 1986). 

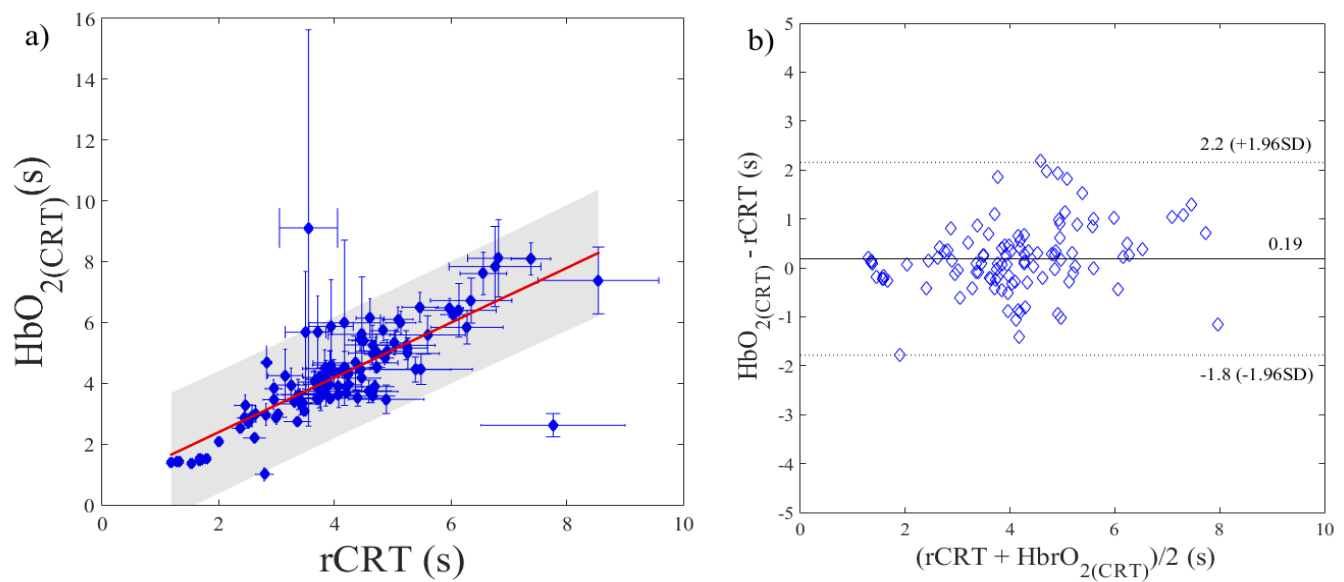

Figura 16. Correlação do tempo de decaimento (110 pontos - cinco repetições de 22 voluntários) da curva $\mathrm{HbO}_{2(\mathrm{CRT})}$ e rCRT. a) Ajuste linear com $\mathrm{R}^{2}=0,66$ e correlação de Pearson=0,81. Área demarcada representa banda de confiança de 95\%. b) Análise BlandAltman, linha cheia simboliza a média da diferença e linha pontilhada são os limites: superior e inferior iguais $1,96 . S D$. Teste $t$ igual $\mathrm{p}=0,05$.
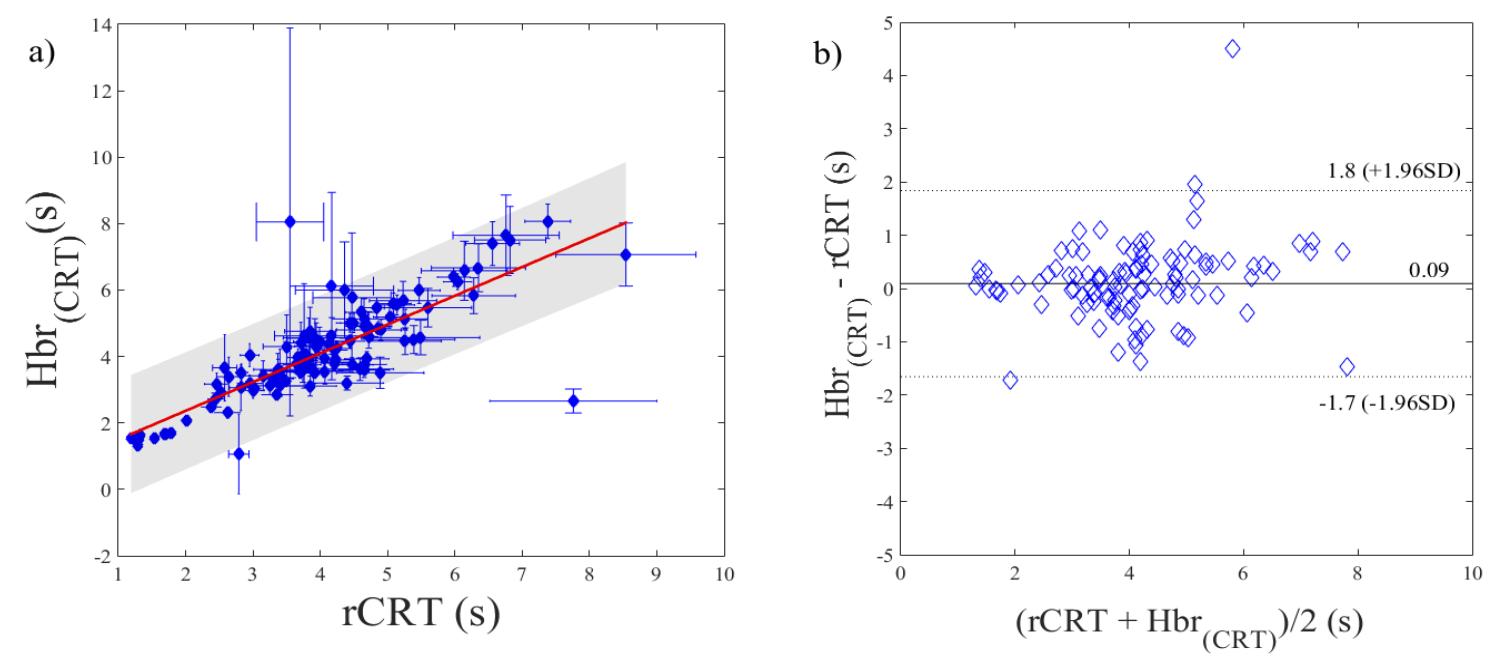

Figura 17. Correlação do tempo de decaimento (110 pontos - cinco repetições de 22 voluntários) da curva do $\operatorname{Hbr}_{(\mathrm{CRT})}$ e rCRT. a) Ajuste linear com $\mathrm{R}^{2}=0,61$ e correlação de Pearson=0,78. Área demarcada representa banda de confiança de 95\%. b) Análise BlandAltman, linha cheia simboliza a média da diferença e linha pontilhada são os limites: superior e inferior iguais $1,96 . S D$. Teste $t$ igual $\mathrm{p}=0,14$. 

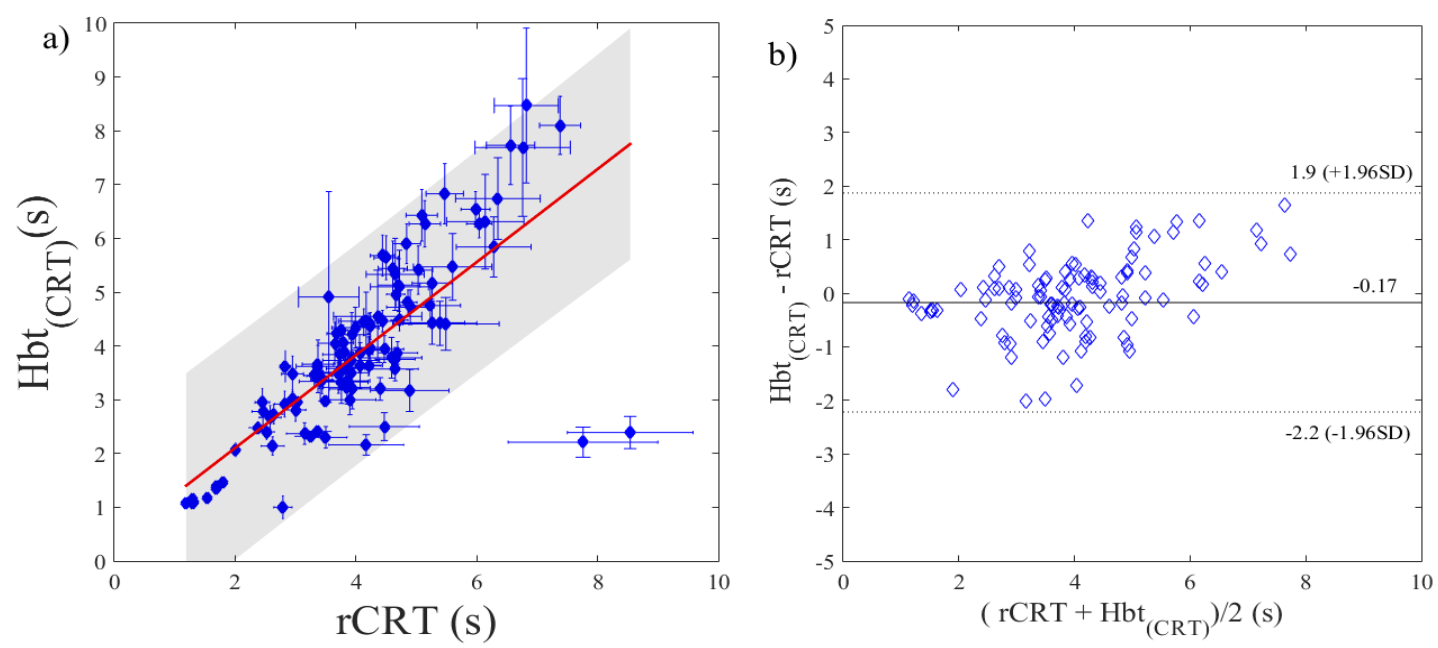

Figura 18. Correlação do tempo de decaimento (110 pontos - cinco repetições de 22 voluntários) da curva do $\mathrm{Hbt}_{(\mathrm{CRT})}$ e rCRT. a) Ajuste linear com $\mathrm{R}^{2}=0,58$ e correlação de Pearson=0,76. Área demarcada representa banda de confiança de 95\%. b) Análise BlandAltman, linha cheia simboliza a média da diferença e linha pontilhada são os limites: superior e inferior iguais $1,96 . S D$. Teste t igual $\mathrm{p}=0,08$.

Os resultados obtidos de rCRT pelo ajuste exponencial da curva gerada pelo canal verde, apresentou alta correlação com valores do ajuste da curva de crescimento da contribuição da hemoglobina oxigenada (Figura 16). Não mostramos os resultados dessas correlações com os outros canais (vermelho e azul), pois em geral não é possível ajustar uma função nesses canais. Esse resultado, sugere correspondência entre o tempo de decaimento do canal verde com a resposta fisiológica da perfusão periférica local. Essa correspondência, até onde sabemos, não tinha sido demonstrada anteriormente na literatura.

\subsubsection{Resposta da compressão}

Os resultados de rCRT obtidos em duas diferentes compressões, mostraram que em alguns participantes (Tabela 4) o aumento da compressão levou ao prolongamento do rCRT. Esse resultado corrobora com o encontrado por Saavedra et al. que verificaram o mesmo comportamento pelo método convencional (SAAVEDRA et al., 1991). Entretanto, esse resultado não é tão claro em alguns voluntários. 
Tabela 4. Valores médios de rCRT obtidos pelo ajuste exponencial da curva do canal verde utilizando os instrumentos de compressão de $7 \mathrm{kPa}$ e $24 \mathrm{kPa}$ para 14 voluntários e os valores da pressão arterial sistólica e diastólica.

\begin{tabular}{cccccccccc}
\hline & \multicolumn{1}{c}{ Pressão Arterial } & \multicolumn{9}{c}{ Compressão } \\
\hline & Sistólica & Diastólica & \multicolumn{3}{c}{ 7 kPa } & \multicolumn{4}{c}{ 24 kPa } \\
\cline { 3 - 10 } & $(\mathbf{m m H g})$ & $(\mathbf{m m H g})$ & \multicolumn{3}{c}{ rCRT (s) } & \multicolumn{4}{c}{ rCRT (s) } \\
\hline P1 & 114 & 74 & 4,2 & \pm & 0,3 & 4,3 & \pm & 0,3 \\
P2 & 103 & 65 & 5,0 & \pm & 0,5 & 4,2 & \pm & 0,2 \\
P3 & 105 & 69 & 2,7 & \pm & 0,2 & 1,8 & \pm & 0,1 \\
P4 & 97 & 60 & 2,3 & \pm & 0,2 & 5,0 & \pm & 1,2 \\
P5 & 102 & 62 & 4,0 & \pm & 0,4 & 3,5 & \pm & 0,3 \\
P6 & 117 & 73 & 2,6 & \pm & 0,1 & 3,3 & \pm & 0,1 \\
P7 & 113 & 63 & 4,4 & \pm & 0,2 & 4,3 & \pm & 0,3 \\
P8 & 101 & 64 & 4,3 & \pm & 0,3 & 3,3 & \pm & 0,1 \\
P9 & 106 & 67 & 7,3 & \pm & 1,1 & 6,1 & \pm & 0,6 \\
P10 & 109 & 71 & 3,8 & \pm & 0,7 & 3,6 & \pm & 0,3 \\
P11 & 124 & 66 & 2,2 & \pm & 0,1 & 2,2 & \pm & 0,1 \\
P12 & 124 & 69 & 2,5 & \pm & 0,2 & 3,2 & \pm & 0,2 \\
P13 & 108 & 71 & 3,4 & \pm & 0,1 & 2,7 & \pm & 0,1 \\
P14 & 137 & 54 & 4,8 & \pm & 0,3 & 10,4 & \pm & 0,7 \\
\hline
\end{tabular}
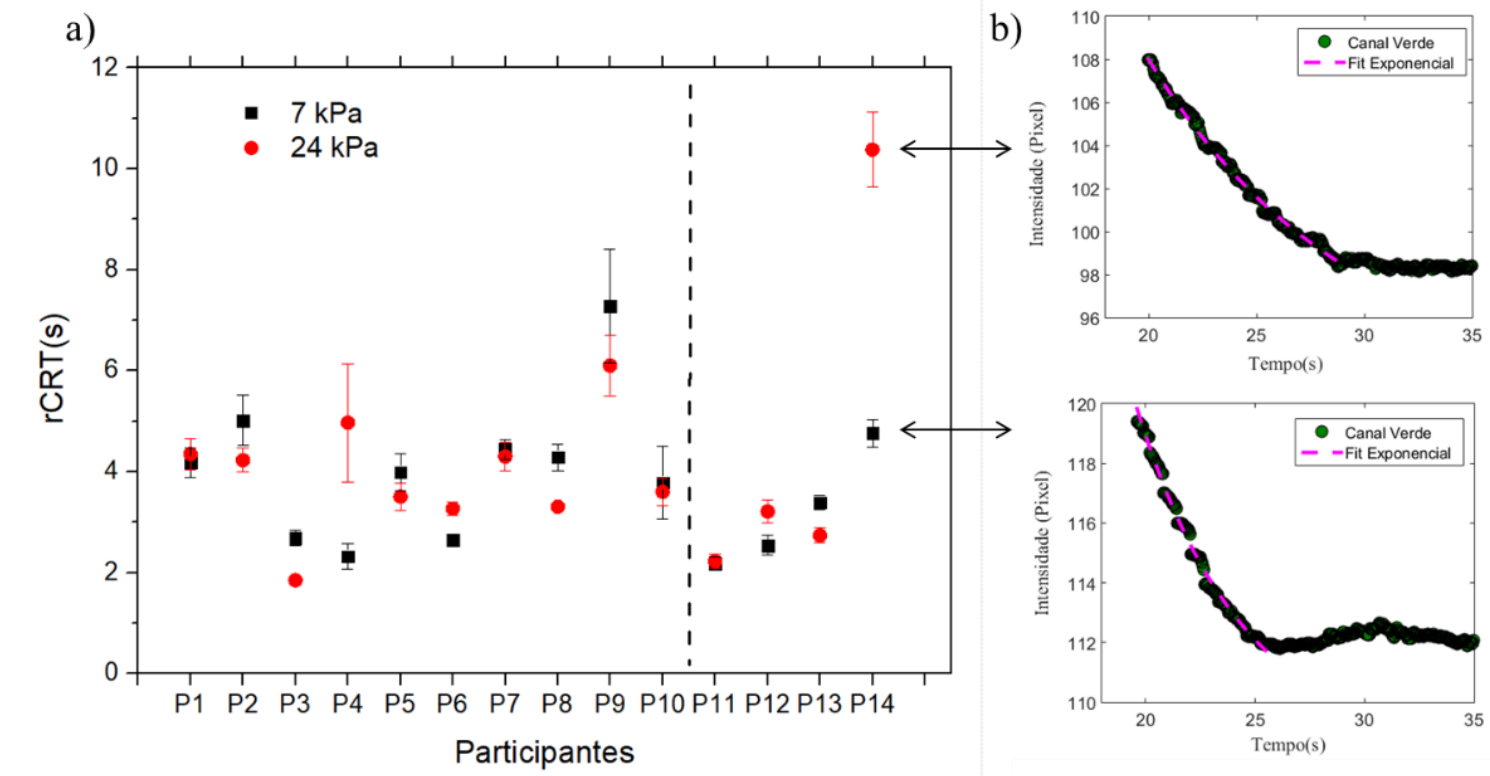

Figura 19. a) Valores médios de rCRT com dois instrumentos de compressão: 7 kPa e 24 kPa. para 14 voluntários. A região demarcada pela linha tracejada vertical, separa o grupo de voluntários do sexo feminino (P1 á P10), do grupo de voluntários do sexo masculino (P11 a P14). Os valores de rCRT e a incerteza foram obtidos a partir do ajuste da curva exponencial. b) Decaimento da intensidade do canal verde para o participante P14 em cada compressão. 
É interessante de se notar, (Figura 19(a)) que em alguns casos o valor do rCRT apresentou baixa variação $(<20 \%)$ em relação com a mudança da compressão exercida localmente na superfície do antebraço. Nos 14 participantes estudados, na compressão de 24 $\mathrm{kPa}, 6$ participantes apresentaram rCRT prolongado, enquanto que para compressão de $7 \mathrm{kPa}$, 8 apresentaram rCRT maior. Em alguns participantes ocorreu mudança significativa no regime da obstrução como no caso dos participantes P4 e P14 apontados na Figura 20. Acreditamos que essas respostas estejam correlacionadas com os valores da pressão arterial. O participante P4 apresentou a mínima pressão sistólica enquanto que o participante P14 apresentou a máxima dentre todos os pasticipantes.

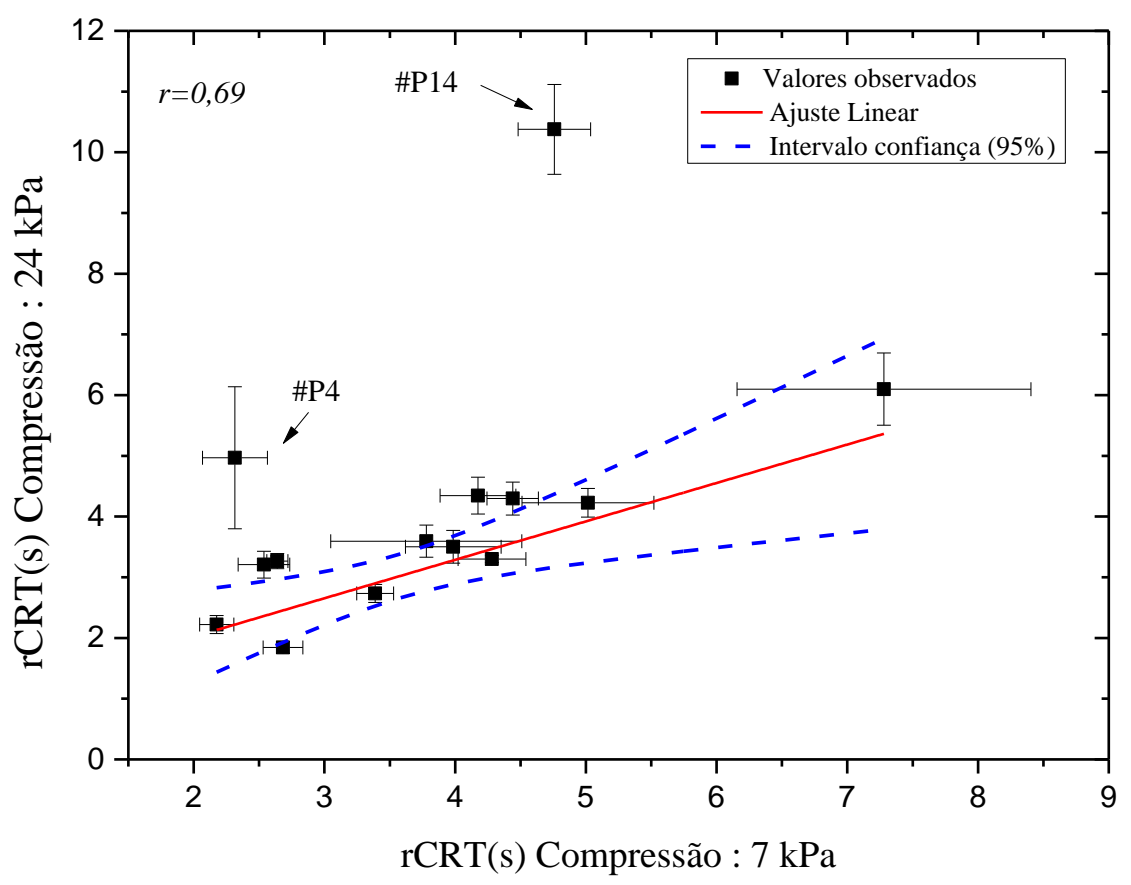

Figura 20. Valores de rCRT para as compressões de $7 \mathrm{kPa}$ e $24 \mathrm{kPa}$. Todos os 14 participantes foram incluídos no ajuste linear $\mathrm{rCRT}_{24 \mathrm{kPa}}=0,63+0,75 * \mathrm{rCRT}_{7 \mathrm{kPa}}$ com correlação de Pearson $\mathrm{r}=0,69$ e banda de confiança (pontilhado azul) de $95 \%$.

A curva da intensidade de cor do canal verde, na compressão de $24 \mathrm{kPa}$, apresentou decaimento lento em relação à compressão de $7 \mathrm{kPa}$ (Figura 19(b)). Como é possível ver, na Figura 21, a compressão de $24 \mathrm{kPa}$ criou uma região avermelhada acentuada ao redor da borda do instrumento de pressão. A estimulação mecânica na superfície da pele pode induzir uma resposta específica no local do estímulo devido à dilatação dos vasos sanguíneos, o que aumenta a fração volêmica do sangue na derme. Essa condição é conhecida como eritema, gerando assim, lentidão no retorno da cor da pele. 

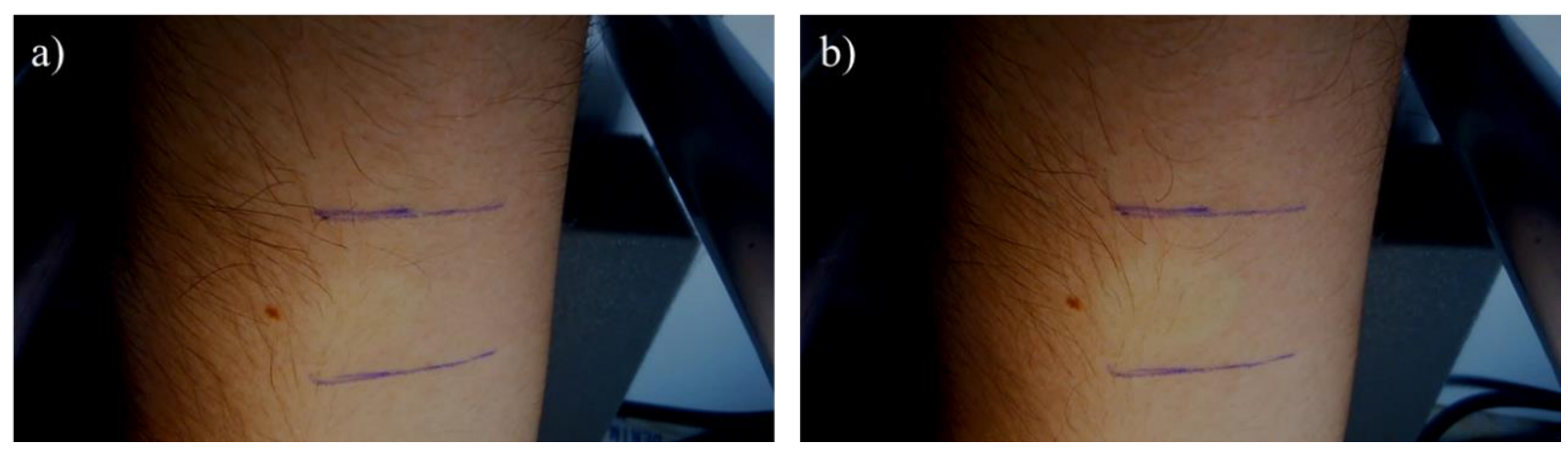

Figura 21. Imagem do antebraço do participante \#P14 após a retirada do instrumento de pressão da pele a) $7 \mathrm{kPa}$ e b) $24 \mathrm{kPa}$.

A vermelhidão da pele na borda do instrumento de pressão pode ser causada pelo deslocamento da água e sangue da região ocluída. Poucos segundos após a remoção do instrumento de pressão a vermelhidão da pele ao redor da base diminui, e dentro da região comprimida aumenta, retornando a cor original da pele. Dos cromóforos existentes na pele, a água possui forte influência na mudança das propriedades ópticas do tecido comprimido. O teor de água está relacionado com profundidade do tecido. Na camada mais externa (estrato córneo), o teor de água depende das condições do ambiente como a umidade atmosférica e representa cerca de $15 \%$. Já nas camadas mais internas (entre 20 e $75 \mu \mathrm{m}$ ) pode atingir cerca de $70 \%$ (RYLANDER et al., 2008). Rylander et al. relatam que compressão da pele força a água a se deslocar com o intuito de diminuir o stress causado pela compressão do instrumento de pressão. Essa hipótese é apoiada por Tuchin, a compressão no tecido gera zonas de desidratação (remoção de sangue e fluido intersticial do local comprimido) reduzindo a espessura do tecido e possivelmente modificando propriedades ópticas, como pode ser observado na Figura 21 pelo aumento de vermelhidão ao redor da base (ponteira) do instrumento de pressão (TUCHIN, 2005; RYLANDER et al., 2008, 2011). Dessa forma, a evitar espúrios nas imagens e consequentemente ruído associado a curva de decaimento do sinal, escolhemos apenas o instrumento de pressão de $7 \mathrm{kPa}$ para a realização dos testes a seguir.

Shinozaki et al, mostram o uso de um dispositivo para quantificar o tempo de enchimento capilar chamado de índice de refil capilar (CRI do inglês, Capillary refill Index) na ponta do dedo, similar a um oxímetro de dedo. Entretanto, esse dispositivo mede o tempo de recuperação do sangue utilizando método óptico (espectro de infravermelho), enquanto na medição de CRT usa a inspeção visual do examinador da mudança da cor da pele. A compressão usada nesse estudo chega a $53 \mathrm{kPa}$ na ponta do dedo (SHINOZAKI et al., 2019b). Por outro 
lado, nossos resultados mostraram que a compressão de $7 \mathrm{kPa}$ foi suficiente para causar branqueamento da pele e assim ser aplicada no teste do CRT, para a avaliação em pacientes com pele sensível ou machucada.

\subsection{4 rCRT com diferentes fototipos de pele}

A alta concentração de melanina em peles fototipos V e VI, dificulta o diagnóstico da mudança da cor da pele após uma dada compressão exercida (MATAS et al., 2001). Sendo assim, o teste de CRT de forma visual, torna-se inviável, o observador apenas visualiza a melanina e não o retorno do sangue no capilar, gerando um valor do tempo de enchimento diferente do verdadeiro. Essa incapacidade de visualizar a mudança de cor em pele escura, dificulta o diagnóstico não só do teste CRT, mas também na avaliação do estado perfusional da pele como o estágio de úlcera por pressão (MATAS et al., 2001).

Um dos objetivos desse trabalho, é a possibilidade de aplicação do teste de CRT em pacientes com pele escura (Escala de Von Luschan Tipos V e VI). Alguns autores (SAAVEDRA et al., 1991; MATAS et al., 2001) relatam a dificuldade em se fazer avaliação visual do CRT e a observação de mudanças sutis na pele em pacientes com fototipos V e VI. Desta forma avaliamos os resultados do teste de CRT com a metodologia desenvolvida em diferentes fototipos. A Figura 22, mostra a imagem do antebraço de dois voluntários de diferentes, fototipo I (Figura 22(a)) e fototipo V (Figura 22(b)), em duas situações: antes e logo após da retirada do instrumento de pressão. Como pode ser observado, em pessoas de pele escura, a mudança de cor da pele após a compressão aplicada, apresenta baixo contraste, impossibilitando o teste visual, como já relatado por alguns autores (MATAS et al., 2001). Entretanto, ao realizar, a análise do teste do rCRT (Figura 22(e,f)) é possível observar que a resposta ao ajuste exponencial da curva da mudança do retorno da cor da pele apresenta bom comportamento em ambos os casos. Desta forma, diferente das alternativas encontradas na literatura, o uso de método de vídeo, permitiu quantificar o CRT para diferentes fototipos de pele. Somado a isso, o uso dos polarizadores circulares na fonte de luz e na câmera, são provavelmente os fatores mais determinantes para a obtenção dos resultados obtidos, outro fator é a forma robusta e automatizada que utilizamos para determinação da região de ajuste da

função exponencial. 

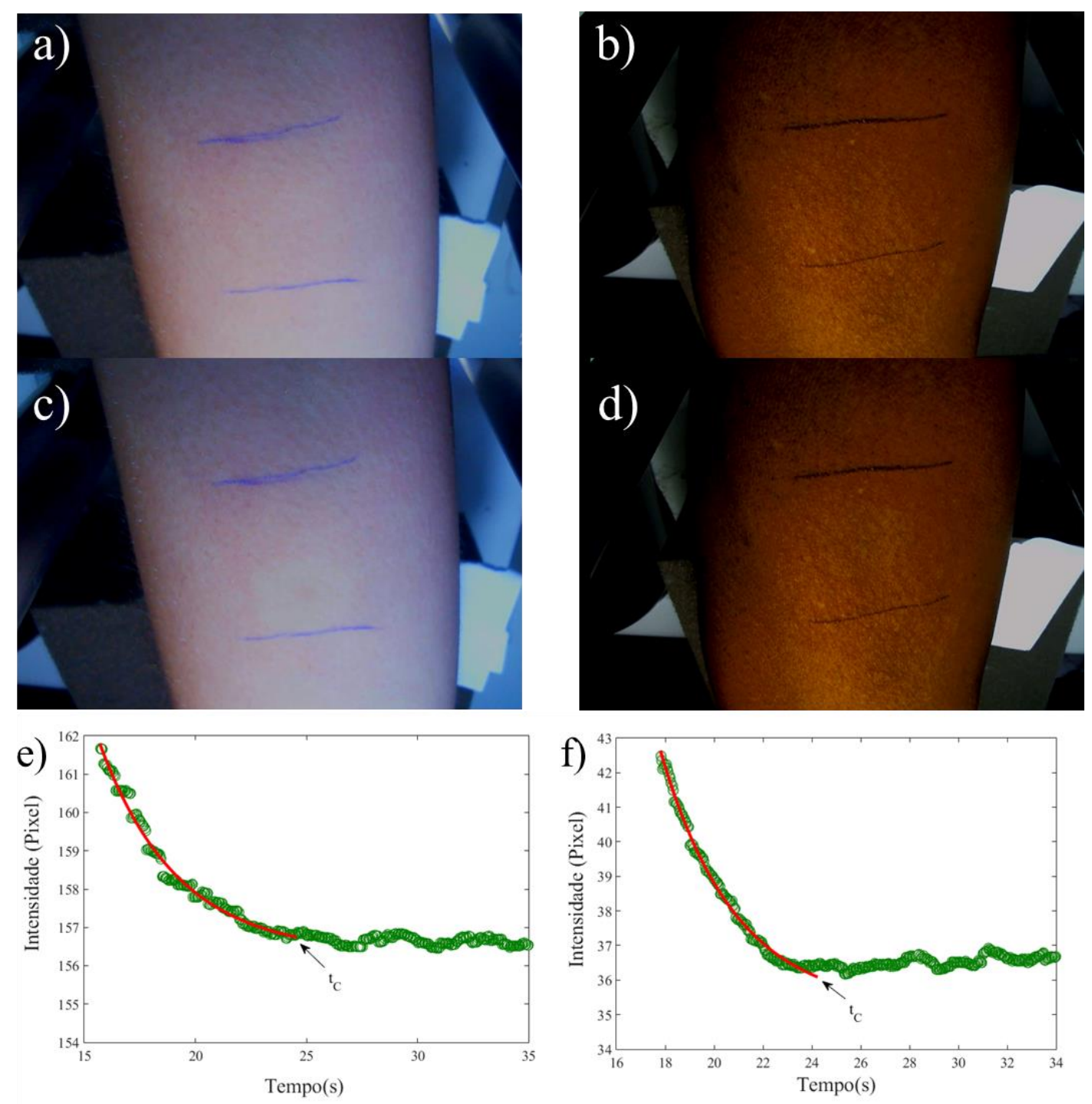

Figura 22. Imagem do antebraço de dois participantes com cores de pele diferente a) Tipo I e b) Tipo V. Região demarcada na pele, mostra a cor do braço antes da compressão aplicada e abaixo, $\left(\begin{array}{lll}c & e & d\end{array}\right)$ após a liberação do instrumento de pressão. Curva do canal verde com ajuste exponencial, até o ponto crítico $\left(t_{c}\right)$.

\subsubsection{Dependência do rCRT com sexo e idade}

A idade e o sexo são fatores importantes que devem ser levados em consideração na avaliação do CRT. A correlação do aumento do CRT em cada grupo está relacionada com diferentes diagnósticos. Em crianças, alguns autores mostram que o CRT está correlacionado com o grau de desidratação (SAAVEDRA et al., 1991; FLEMING et al., 2015). Já em adultos, pode ser uma medida preditiva: do nível de hipovolemia em pacientes em estado de choque; 
infecções graves e descontrole nos níveis de lactato (PICKARD; KARLEN; ANSERMINO, 2011). Entretanto, em indivíduos saudáveis, até o momento, não existem evidencias publicadas que suportem faixas de valores que devem ser considerados normais para cada faixa etária e sexo.

O resultado do Teste ANOVA de variância de Kruskal-Wallis não mostrou diferença estatisticamente significativa $(p>0,05)$ entre os valores médios de rCRT dos grupos masculino e feminino na faixa etária de 20 a 49 anos (Figura 23). Esse resultado concorda com o obtido através do mesmo método por Schriger et al. (SCHRIGER; BARAFF, 1988).

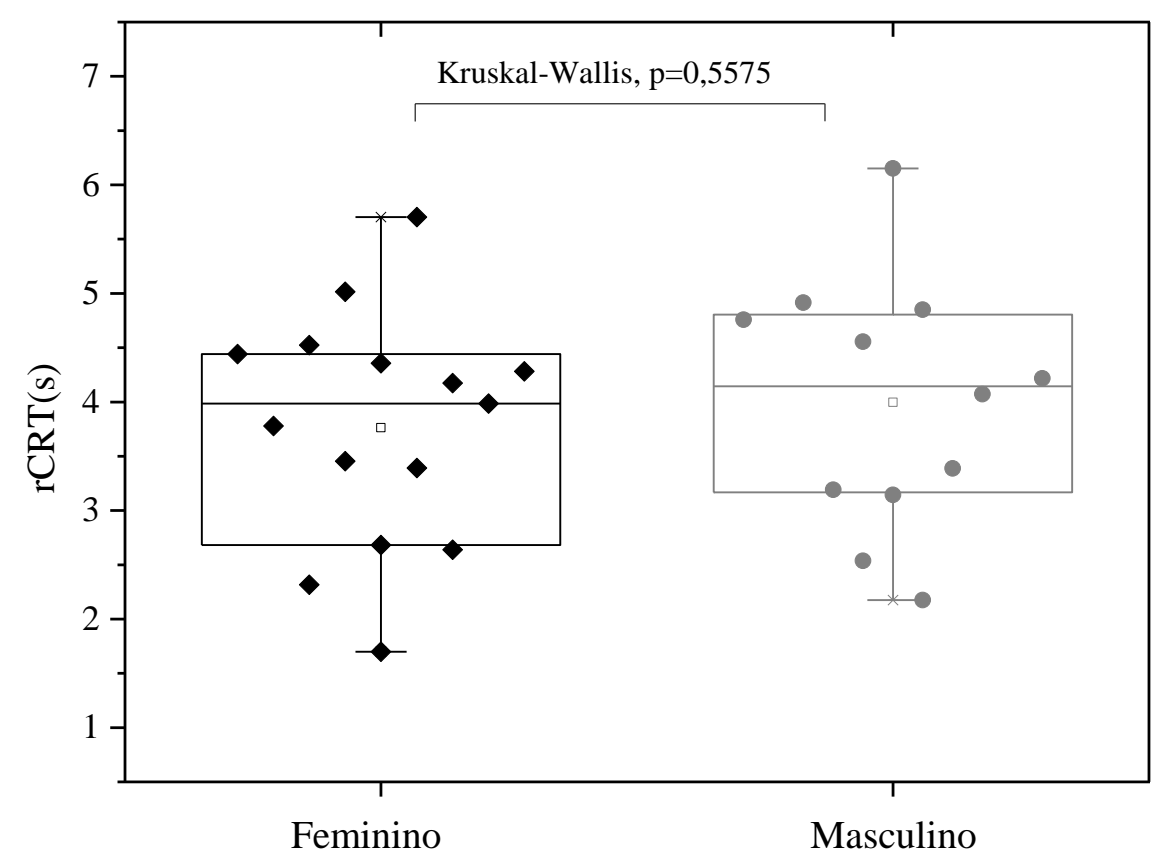

Figura 23. Boxplot da distribuição dos valores médios de rCRT (s) separados por sexo, na faixa etária de 20 a 49 anos. Resultado de Teste ANOVA de variância de Kruskal-Wallis, não apresentou significância, $\mathrm{p}=0,5575$.

Schriger et al. apontaram diferença nos valores do teste de CRT em relação à faixa etária (SCHRIGER; BARAFF, 1988). Os resultados obtidos pelo trabalho de Schriger et al.estão mostrados na Tabela 5, com os obtidos nesse estudo. Esses resultados indicam a relação entre idade e o valor de CRT, de modo geral, em adultos o tempo de enchimento, cresce com o aumento da idade pois ocorre diminuição da resistência capilar nos vasos periféricos, o que faz com o tempo de retorno após a compressão, seja mais lento. Anderson et al., mostraram 
aumento de cerca de 3\% a cada década na idade nos valores de CRT (ANDERSON et al., 2008a).

Tabela 5. Valores de CRT obtidos para voluntários saudáveis, com o teste visual e o resultado deste trabalho.

\begin{tabular}{|c|c|c|c|c|c|c|c|c|c|}
\hline \multicolumn{10}{|c|}{ Tempo de Enchimento Capilar CRT (s) } \\
\hline & \multirow{2}{*}{ Método } & \multicolumn{3}{|c|}{ Crianças } & \multicolumn{3}{|c|}{ Adultos (20 a 49 anos $)$} & \multirow{2}{*}{\multicolumn{2}{|c|}{$\begin{array}{l}\text { Idosos }(50-95 \text { anos }) \\
\mathrm{N}\end{array}$}} \\
\hline & & $\mathbf{N}$ & & $\mathbf{N}$ & Mulheres & $\mathbf{N}$ & Homens & & \\
\hline Schriger e Baraff & Tradicional & 100 & $0,81(1,9)^{*}$ & 77 & $1,2(2,9)^{*}$ & 27 & $1(1,6)^{*}$ & 100 & $1.5(4.5)^{*}$ \\
\hline Este trabalho & rCRT & - & - & 15 & $3,7(4,3)^{*}$ & 12 & $3,9(4,7)^{*}$ & 8 & $4,9(5,7)^{*}$ \\
\hline
\end{tabular}

*Limite superior em $95 \%$ do intervalo de confiança

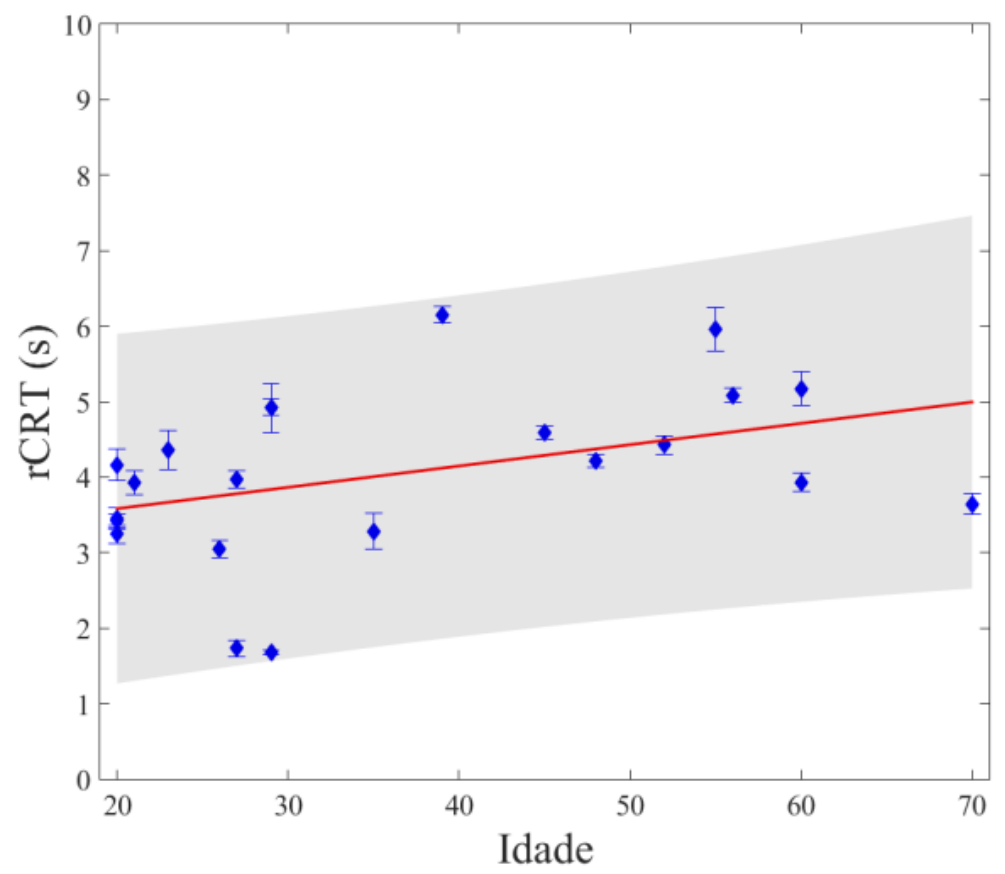

Figura 24. Tendência do rCRT médio com a idade. Ajuste linear (linha continua) com r=0.48 e $\mathrm{p}<0.05$. Barra de erro de cada ponto experimental representa o desvio padrão de cinco medidas. A região cinza representa o intervalo de confiança de $95 \%$, da distribuição dos pontos em torno do ajuste linear.

A Figura 24 mostra os valores médios das 5 medições de 22 participantes em relação com a idade, como pode ser visto a linha de tendência leva a um aumento do CRT com a idade. Resultado já observado por alguns estudos, (SCHRIGER; BARAFF, 1988; ANDERSON et al., 2008a) o Tempo de Enchimento Capilar é prolongado com o aumento da idade. 


\subsubsection{Relação do teste de rCRT na avaliação inter-observadores}

Estudamos a relação inter-observador, pelo método de Bland-Altman. Nessa etapa, alguns vídeos foram excluídos, pois em alguns casos a mudança de cor após a compressão apresentou baixo contraste entre a ROI e a região adjacente impossibilitando a realização do teste de CRT de forma visual. Os resultados estão mostrados nas Figura 25, 26 e 27. A análise pelo gráfico de Bland-Altman permite a identificação de problemas sistemáticos entre as repetições.
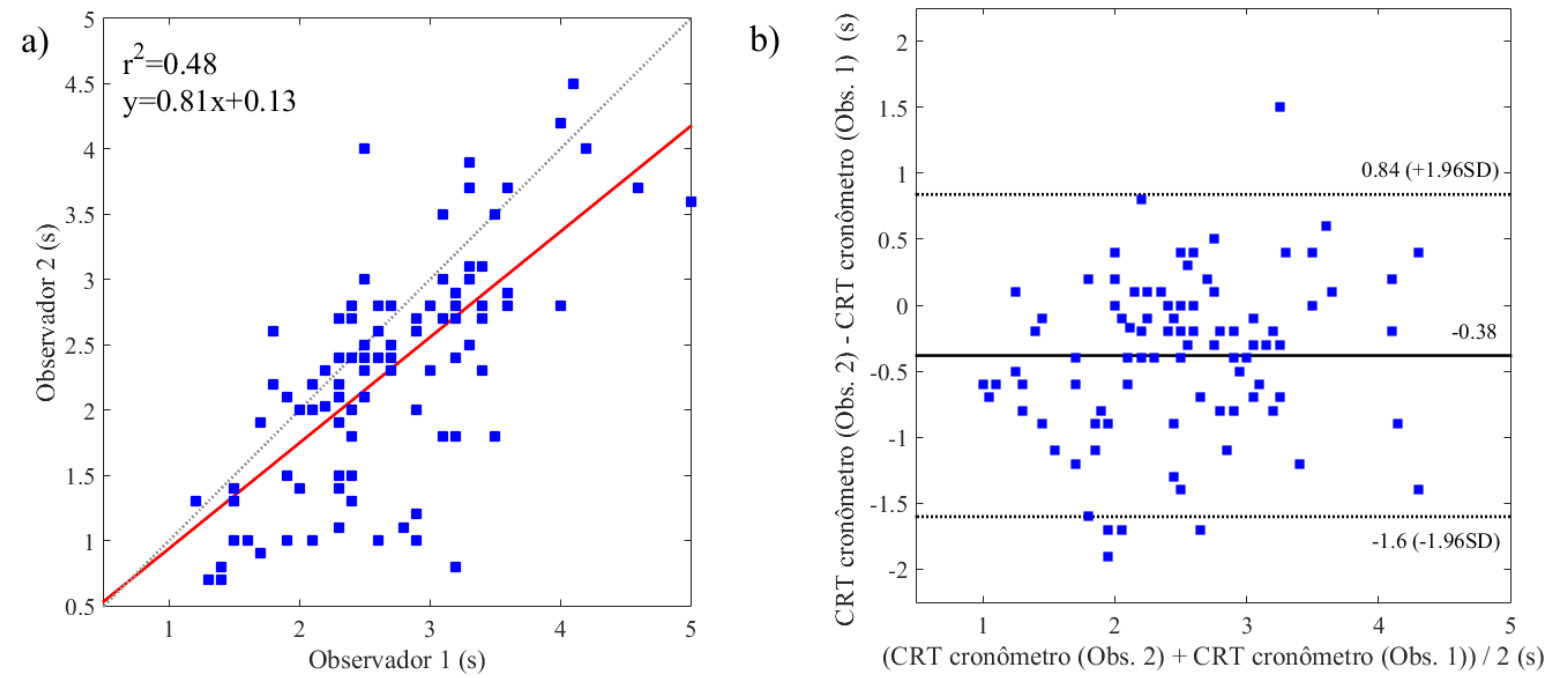

Figura 25. Tempo de enchimento capilar realizado pelo teste visual por dois observadores diferentes (Observador 1 e Observador 2) a) Distribuição dos dados obtidos pelo teste visual, $\mathrm{R}^{2}=51$ b) Análise Bland-Altman, linha cheia simboliza a média da diferença e linha pontilhada são os limites: superior e inferior iguais 1,96.SD. 

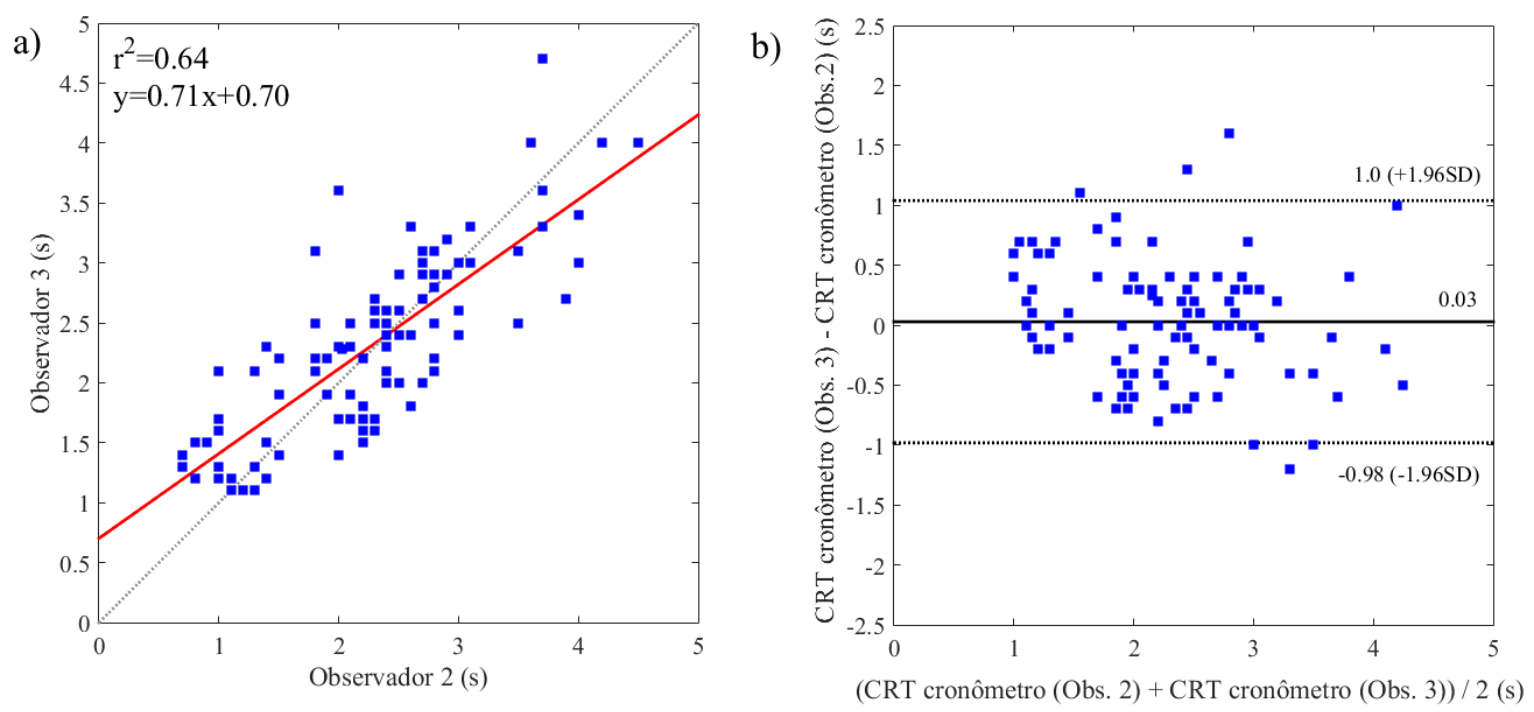

Figura 26. Medidas do tempo de enchimento capilar realizado pelo teste visual por dois observadores diferentes (Observador 2 e Observador 3) a) Distribuição dos dados b) Análise Bland-Altman, linha cheia simboliza a média da diferença e linha pontilhada são os limites: superior e inferior iguais 1,96.SD.
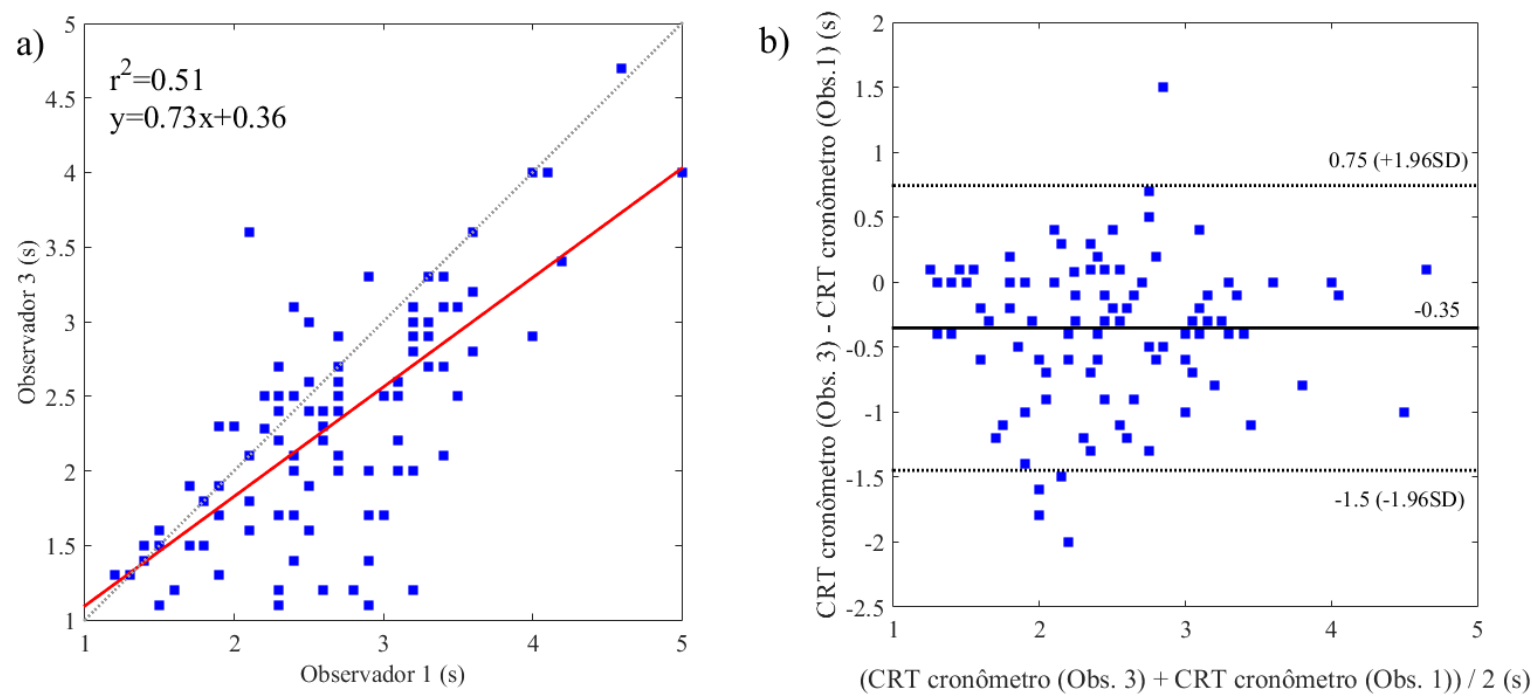

Figura 27. Medidas do tempo de enchimento capilar realizado pelo teste visual por dois observadores diferentes (Observador 1 e Observador 3). a) Distribuição dos dados. b) Análise Bland-Altman, linha cheia simboliza a média da diferença e linha pontilhada são os limites: superior e inferior iguais $1,96 . S D$. 
Apesar da alta variabilidade na determinação do CRT realizado a partir da observação dos vídeos, por três observadores, os resultados mostraram correlação significativa ( $r=P e a r s o n)$, para os observadores 2-3 (Figura 26) r=0,78. Já entre os observadores 1-2 (Figura 25) e 1-3 (Figura 27) apresentaram correlação menor, $r=0,68$ e $r=0,65$ respectivamente. Nossos resultados, pelo método de Bland-Altman apresentaram limites de 0,75 a 1,6 s. Uma possível explicação desses resultados esteja na forma de aquisição das imagens, como o uso dos polarizadores circulares, garantindo luz polarizada sem a interferência de outras fontes não polarizadas. Sem o uso dos polarizadores, como mostrados na literatura (ANDERSON et al., 2008b; VALENZUELA ESPINOZA; WELSH; DUBIN, 2014a; MARIA et al., 2016; SHINOZAKI et al., 2019a), a resposta é diferente, esses estudos mostraram apresenta alta variabilidade entre os observadores

\subsubsection{Teste de Reprodutibilidade do rCRT}

O teste de reprodutibilidade foi realizado em 22 participantes, foram realizadas cinco medidas consecutivas (intervalo de cerca 30 segundos) a fim de avaliar a estabilidade das medidas. A Figura 28(a) apresenta o histograma da distribuição dos dados de todos os voluntários, a média do rCRT foi de 4,4 $\pm 1,4 \mathrm{~s}$.
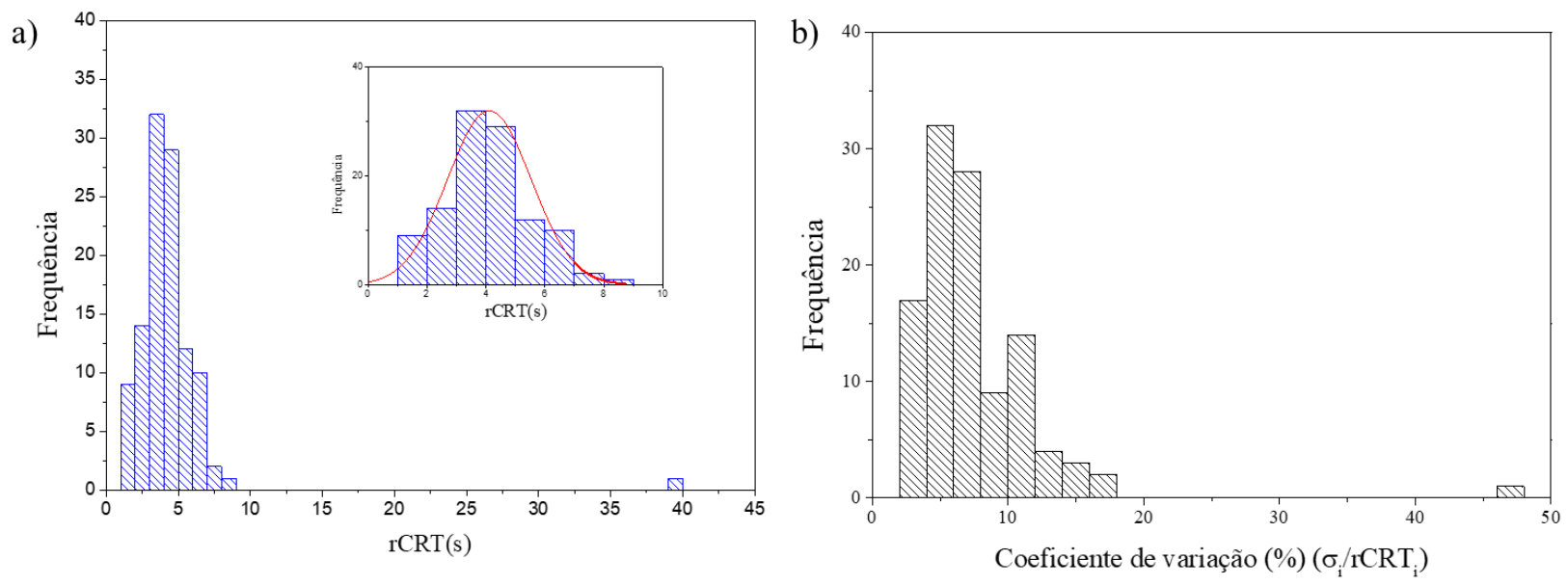

Figura 28. Distribuição de 110 valores de rCRT (5 repetições de 22 participantes). A tendência dos pontos segue uma distribuição Normal (Linha em vermelho). b) Histograma da resposta do coeficiente de variação das medidas, calculado pela razão entre a incerteza do ajuste da curva $\left(\sigma_{\mathrm{i}}\right)$ e o valor de rCRT dado: $\sigma_{\mathrm{i}} / \mathrm{rCRT}_{\mathrm{i}}$, para cada uma das 110 medidas. 
Calculamos o coeficiente de variação (CV) pela relação: $\sigma_{i} / \mathrm{rCRT}_{\mathrm{i}}$ (Figura 28(b)). O coeficiente de variação médio foi de $7 \%(2.2$ - 46.8) \%. Um único participante apresentou variação maior que $40 \%$ no valor do rCRT. Na maioria dos participantes, o CV entre às cinco medidas sucessivas, foi baixa $(<10 \%)$. Entretanto, em alguns participantes o CV foi alto, chegando a $46 \%$ em um participante.

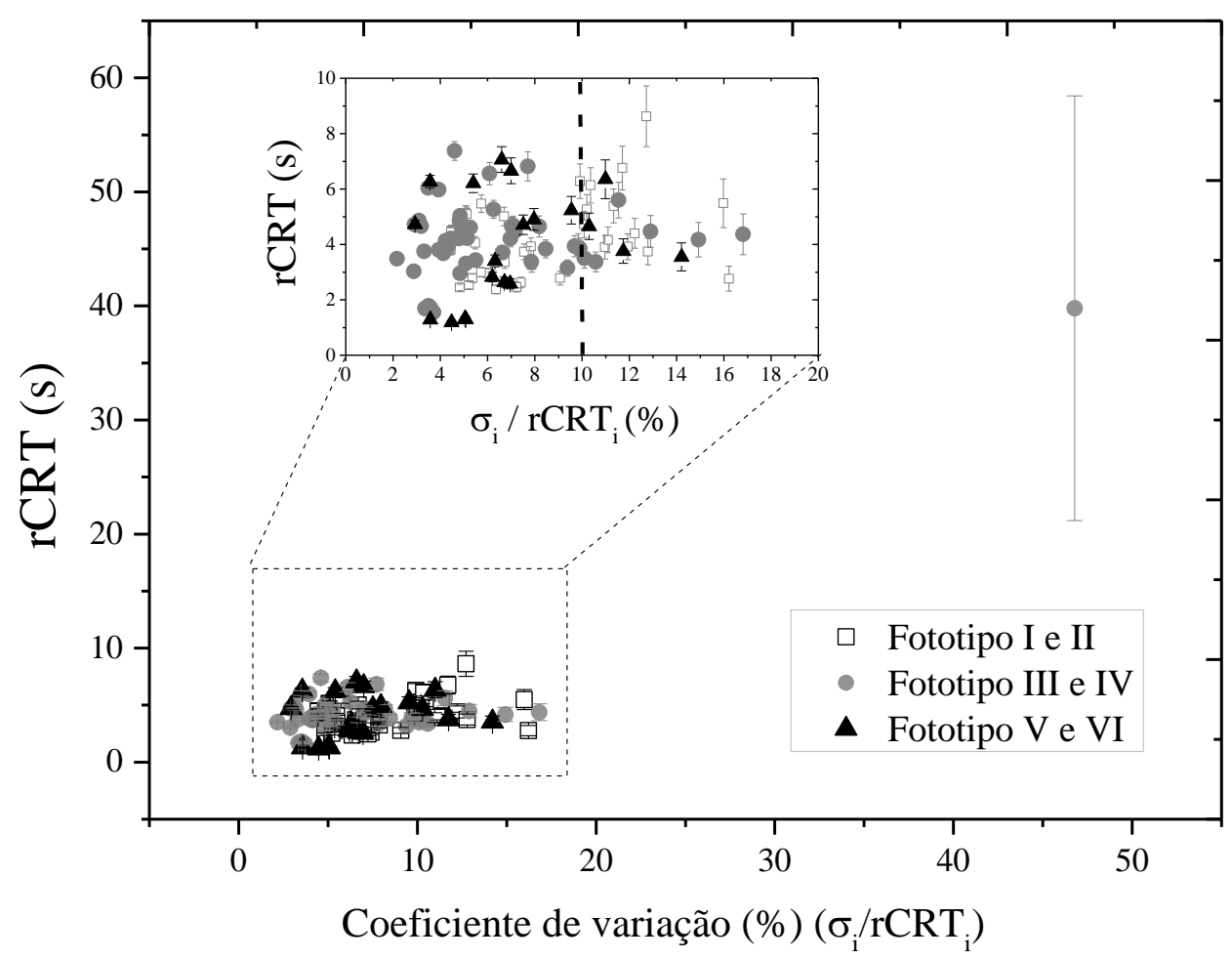

Figura 29. Valores do teste do Tempo de Enchimento Capilar pelo modo de reflexão (rCRT) em relação ao coeficiente de variação. Inset mostra zoom do intervalo do coeficiente de variação ( 0-20 \%), neste, linha pontilhada delimita a posição de $10 \%$ ponto escolhido para o criterio de rejeição. Os pontos mostram participantes de diferentes fototipos.

Durante o teste, alguns fatores podem inferir no estado de ativação do sistema nervoso simpático do voluntários. Acreditamos que o os valores altos do coeficiente de variação, possam estar relacionados com o aumento ou diminuição da frequência cardíaca (HR) durante o experimento, o que pode gerar altas variações nos valores de rCRT encontrados nesse estudo. Modificações na HR podem levar a alteração pontual da pressão arterial (PA) e ativação do sistema nervoso simpático, podendo alterar a microcirculação na perfusão periférica, e até mesmo alterar a viscosidade do sangue (JACQUET-LAGRÈZE et al., 2019). Fatores esses que levariam ao aumento do rCRT, estudamos essas relações com mais detalhes no Capítulo 4. A 
fim de garantir uma métrica que minimize o erro associado a uma única medição, definimos um critério de rejeição. Este critério sugere que a incerteza (IC 95\%) provinda do ajuste da curva do decaimento do canal verde, pode ser um indicador que a medida precisa ser repetida. Para essa investigação, fixamos o critério aceitável em menor que 10\% sobre o valor de rCRT em relação a sua incerteza (IC 95\%), como mostrado pela linha pontilhada na Figura 29. Valores de coeficiente de variação $\left(\sigma_{\mathrm{i}} / \mathrm{rCRT}_{\mathrm{i}}\right)$ acima de $10 \%$ foram excluídos (Figura 30). A rejeição desses valores leva a exclusão de 24 pontos.

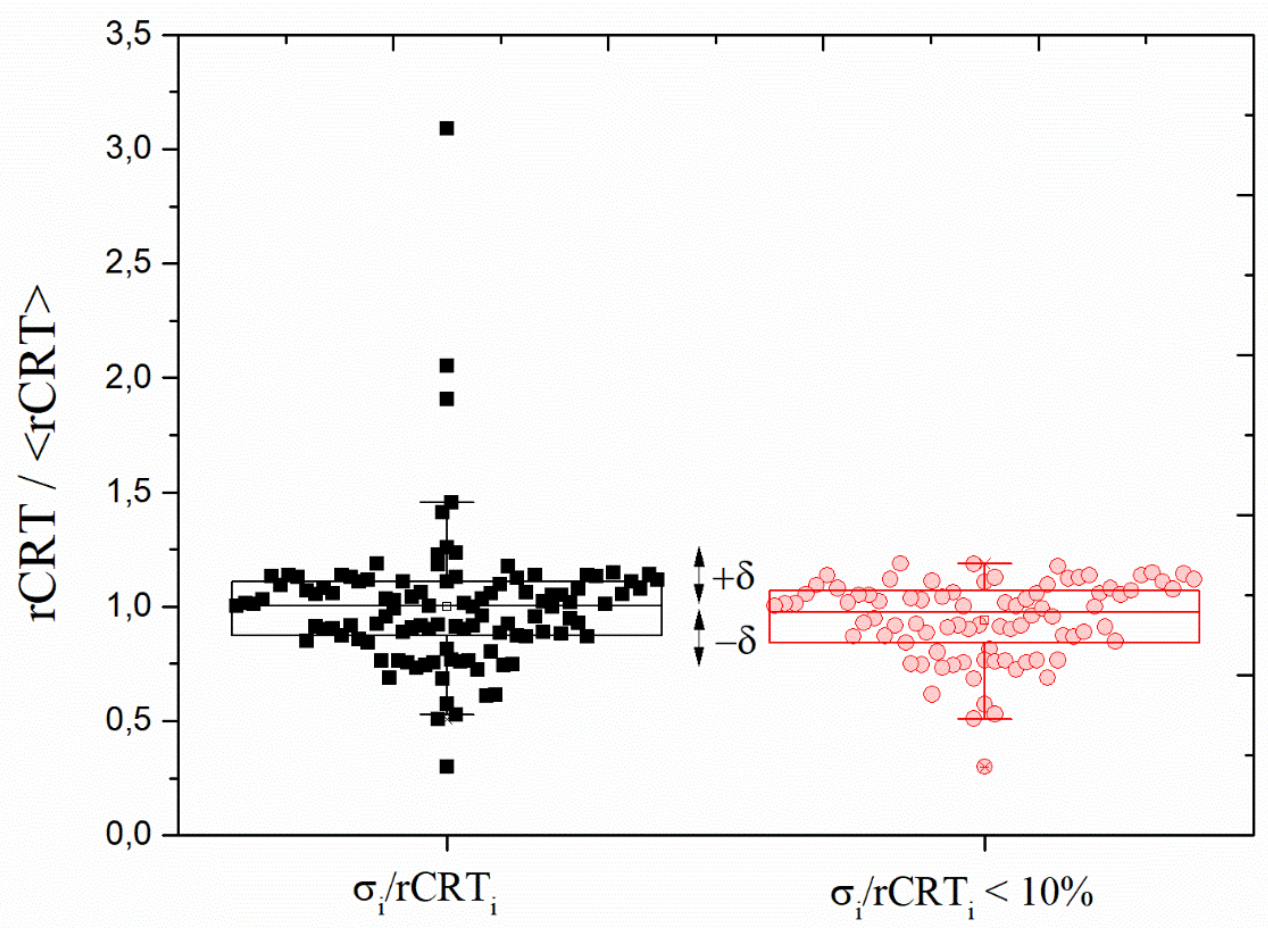

Figura 30. Distribuição do CV do rCRT normalizado pela média dos rCRT de cada voluntário. Quadrados: pontos antes da exclusão do critério de rejeição e círculos: após a análise de rejeição (rejeitados 24 pontos). $\delta$ é intervalo de incerteza especificado na Tabela 6 . Notar que os pontos experimentais estão dispostos em posições aleatórias diferentes no eixo horizontal em cada boxplot (Origin 9.0 trial version).

Para a análise do intervalo de incerteza $(\delta)$ (Máximo desvio aceitável em relação rCRT ponderado sob a média das cinco repetições), estabelecido pelo método proposto neste Capítulo. Fixamos os intervalos: $\pm 10 \%, \pm 15 \%, \pm 20 \%$ e $\pm 34 \%$, a fim de verificar uma faixa aceitável sem prejudicar o teste, como mostra na Figura 30. Esses intervalos causaram rejeição de um número $n$ de pontos, os resultados estão mostrados na Tabela 6 . 
Tabela 6. Resultado dos intervalos de incerteza $(\delta)$ para 86 pontos após a exclusão dos valores de coeficiente de variação - $\sigma_{\mathrm{i}} / \mathrm{rCRT}_{\mathrm{i}}>10 \%$.

\begin{tabular}{|c|c|c|c|c|}
\hline \multirow{2}{*}{$\mathrm{N}=86$} & \multicolumn{4}{|c|}{ Máximo Desvio (ס) } \\
\hline & $\pm 10 \%$ & $\pm 15 \%$ & $\pm 20 \%$ & $\pm 34 \%$ \\
\hline $\mathbf{n}$ & 56 & 63 & 67 & 81 \\
\hline Acerto & $65 \%$ & $73 \%$ & $78 \%$ & $94 \%$ \\
\hline
\end{tabular}

A falta de um "padrão ouro" para o CRT impede uma estimativa mais usual sobre o grau de confiança das reprodutibilidades do rCRT. Os resultados mostrados na Tabela 6 sugerem que realizando o teste de rCRT com a metodologia descrita nesse capítulo uma única vez, e aceitando o critério de rejeição do coeficiente de variação maior que $10 \%$ ( $\left.\sigma_{\mathrm{i}} / \mathrm{rCRT}_{\mathrm{i}}>10 \%\right)$, e fixando intervalo de incerteza $(\delta)$ de $\pm 20 \%$ (rCRT ponderado pela média), isto é os resultados mostram que em $78 \%$ dos casos o valor de rCRT obtido ajuste da curva do canal verde se repetiria na segunda medida dentro do intervalo $r C R T / \overline{r C R T} \approx 0,8 a 1,2$.

\subsubsection{Comportamento do rCRT com obstrução}

Realizamos um experimento para estudar os efeitos da obstrução (bloqueio com um manguito no braço esquerdo) nos testes de rCRT. Esse estudo foi dividido em duas partes:

i) Estudamos as modificações nas propriedades ópticas da superfície da pele em resposta com o tempo e a obstrução, utilizando como métrica o Índice de Eritema (EI).

ii) Analisamos a resposta do teste rCRT simultaneamente com a variação da obstrução.

\subsubsection{Estudo piloto : Influência da obstrução na intensidade dos canais RGB}

Neste estudo piloto aferimos a pressão arterial durante obstrução por $60 \mathrm{~s}$ com oclusão arterial de $40 \mathrm{mmHg}$, o que foi visto que a pressão arterial sistólica aumenta na 
ordem de $10 \mathrm{mmHg}$ durante a obstrução. O aumento da pressão arterial é causado pela vasodilatação provocada pelo influxo da artéria braquial, consequentemente altera a quantidade de volume de sangue na ROI (NAKANO et al., 2016), modificando assim, a resposta dos canais RBG durante a obstrução com a braçadeira.

Sendo assim, verificamos a influência da obstrução nas propriedades ópticas da superfície da pele. Avaliamos as modificações da reposta dos canais RGB durante a obstrução de $20 \mathrm{mmHg}$ e $40 \mathrm{mmHg}$ de duração de cerca de 40 s. A obstrução realizada na parte superior do braço, insuflando o manguito, tanto com obstrução de $20 \mathrm{mmHg}$ e $40 \mathrm{mmHg}$ causa redução da intensidade dos canais, indicados pela seta na Figura 31. Também é possível ver que após a liberação causa aumento na intensidade.
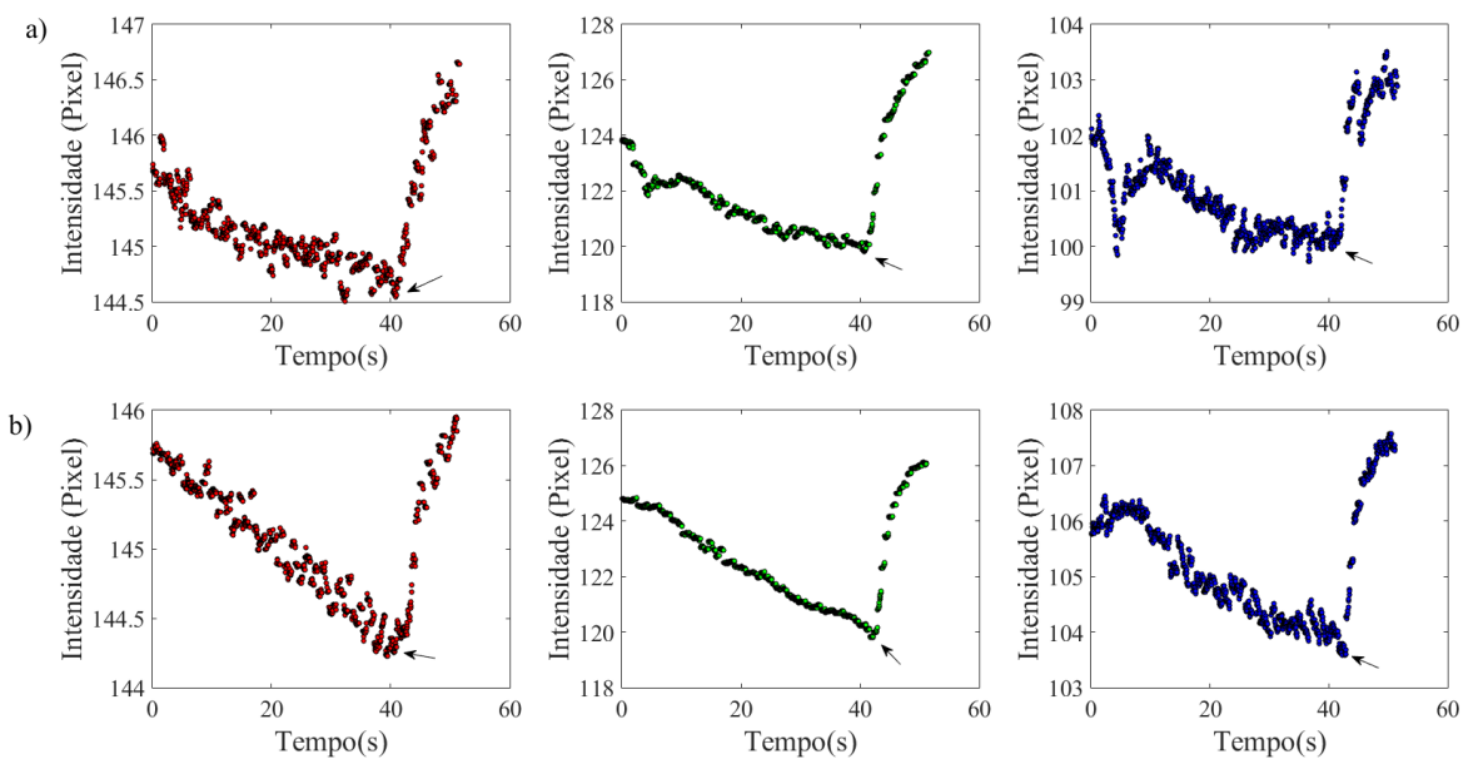

Figura 31. Intensidade no tempo dos canais RGB com obstrução de cerca de $40 \mathrm{~s}$, com obstrução: a) 20 mmHg e b) 40 mmHg. A seta mostra momento de liberação da obstrução.

O estudo piloto teve o intuito de verificar a dinâmica temporal dos canais em resposta com a obstrução. O crescimento significativo na intensidade, como mostra na Figura 31, após a liberação (depois de 40 s) ocorre a necessidade de espera entre as medidas, pois o crescimento na intensidade dos canais pode causar mudanças significativas nos resultados quando comparados. Pensando nisso, utilizamos o tempo de espera de 2 minutos, tempo necessário para ocorrer o retorno da intensidade inicial, ou seja, retorno da cor da pele no estado inicial do experimento, para assim, ser capaz de ter valores comparativos. Esse tempo foi usado no protocolo descrito na seção a seguir. 


\subsubsection{2 Índice de Eritema com obstrução}

Foi realizado um experimento com o intuito de se estudar o comportamento dos valores do índice de eritema durante a obstrução. Para isso, foi criado um protocolo para a realização do experimento, como ilustrado na Figura 32. Foram recrutados 7 participantes, os quais participaram de outros experimentos descritos nesse capítulo. Foram realizados duas obstruções com um esfigmomanômetro manual (Modelo mf-213 More fitness) de $20 \mathrm{mmHg}$ e $40 \mathrm{mmHg}$ com duração de 30 e 60 segundos no braço esquerdo dos participantes e, assim, adquiridos vídeos simultaneamente. Foram realizados duas repetições de cada obstrução, entre cada uma delas, foi solicitado ao voluntário que aguardasse 2 minutos com os braços posicionados paralelo ao corpo. Os vídeos registraram a mudança na intensidade RGB por $35 \mathrm{~s}$.

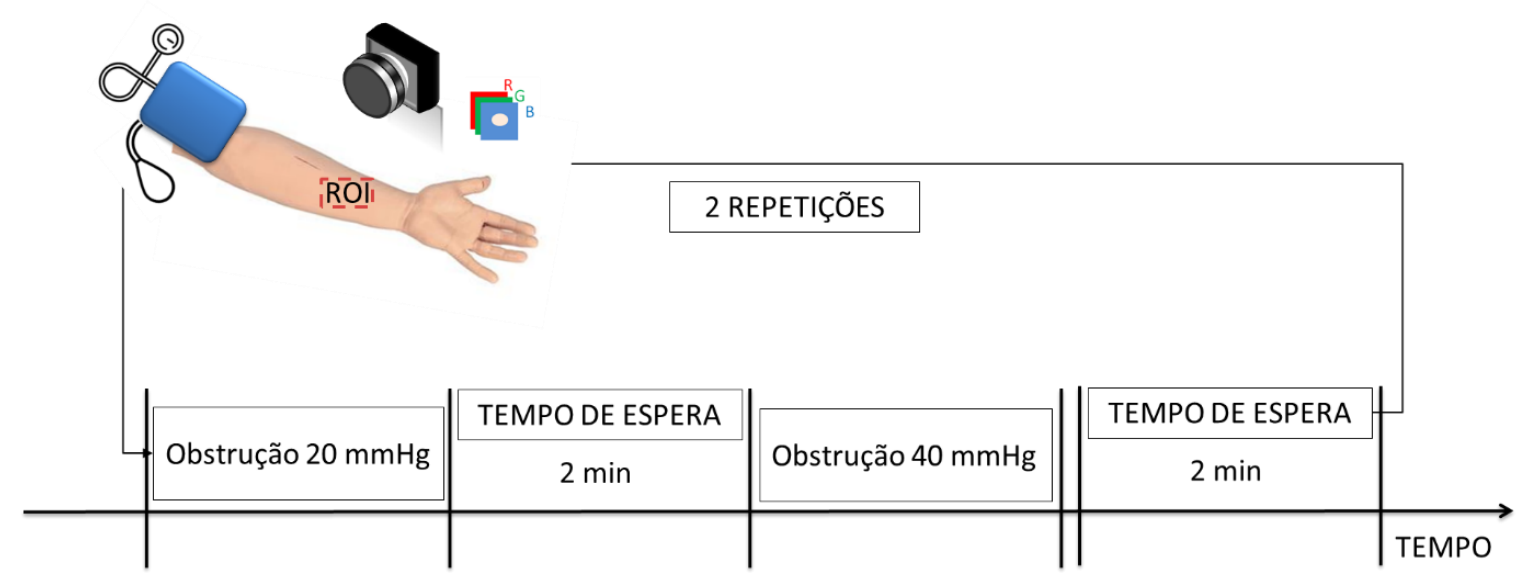

Figura 32. Protocolo usado para o teste da obstrução.

Para avaliação nas mudanças causadas na superfície da pele durante a obstrução, utilizamos a métrica do Índice de Eritema (Eq. 2.9), os resultados obtidos foram comparados com os valores de referência (sem obstrução). Nas obstrução de 40 mmHg com durações de 60 s, alguns participantes relataram dormência nas mãos durante o experimento, para esses casos, o teste foi anulado. Alguns participantes foram excluídos, devido ao alto ruído nas imagens, causado pela a movimentação do braço do participante durante o experimento.

As mudança na oxigenação em resposta à vasodilatação gerada pela obstrução, faz com que a pele adquira cor avermelhada o que possibilita calcular o Índice de Eritema (EI), expresso pela equação (YAMAMOTO et al., 2008): 


$$
\mathrm{EI}=\log \left(\frac{1}{\mathrm{R}_{\text {green }}}\right)-\log \left(\frac{1}{\mathrm{R}_{\text {red }}}\right),
$$

onde $\mathrm{R}_{\text {green,red }}$ é a intensidade normalizada do nível de intensidade de cada canal adquirido.

O resultado da dependência da cor da pele em resposta com a isquemia causada pela obstrução (Figura 33) corresponde com o esperado pelo cálculo do índice de eritema (EI), assim, conforme aumentamos a obstrução, maior o EI, fato explicado por dois fatores, segundo Nakano et al.(NAKANO et al., 2018) quando o influxo arterial braquial atinge um platô (após 80s de oclusão), o volume sanguíneo no braço continuará aumentando, causado pela saída do líquido intersticial que pode acumular fora dos vasos (NAKANO et al., 2016), mas também está associado com o aumento de óxido nítrico (NO) nos vasos sanguíneos da derme, substância capaz de modular o tônus microvascular na pele causando mudança na permeabilidade vascular (CLOUGH, 1999). Aumentando assim a cor avermelhada da pele e consequentemente o aumento do Índice de Eritema com o aumento da obstrução. Como mostrados nas Figura 34 , a distribuição dos valores do índice de eritema em resposta com o tempo de obstrução $30 \mathrm{~s}$ e $60 \mathrm{~s}$ respectivamente.

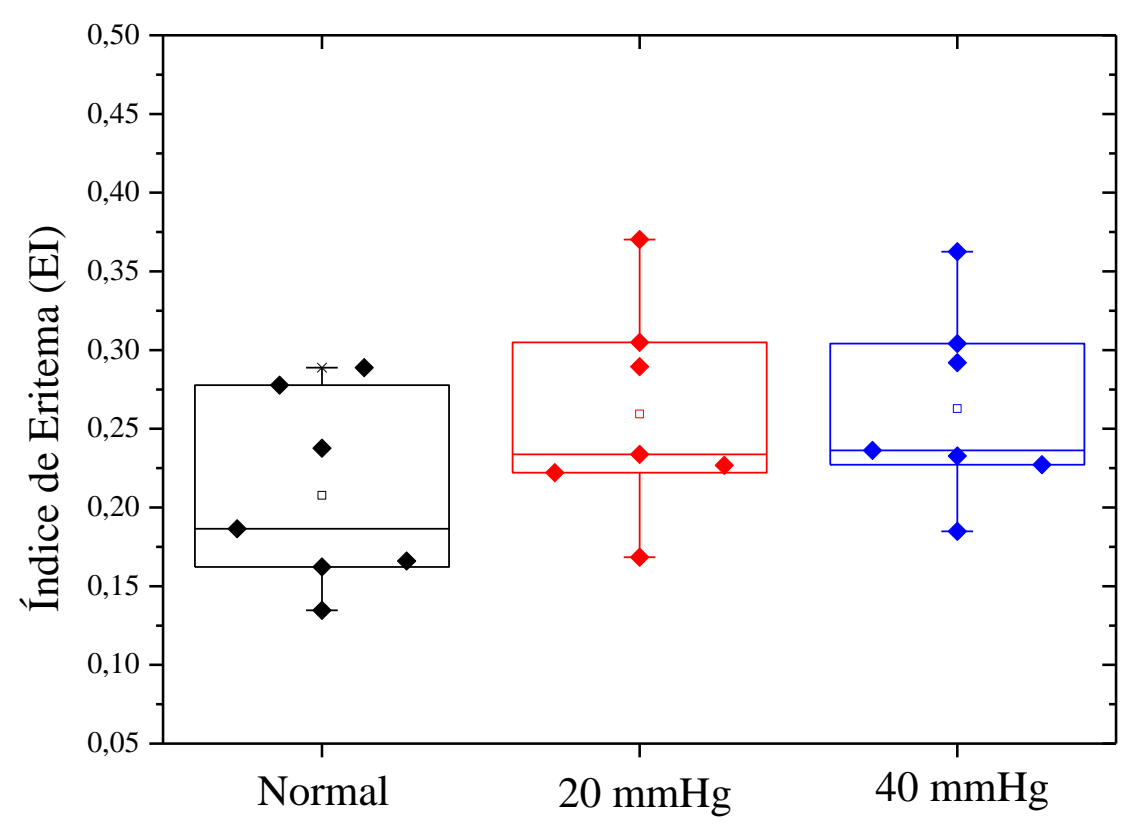

Figura 33. Valores Médios do Índice de eritema (EI) adquirido a partir do vídeo do antebraço de 7 voluntários sem obstrução(estado normal), com obstrução de 20 mmHg e 40 mmHg, com duração de $30 \mathrm{~s}$. 


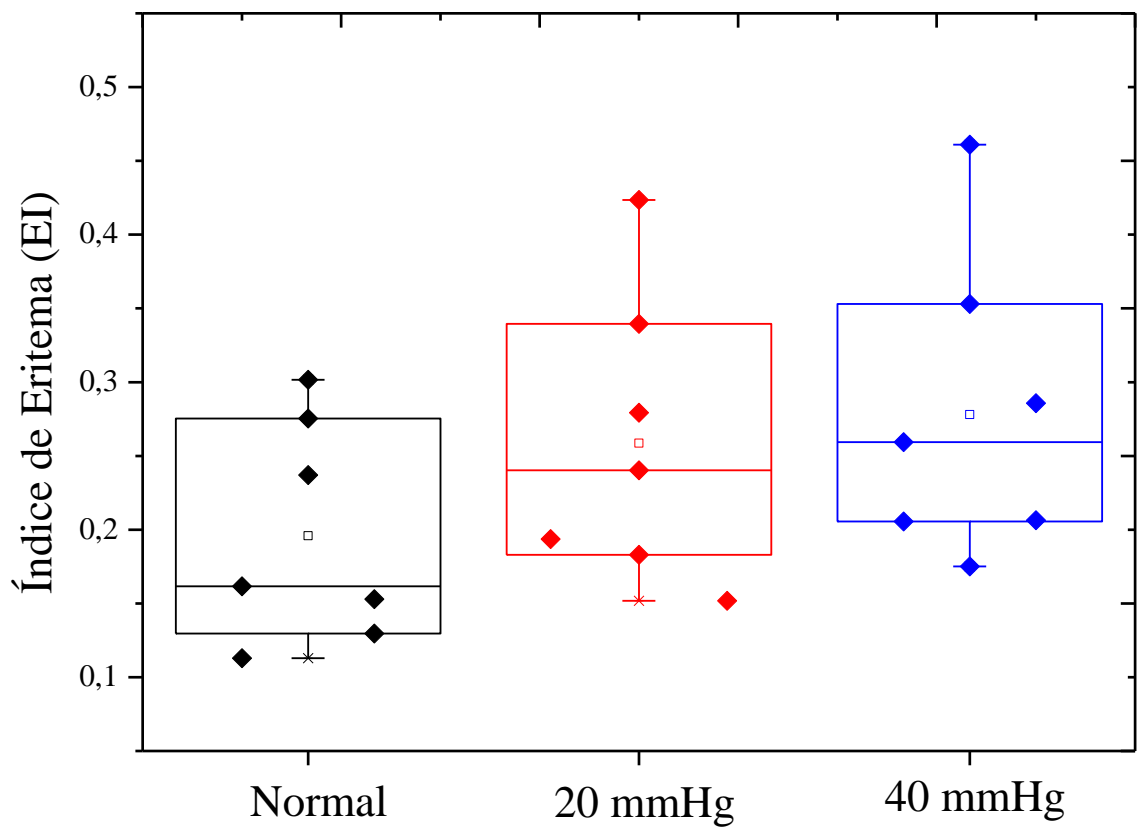

Figura 34. Valores Médios do Índice de eritema (EI) adquirido a partir do vídeo do antebraço de 7 voluntários sem obstrução (estado normal), com obstrução de 20 mmHg e 40 mmHg, com duração de $60 \mathrm{~s}$.

\subsubsection{Estudo do rCRT}

$\mathrm{Na}$ segunda etapa, estudamos a resposta do teste do tempo de enchimento capilar por reflexão (rCRT) em resposta com oclusão realizada no braço esquerdo. Para isso, foram recrutados outros seis voluntários. O objetivo dessa etapa é estudar a relação entre o aumento de pressão arterial induzida pela oclusão em resposta com os valores do rCRT.

Com o protocolo descrito na Seção anterior (Figura 32) foi adquirido as imagens, entretanto, desta vez, simultaneamente com as obstruções (20 mmHg e $40 \mathrm{mmHg}$ ) com duração de $60 \mathrm{~s}$, foi realizado o teste de $\mathrm{rCRT}$, exercendo compressão de $7 \mathrm{kPa}$ no antebraço esquerdo por $5 \mathrm{~s}$. Os resultados mostram que o leve eritema não impediu a realização do rCRT. Como é possível observar na Figura 35, o aumento da oclusão leva à diminuição do rCRT, de forma que a resposta da ativação do aumento da pressão arterial sistólica causada pela obstrução (como mostrou no estudo piloto descrito na Seção 2.4.8.1) gera resposta na perfusão periférica. A correlação dos valores de rCRT com os vários parâmetros fisiológicos medidos encontra-se no 
Apêndice B, no entanto são necessárias mais pesquisas para entender o significado fisiológico e a faixa normal dos valores para cada um dos parâmetros estudados.

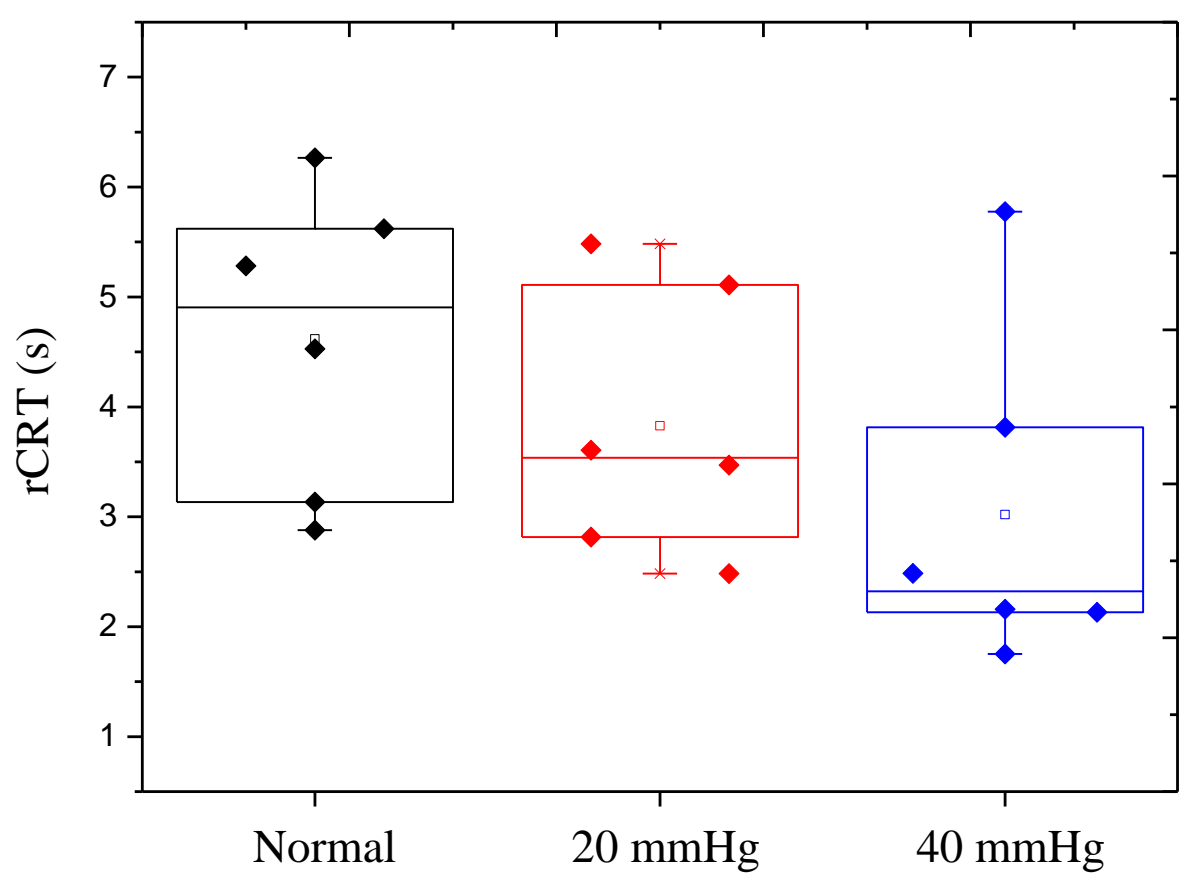

Figura 35. rCRT em resposta com o aumento da oclusão com duração de 60 s em 6 participantes.

\subsection{Conclusão parcial}

Este estudo mostrou boa concordância da dinâmica temporal do canal verde sugerindo que a metodologia abordada permite a determinação de um tempo característico (rCRT) que pode ser relacionado quantitativamente e de forma objetiva com o CRT.

Uma das limitações esse método é a alta dependência da movimentação do braço dos participantes durante a medição, pois o movimento altera a intensidade da luz que penetra na pele, alterando a distância da fonte de luz, e modifica a orientação da superfície da pele em relação à fonte de luz. Entretanto, o uso dos polarizadores, na fonte de luz e na câmera contornam essa limitação. Consequentemente possibilita quantificar o rCRT em diferentes fototipos de peles.

Utilizando um dispositivo com leve compressão $(7 \mathrm{kPa})$ na superfície da pele, foi suficiente para causar mudanças na cor da pele e assim quantificar o rCRT, podendo ser 
aplicado em pacientes com pele sensível ou danificadas, como é o caso de pacientes diabéticos ou idosos.

Os resultados do teste visual mostraram fraca correlação entre os observadores, mostrando a necessidade em se ter uma metodologia que proporcione o resultado do CRT de forma reprodutível.

Por fim, a metodologia aqui proposta garante que realizando o teste em uma única medida e aceitando o critério de rejeição em relação ao coeficiente de variação $\left(\sigma_{i} / r_{C R T}\right)$ para valores maiores que $10 \%$, e intervalo de incerteza $(\delta)$ maiores que $\pm 20 \%$, os resultados mostram que em mais de $78 \%$ dos casos o valor de rCRT obtido pelo ajuste da curva do canal verde se repetiria na segunda medida. Assim, o método rCRT é bastante promissor. 


\section{CAPÍTULO 3}

A fotopletismografia é uma das técnicas mais populares para o monitoramento das condições fisiológicas. Por ser um método não invasivo, tem sido amplamente aplicado em dispositivos portáteis, além de dispensar a utilização de um sinal de referência, se tornou um dispositivo mais acessível do que os atuais sistemas de monitoramento de Eletrocardiografia (ECG). Neste capítulo buscamos uma relação entre a perfusão periférica com a circulação na aorta torácica através da análise de fotopletismografia de dedo.

\section{Fotopletismografia}

\subsection{Fisiologia do Sinal fotopletismográfico}

A morfologia do sinal de PPG é similar ao pulso da pressão arterial, entretanto, o contorno da onda não é o mesmo, como pode ser visto na Figura 36 (HALL; GUYTON, 2011). A relação entre o sinal PPG e o pulso de pressão foi quantificado por Millasseau et al. (MILLASSEAU et al., 2002). Os vasos sanguíneos da ponta do dedo possuem abundância de receptores alfas adrenérgicos que afeta a vasoconstrição das artérias e veias (estreitando os vasos sanguíneos), assim, a sensibilidade causada pela mudança no sistema simpático é maior do que quando comparado com outras áreas do corpo como ponta da orelha. (ALIAN; SHELLEY, 2014).

A pulsação se torna menor nas artérias menores como arteríolas e principalmente nos capilares (Figura 36). Somente quando a pulsação da aorta é alta, se tem modificações nos capilares. A diminuição progressiva das pulsações na periferia é chamada amortecimento dos pulsos de pressão, possuindo duas causas principais (HALL; GUYTON, 2011):

i. Resistência circulatória: as pulsações amortecidas devido à uma pequena quantidade de sangue que flui para frente da onda de pulso de forma a distender o próximo segmento do vaso; quanto maior a resistência, menor a probabilidade para que este fenômeno aconteça.

ii. Complacência: quanto mais complacente um vaso, maior a quantidade de sangue necessária na frente da onda de pulso, causando um aumento na pressão. 


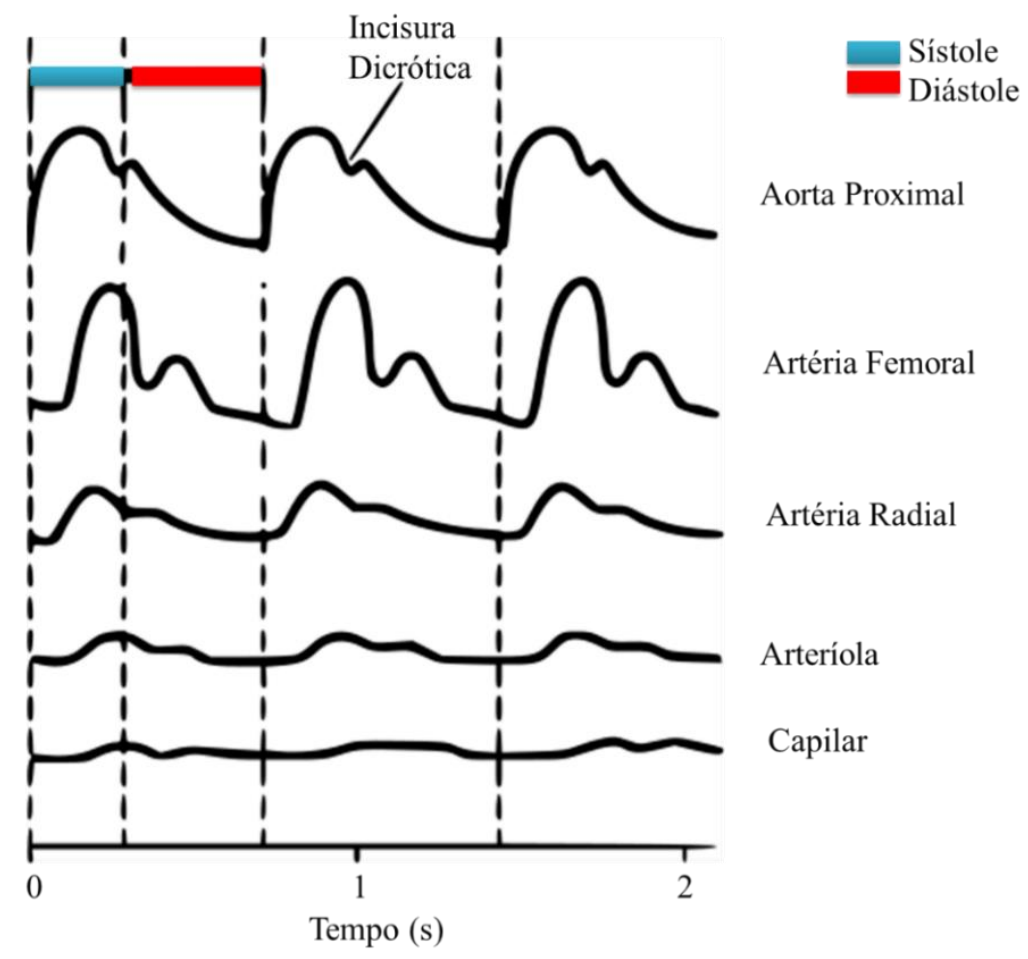

Figura 36. Contorno do pulso de pressão que se propaga no sistema circulatório. Aorta Proximal, Artérias Femoral e Radial, Arteríola e Capilar. Fonte: adaptado (HALL; GUYTON, 2011).

Portanto, o grau de amortecimento é diretamente proporcional ao produto da resistência e da complacência (HALL; GUYTON, 2011). Usualmente o pulso de PPG exibe dois picos e um ponto de inflexão (Figura 37). O primeiro pico aparece precocemente na sístole e o segundo pico é tardio e aparece na fase inicial da diástole. Os picos são separados por um ponto de inflexão chamado incisura dicrótica. $\mathrm{O}$ primeiro pico é formado principalmente pela transmissão da onda de pressão ao longo da extensão das artérias entre o ventrículo esquerdo e a extremidade do dedo, onde é gerada uma alteração de volume do sangue e o sinal é gravado medindo a transmissão da luz infravermelha na ponta do dedo. Como ilustra a Figura 37, a componente sistólica da forma de onda surge principalmente como uma onda de pressão progressiva transmitida (T) ao longo de um caminho direto do ventrículo esquerdo para o dedo (MILLASSEAU et al., 2002). O segundo pico (componente diastólica) surge principalmente das ondas de pressão transmitidas ao longo da aorta para pequenas artérias na parte inferior do corpo, onde são refletidos de volta como uma onda refletida (R) (MILLASSEAU et al., 2002). A onda de pulso é transmitida ao longo da aorta e das grandes artérias até os sítios de reflexão, onde são refletidas e retornam para aorta e subsequentemente para a raiz da artéria subclávia, 
sendo transmitidas artéria radias até a ponta dos dedos. Alguns estudos (MILLASSEAU et al., 2000; BARUCH et al., 2011; ELGENDI, 2012) mostraram que os picos diastólicos do sinal de PPG são menos expressivos em idosos e pessoas sedentárias.

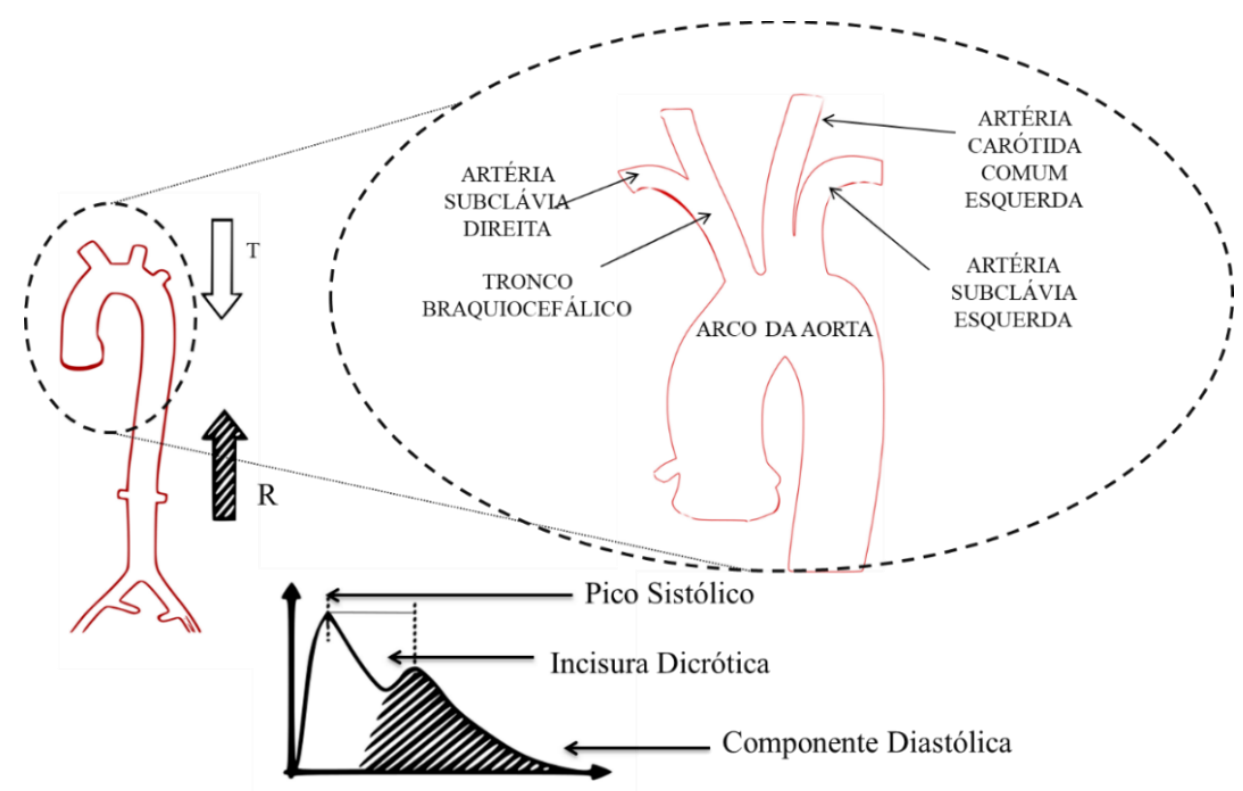

Figura 37. Modelo da formação do sinal de PPG. Arco aórtico com as artérias principais e sentido da onda transmitida $(\mathrm{T})$, onda refletida (R) devido aos sítios de bifurcação. Fonte: adaptado (MILLASSEAU et al., 2002; ELGENDI, 2012).

\subsection{Pulsação do sangue}

A interação da luz com a pele, tecidos e sangue é complexa (ANDERSON; PARRISH, 1981; MOYLE, 2002) e inclui processos ópticos de espalhamento, absorção reflexão, transmissão e fluorescência, pois reflete nas diferentes estruturas (MOYLE, 2002).

A luz que penetra o tecido biológico é absorvida ao longo do seu caminho por diferentes substâncias (WEBSTER, 1997), como estruturas biológicas e compostos químicos que absorvem no mesmo comprimento de onda que a hemoglobina encontrada no sangue arterial. Devido ao ritmo cardíaco, a absorção da luz nas artérias e arteríolas aumenta durante a sístole e diminui durante a diástole (MOYLE, 2002), representando uma variação 1-2\% da absorção total. Será discutido nas Seções a seguir como a variação da absorção da luz está relacionada com o aumento de diâmetro das artérias e arteríolas durante a sístole. 


\subsection{Componentes da onda de PPG}

O sinal produzido pela luz ao atravessar a pele é separado em duas componentes: continua ou estática (DC) e alternada (AC). A componente DC, corresponde ao sinal óptico transmitido ou refletido detectado pelo tecido e depende da estrutura do tecido (pigmentação da pele) e do volume médio de sangue arterial e venoso. Essa, possui pouca variação devido a respiração; a termorregulação e a atividade do sistema nervoso. A componente AC mostra alterações no volume sanguíneo que ocorre entre as fases sistólica e diastólica do ciclo cardíaco. Essa parte não excede 1-2\% da quantidade de absorbância da componente DC (WEBSTER, 1997). A frequência fundamental da componente AC depende da frequência cardíaca (MOYLE, 2002). A Figura 38, mostra de forma esquemática a mudança de intensidade do sinal do pulso de fotopletismografia durante a propagação da luz na pele. Durante um ciclo cardíaco, o diâmetro das artérias ou arteríolas, modificam de $d$ min para $d$ max.

Na sístole, o diametro da artéria aumenta (dmax) devido ao aumento da pressão, nessa fase, a intensidade de luz, escrita como (WEBSTER, 1997) baseada na Lei de Beer-Lambert (Eq. 2.2):

$$
I_{L}=I_{O} \exp \left(-\varepsilon_{D C}(\lambda) c_{D C} d_{D C}\right) \exp \left(-\left[\varepsilon_{H b}(\lambda) c_{H b}+\varepsilon_{H b O_{2}}(\lambda) c_{H b O_{2}}\right] d \max \right),
$$

onde $I_{L}$ é intensidade de luz transmitida e na sístole essa intensidade é mínima (low peak), $I_{O}$ a quantidade de luz incidente. Já, durante a diástole a intensidade de luz transmitida é alta $\left(I_{H}\right)$ e o diametro durante esta fase é mínimo $d \min$ :

$$
I_{H}=I_{O} \exp \left(-\varepsilon_{D C}(\lambda) c_{D C} d_{D C}\right) \exp \left(-\left[\varepsilon_{H b}(\lambda) c_{H b}+\varepsilon_{H b O_{2}}(\lambda) c_{H b O_{2}}\right] d \min \right),
$$

onde $\varepsilon_{D C}(\lambda) c_{D C} d_{D C}$ são coeficientes da componente não pulsátil (DC).

No oximetro clinico, apenas a componente AC da luz absorvida é exibida (WEBSTER, 1997), como mostrado na Figura 38(b) . A componente DC criada principalmente pela absorção de luz pelo tecido circundante é eliminada para garantir que a forma de onda permaneça na tela de exibição. Esses dispositivos possuem uma função de ganho automática projetada para maximizar o tamanho do pulso exibido, o que permite analisar a amplitude do pulso (SHELLEY, 2007; TAMURA et al., 2014). 

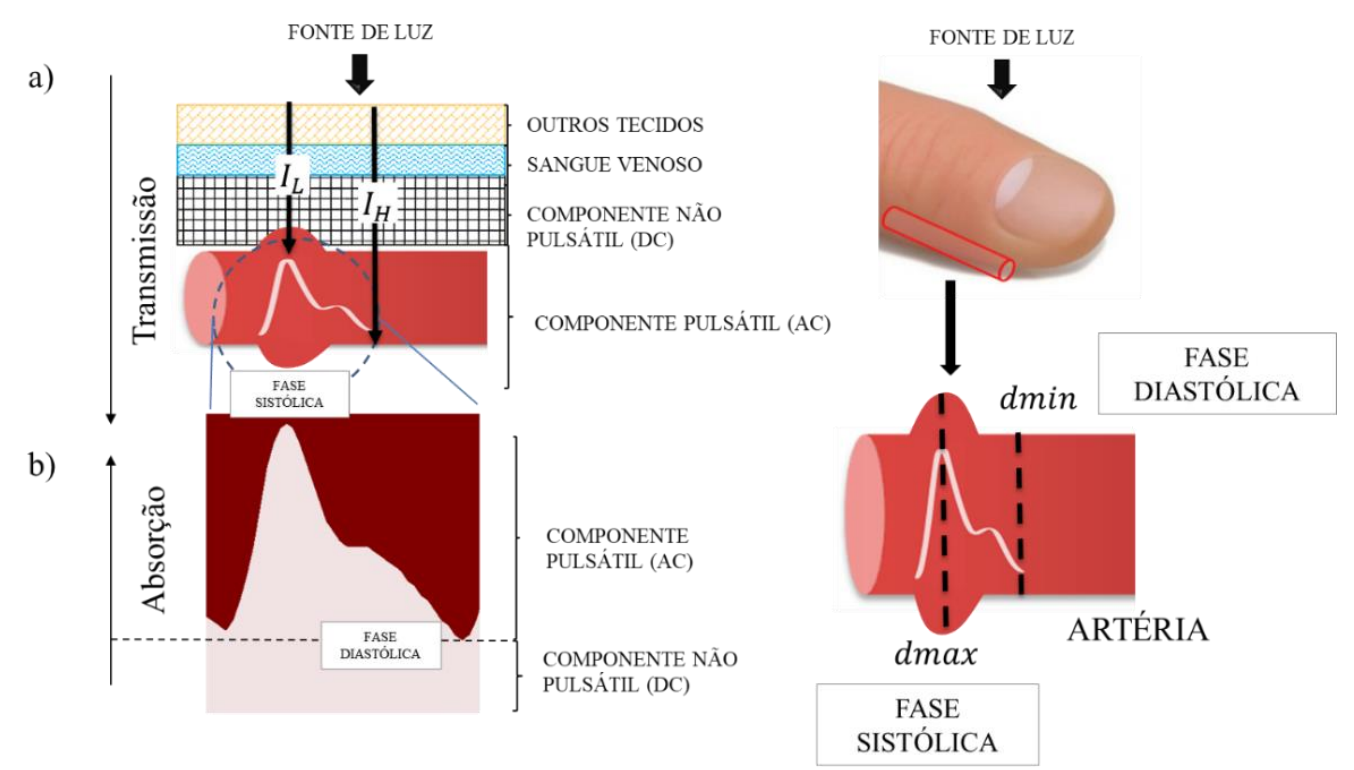

Figura 38. Modelo esquemático da variação da atenuação da luz no tecido separado pelas componentes AC e DC. a) Interação da luz em cada camada e Gráfico da Transmissão apresenta aumento na diástole e diminuição na sístole. b) Gráfico de absorção do sinal de fotopletismografia no tempo do sinal obtido pelo oxímetro no dedo esquerdo de um voluntário da pesquisa, picos máximos de absorção na sístole e mínimo na diástole. Fonte: Adaptado (TAMURA et al., 2014).

\subsection{Modos de operação da fotopletismografia}

O PPG mais utilizado é o de forma não invasiva e opera no comprimento de onda vermelho $(660 \mathrm{~nm})$ ou próximo do infravermelho $(940 \mathrm{~nm})$. Sua forma de onda mais conhecida é o pulso periférico e é sincronizado a cada batimento cardíaco (WEBSTER, 1997). Este sinal é comumente modelado pela Lei Beer-Lambert (Eq.2.1), (Figura 39) que descreve a quantidade de luz absorvida por uma amostra, como uma relação da atenuação com a penetração da luz no tecido. A absorbância da luz nas artérias aumenta durante a sístole, principalmente devido à maior quantidade de substâncias absorventes (hemoglobina), associado ao fato de que o comprimento do caminho óptico (d) aumenta (WEBSTER, 1997).

A variação temporal na intensidade da luz recebida pelo fotodetector depende principalmente de alguns fatores:

- Variações no fluxo total de sangue (venoso e arterial),

- Orientação e concentração dos eritrócitos (WEBSTER, 1997). 


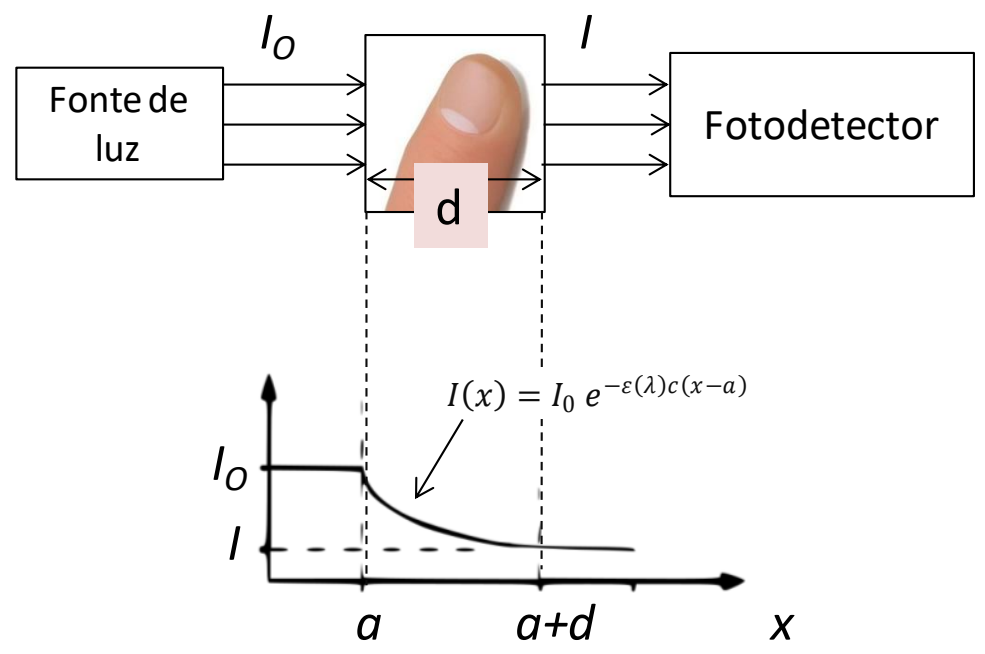

Figura 39. A intensidade de luz incidente $I_{0}$ que se propaga a uma distância (a) até atingir o meio (d), a partir desse ponto, a intensidade decai exponencialmente com a distância de penetração devido a absorção do meio. A intensidade de luz (I) é determinada pela Lei de Beer-Lambert a partir desse ponto, se mantém constante até atingir o fotodetector. Fonte: adaptada (WEBSTER, 1997).

O PPG possui dois modos de operação (Figura 40) (Tamura et al. 2014b):

i. Modo de transmissão (Figura 40(a)): a luz após ser transmitida pelo meio é detectada por um fotodetector posicionado oposto à fonte de luz, entretanto, o local de medição pode ser um fator limitador. O sensor deve estar localizado em um local onde a luz transmitida possa ser facilmente detectada, como a ponta do dedo, lóbulo da orelha, septo nasal, bochecha, língua (estes três últimos, somente usados em anestesia). A ponta do dedo e o lóbulo da orelha são as posições mais utilizadas na clínica, mesmo com perfusão sanguínea limitada. Além disso, são mais suscetíveis a baixas temperaturas. A maior desvantagem é que o sensor na ponta do dedo interfere nas atividades diárias.

ii. Modo de reflexão (Figura 40(b)): o fotodetector detecta a luz que é retrocedida (espalhada ou refletidas) em tecidos, ossos e vasos sanguíneos em vários locais de medição como antebraço, coxa e testa (MOYLE, 2002). No entanto, este modo é afetado por artefatos de movimento como atividade física, corrompendo o sinal e limitando a acurácia dos parâmetros fisiológicos obtidos. 
a)

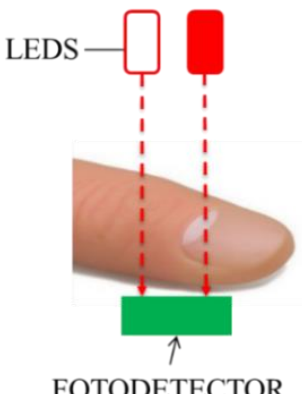

b)

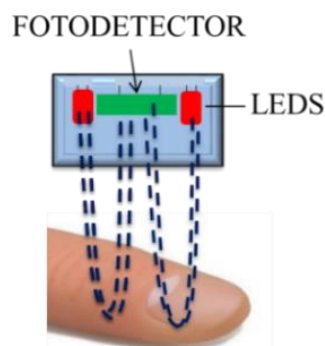

Figura 40. Modelo esquemático de um dispositivo oxímetro medido na ponta do dedo a) tipo de transmissão e b) modo reflexivo.

\subsection{Fatores que afetam o sinal do PPG}

Alguns fatores fisiológicos afetam no formato do pulso do sinal do PPG. Segundo Khan et al. a hipertensão essencialmente afeta as propriedades regionais da parede da aorta. Essas alterações se manifestam pelo aumento: da velocidade de onda periférica e das reflexões das ondas ao longo da aorta (KHAN et al., 2018). A Tabela 7 mostra alguns dos fatores que afetam a amplitude do sinal do PPG (SHELLEY, 2007)

Tabela 7. Alguns dos fatores que afetam a amplitude do pulso de PPG.

Fatores que afetam a amplitude do pulso de PPG:

\section{Diminuição da amplitude:}

Vasoconstrição;

Farmacológica: epinefrina e fenilefrina;

Psicológica: estado de stress, frio.

\section{Aumento da amplitude}

Vasodilatador;

Farmacológica: nitroprussiato;

Psicológica: sedação, calor;

Anestesia - Bloqueio Regional - Simpático (espinha e peridural).

Fonte adaptado (SHELLEY, 2007) 


\subsection{Análise do pulso de fotopletismografia}

Um modo de estudar o PPG, é avaliar o contorno de onda, para isso é preciso entender como o pulso se forma. Durante o ciclo cardíaco, os eritrócitos mudam de posição. Na diástole, tendem a alinhar seu diâmetro paralelamente à direção do fluxo, enquanto na sístole o alinhamento é perpendicular ao fluxo, o que leva ao aumento da absorção da luz nesta fase (MOYLE, 2002). Essa hipotese corrobora com o encontrado por Kamshilin et al..Os autores utilizaram um modelo de obtenção do sinal de PPG de forma remota (modo de reflexão) (KAMSHILIN; MARGARYANTS, 2017) baseado na interação da luz com o tecido (HALL; GUYTON, 2011). Assim, o sinal de PPG se origina da modulação do volume sanguíneo no leito capilar, que é induzido pela pressão transmural pulsátil das artérias

Com isso, na sistole, propaga mais fluxo sanguineo nas arterias do que na diástole, fazendo com que o diâmetro das arterias aumente devido ao aumento da pressão. Na sístole, a pressão transmural (pressão de enchimento do ventriculo esquerdo) comprime o tecido conjuntivo da derme, que possui somente capilares sanguíneos e linfáticos que são incompressíveis e não pulsam na frequência cardíaca.

O pulso registrado em membros periféricos é influenciado principalmente pela característica da árvore arterial (MILLASSEAU et al., 2002; NOVAIS, 2006; NICHOLS et al., 2007). Essas alterações são devido à mudança de impedância nas bifurcações de grandes artérias, enrijecimento e aumento da velocidade de onda de pulso. Deste modo, as grandes artérias podem ser estudadas utilizando a avaliação do pulso periférico (MILLASSEAU et al., 2002).

Para verificar essa alterações no formato do pulso, Baruch et al, propõe o uso da Através da Análise de Decomposição de Pulso (PDA) (BARUCH et al., 2011). A partir desta, é possível modelar um único pulso como uma superposição linear de funções de base (COUCEIRO et al., 2015). Pelo algoritmo de otimização por aproximação de um dado pulso pelo modelo PDA (TIGGES et al., 2017) é possível obter o tempo de ejeção do ventrículo esquerdo pelo sinal de PPG da ponta do dedo (COUCEIRO et al., 2015). Diferentes modelos têm sido empregados na literatura, incluindo superposição com quatro gaussianas (SORELLI; PERRELLA; BOCCHI, 2018), e também outras funções como Log-Normal e Rayleigh (GOSWAMI; CHAUDHURI; MUKHERJEE, 2010). 
A Figura 41 mostra esquematicamente o modelo de PDA. O pulso de pressão primário marcado por $\mathrm{P}_{\mathrm{O}}$, origina os pulsos $\mathrm{P}_{1}$ e $\mathrm{P}_{2}$ devidos aos locais de reflexão renal e ilíaca respectivamente nos quais o pulso $\mathrm{P}_{\mathrm{O}}$ atingiu (BARUCH et al., 2011; TIGGES et al., 2017). O pulso $\mathrm{P}_{1}$ é comumente conhecido como o "segundo pico sistólico". Os locais de reflexão são causados por pulsos de pressão arterial refletido que se propagam na direção contrária do pulso de pressão arterial, devido à contração do ventrículo esquerdo (BARUCH et al., 2014). As ondas de pressão refletidas $\left(\mathrm{P}_{1}\right.$ e $\left.\mathrm{P}_{2}\right)$ alcançam o arco aórtico e chegaram às artérias subclávias e se propagam para a periferia arterial do braço, seguindo o pulso de pressão Po que, além de viajar pela aorta, chega às artérias do braço. Os pulsos $\left(\mathrm{P}_{1}\right.$ e $\left.\mathrm{P}_{2}\right)$ chegarão com certos atrasos devido à passagem "extra" das artérias centrais, estes são formados em parte pela pressão transmitida ao longo da aorta e grandes artérias até regiões de impedância, onde são refletidos novamente pela aorta (MILLASSEAU et al., 2002; BARUCH et al., 2011). Este fato, explica sucintamente a presença de três ondas no envelope do pulso de pressão que é observado na artéria periférica do braço, como nas artérias radial ou digital.
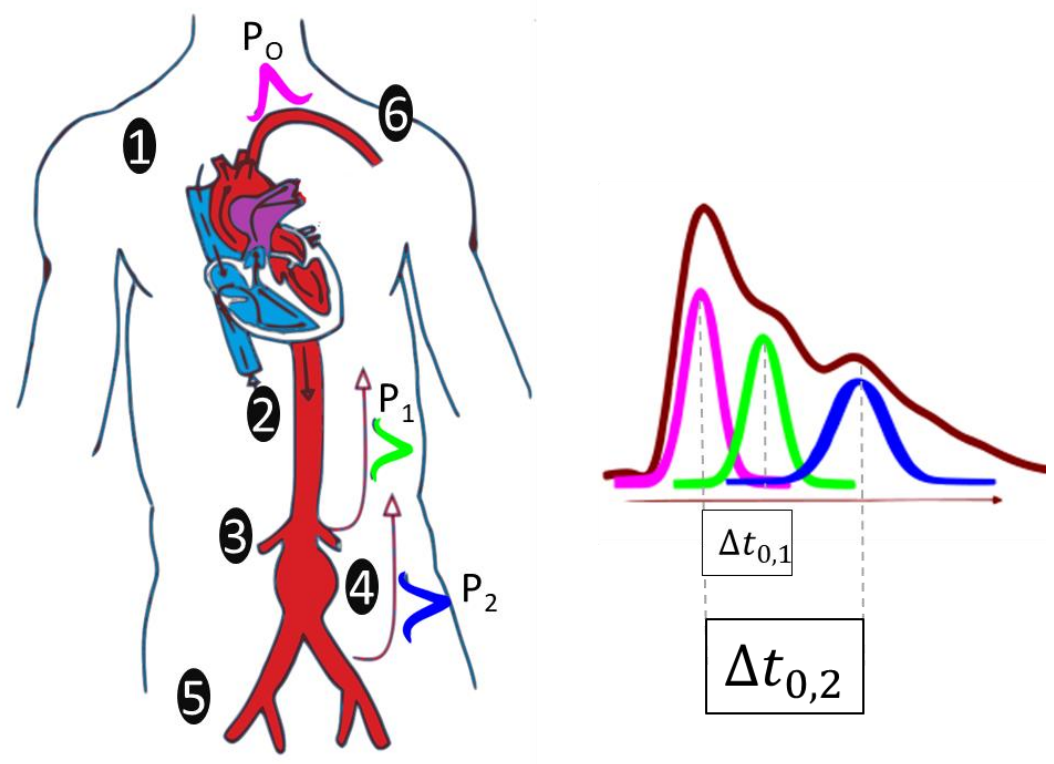

Figura 41. Esboço do sistema arterial e seu efeito na forma do pulso de pressão na artéria radial. Legenda: (1) Arco aórtico (2) Aorta Torácica (3) Artéria Renal (4) Aorta Abdominal (5) Artéria Ilíaca (6) Artéria Braquial. Locais de reflexão: artérias renais (3) e bifurcação ilíaca (5), dão origem aos pulsos refletidos (P1 e P2) que acompanham a ejeção primária do ventrículo esquerdo. Fonte: Adaptada (LATHAM et al., 1985; BARUCH et al., 2011). 
Latham et al. utilizaram métodos invasivos posicionados na artéria central, a fim de verificar a existência de dois grandes sítios de reflexão nas artérias centrais (LATHAM et al., 1985). Como mostra a Figura 41, assinalados pelos números 3 e 5 respectivamente. Com a hipótese, da existência dos sítios de reflexão, torna possível propor um modelo simples da propagação do pulso e predizer o tempo de chegada de cada onda durante seu percurso a partir do ajuste da curva do PPG. O primeiro sítio de reflexão está situado entre a aorta torácica e abdominal, que é marcada por uma diminuição significativa do diâmetro e mudança na elasticidade da parede do vaso, o segundo, surge da junção entre a aorta abdominal e a artérias ilíaca. Esses locais de reflexão são, respectivamente, referidos como o local de reflexão "renal" e "ilíaco" (TIGGES et al., 2017).

A presença das reflexões entre os sítios centrais foi sugerida por Kriz et al. (KŘÍŽz; ŠEBA, 2008). A estrutura do pulso de pressão arterial radial pode ser explicada pela interação do pulso primário de pressão de ejeção do ventrículo esquerdo com dois locais de reflexão aórtica. Com a diminuição drástica do diâmetro do vaso os sítios de reflexão, podem desenvolver até uma quinta componente de reflexão (onda), entretanto, reflexões de ordem superior, são menos relevantes para a análise quantitativa, devido as características do sinal (alto ruído) e além que ondas com baixa amplitude podem ser facilmente absorvidas pelo envelope do pulso seguinte do ciclo cardíaco a menos que a frequência cardíaca do próximo pulso seja menor (BARUCH et al., 2011).

Trabalhos experimentais e previsões de modelos, mostram a possibilidade da extração de alguns parâmetros importantes da característica do pulso pelo método PDA. A diferença do tempo entre a chegada da onda primária $\left(\mathrm{P}_{\mathrm{O}}\right)$ e a onda de reflexão ilíaca $\left(\mathrm{P}_{2}\right)$, referido como tempo de atraso $\left(\Delta t_{0,2}\right)$ rastreia mudanças na pressão do pulso arterial (BARUCH et al., 2011; TIGGES et al., 2017). A diferença nos tempos de chegada da onda primária e das ondas de reflexão, são determinados pelas velocidades com as quais as ondas se propagam. No caso da reflexão ilíaca, o comprimento do caminho é maior que a onda primária, quase o dobro do comprimento do tronco. Mais importante, ambos os pulsos viajam em velocidades diferentes porque suas amplitudes de pressão são diferentes. Especificamente, a amplitude do pulso de reflexão ilíaca, que é determinada pelo coeficiente de reflexão do local de reflexão ilíaca, é da ordem de $40 \%$ da pressão de pulso (BARUCH et al., 2011).

Neste capítulo, avaliamos pulsos consecutivos do sinal de PPG com o modelo PDA, utilizando duas funções de onda, a função gaussiana, já conhecida pela literatura (RUBINS, 2008; LIU et al., 2013, 2014; BARUCH et al., 2014) e a função secante hiperbólica sendo 
descrita pela primeira vez na literatura, com o intuito de extrair características do pulso, em resposta do formato de onda da perfusão periférica, somados com a característica da onda precedente.

\subsection{Metodologia}

\subsubsection{Participantes}

Foram recrutados 54 voluntários com idade entre 20 e 70 anos. Todos os participantes receberam instrução e assinaram o Termo Livre Esclarecido (Protocolo $\mathrm{n}^{\circ}$ 2.926.258 da FFCLRP/USP) (Anexo 1). Nesse estudo, 4 participantes, participaram de mais de uma etapa do experimento e foram excluídos 12 participantes pois não enquadravam nos critérios de inclusão (Tabela 8).

Tabela 8. Característica dos 42 participantes. $f$-feminino, $m$-masculino, $I M C$-índice de massa corpórea, SBP-Pressão Sistólica, DBP-Pressão Diastólica, HR-Frequência Cardíaca.

\begin{tabular}{lcc}
\hline $\mathrm{N}=42$ participantes $(24 \mathrm{f}, 18 \mathrm{~m})$ & Média & $\pm \mathrm{SD}^{*}$ \\
\hline Idade $($ anos $)$ & 36 & 15 \\
$\mathrm{IMC}\left(\mathrm{kg} / \mathrm{m}^{2}\right)$ & 25 & 4 \\
$\mathrm{SBP}(\mathrm{mmHg})$ & 117 & 17 \\
$\mathrm{DBP}(\mathrm{mmHg})$ & 73 & 12 \\
$\mathrm{HR}(\mathrm{BPM})$ & 77 & 11 \\
\hline
\end{tabular}

*SD - Desvio Padrão

\subsubsection{Procedimento Experimental}

Esse experimento foi realizado simultaneamente com os experimentos descritos no Capítulo 2. Para a realização do experimento, foi solicitado ao participante que não utilizasse esmaltes nas unhas da mão, a fim de evitar artefatos durante a aquisição dos dados, também, foi pedido que desligassem aparelhos eletrônicos durante a realização do experimento. 
Inicialmente os participantes permaneceram cerca de 15 minutos sentados confortavelmente, em uma cadeira com regulagem de altura de forma que os pés ficassem apoiados no chão e a mão direita apoiada na coxa direita, em uma sala, com temperatura ambiente de $21^{\circ} \mathrm{C}$. Durante esse tempo, o sinal do PPG foi monitorado por um Oxímetro de dedo (Modelo CMS50D), posicionado no dedo indicador esquerdo, conectado por um cabo USB a um computador (Windows 7), armazenando pontos do batimento por todo o tempo de experimento, a uma taxa de amostragem de $60 \mathrm{~Hz}$. Após a redução da flutuação dos picos sistólicos do sinal do PPG em conjunto com a normatização do sinal da frequência cardíaca (HR) foi adquirido cerca de 2 minutos do sinal do PPG pelo oxímetro no dedo indicador esquerdo. Para o processamento, foi selecionado uma região com 20 pulsos consecutivos essa região levou em conta a menor flutuação entre os picos sistólicos.

\subsubsection{Análise de onda do PPG}

Para obter os valores dos tempos de atraso $\left(\Delta t_{0,1}\right.$ e $\left.\Delta t_{0,2}\right)$ de cada pulso, foi aplicado o método da PDA. Diferentes modelos de PDA têm sido sugeridos na literatura, incluindo uma superposição com quatro gaussianas (SORELLI; PERRELLA; BOCCHI, 2018), e também as funções Log-Normal e Rayleigh (GOSWAMI; CHAUDHURI; MUKHERJEE, 2010). A função gaussiana é a mais aceita na literatura para PDA (RUBINS, 2008; LIU et al., 2013, 2014; BARUCH et al., 2014). Neste trabalho estudamos pela primeira vez o uso da secante hiperbólica para PDA e comparamos os resultados com PDA equivalentes utilizando gaussianas. A secante hiperbólica foi escolhida como candidata porque tem o perfil de uma gaussiana de abas altas e longas, e é um solução para amplitude de pulsos propagantes em fluidos (ZHANG; ZHANG, 2010).

Alguns autores relatam (RUBINS, 2008; BARUCH et al., 2014; LIU et al., 2014; TIGGES et al., 2017) o uso de 2 a 5 ondas para a análise do PDA em um mesmo pulso de PPG. No entanto, análises com mais de três ondas, levam a adição de ruído e por apresentarem amplitudes mais baixas podem ser absorvidas pelo envelope do pulso seguinte do ciclo cardíaco. Com isso, optou por utilizar três ondas $(\mathrm{w}=1,2,3)$ para cada função:

$$
f_{G_{w}}=\sum a_{G_{w}} \exp \left[\frac{-\left(t-\mu_{G_{w}}\right)^{2}}{2 \sigma_{G_{w}}^{2}}\right], \quad w=1,2,3 \quad t \geq 0,
$$




$$
f_{s h_{w}}=\sum a_{S h_{w}} \operatorname{sech}\left[\frac{\left(t-\mu_{s h_{w}}\right)}{\sigma_{s h_{w}}}\right], w=1,2,3 \quad t \geq 0,
$$

onde $f_{G_{w}}$ é a função de onda gaussiana e $f_{s h_{w}}$ é a função de onda secante hiperbólica, $a_{G_{w}} \mathrm{e}$ $a_{S h_{w}}$ são amplitudes, $\mu_{G_{w}}$ e $\mu_{s h_{w}}$ posições centrais, $\sigma_{G_{w}}$ e $\sigma_{s h_{w}}$ larguras das ondas gaussiana e secante hiperbólica, respectivamente.

Utilizando o método proposto por Baruch et al. de decomposição de pulso (PDA), foi escrito um programa (Anexo 3) em MATLAB. Para cada participante, foi obtido uma curva do sinal de PPG (Figura 42). A curva do PPG foi suavizada por um filtro Savitsky-Golay (ordem 3, janelamento 21). Para analisar a estabilidade ou reprodutibilidade das medidas, assumimos a hipótese de que pulsos subsequentes devam ser, em média, similares. Para essa análise, foram escolhidos a região da curva do sinal de PPG com menor flutuação entre os pulsos (Figura 42(a)). Sendo assim, utilizou-se uma sequência de 20 pulsos, os valores obtidos de $\Delta t_{0,1}$ e $\Delta t_{0,2}$ são valores médios.

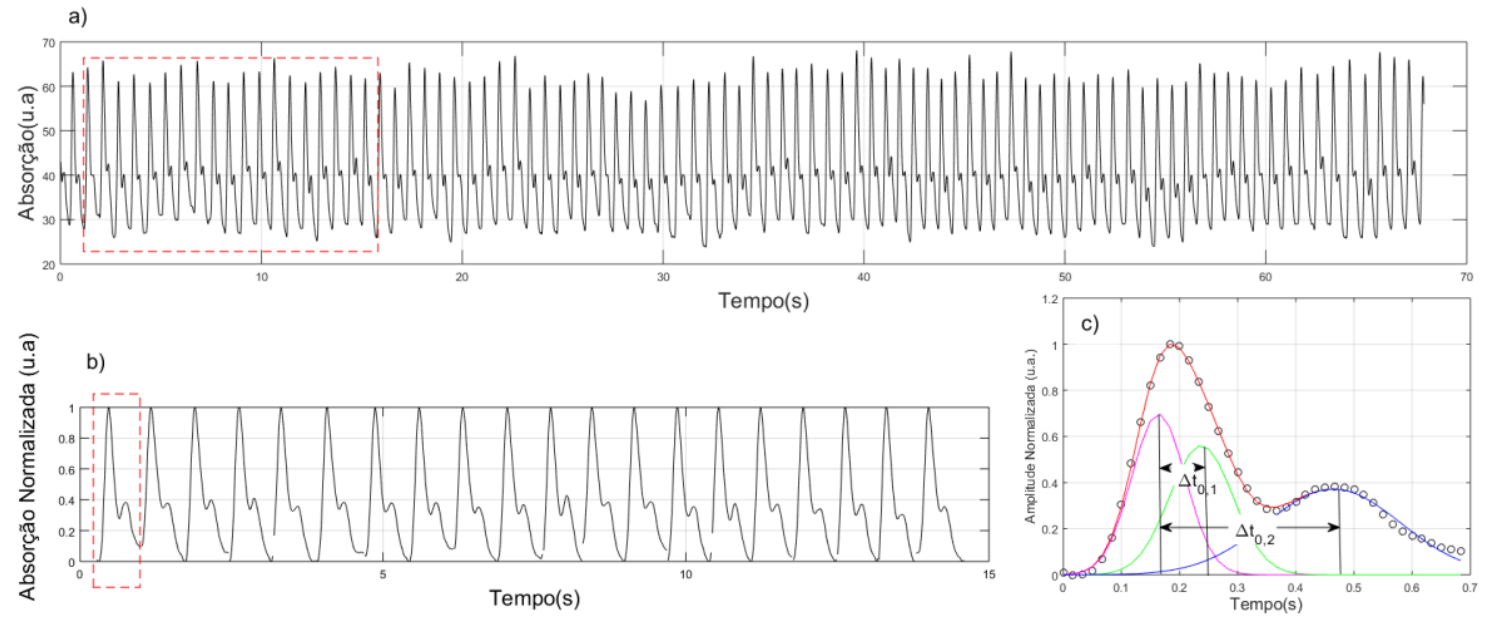

Figura 42. a) Curva do PPG de um voluntário, b) Detalhe de (a), para cada pulso foram ajustadas três ondas com gaussianas, e depois três ondas secante hiperbólica. c) Ajustes de um pulso de PPG e tempos de atraso $\left(\Delta t_{0,1}\right.$ e $\left.\Delta t_{0,2}\right)$ entre os picos das ondas.

Cada pulso (Figura 42(b)) foi ajustado pela função lsqcurvefit do MATLAB com algoritmo Levenberg-Marquadt (HAND, 2011) de modo interativo para minimização de Quiquadrado. Cada pulso foi é separado individualmente e normalizado (Ficando o pico da sístole igual a 1) como mostra na Figura 42(c). 
As ondas são defasadas umas das outra (Figura 42(c)), deste modo, os valores obtidos no ajuste dos parâmetros: de $\mu_{G_{w}}$ e $\mu_{s h_{w}}$ para cada onda, mostra as posições de cada um dos picos: $w=1 \rightarrow P_{O}, w=2 \rightarrow P_{1}$ e $w=3 \rightarrow P_{2}$. Desta maneira, é possível calcular os tempos de atraso $\left(\Delta t_{0,1}\right.$ e $\left.\Delta t_{0,2}\right)$ para cada pulso (Figura 42(c)). Sendo $\Delta t_{0,1}:$ o tempo de atraso entre o pico da primeira onda $\left(P_{O}\right)$ e do pico a segunda $\left(P_{1}\right)$ e $\Delta t_{0,2}$ : o tempo de espera entre o pico da primeira onda $\left(P_{O},\right)$ e da terceira $\left(P_{2}\right)$. Foi estudado a variabilidade dos tempos de atraso de uma série de 20 pulsos consecutivos. Para isso, foi calculado a diferença do anterior com o sucessor. Tal diferença foi denominada $\delta \Delta t_{0,1}$ para o tempo de atraso $\Delta t_{0,1}$ e $\delta \Delta t_{0,2}$ para o tempo de atraso $\Delta t_{0,2}$.

\subsection{Resultados e Discussões}

\subsubsection{Tempo de atraso das ondas}

A distribuição dos valores de $\Delta \mathrm{t}_{0,1}$ e $\Delta \mathrm{t}_{0,2}$ de ambas decomposições: função secante hiperbólica e função gaussiana apresentaram valores esperados pela literatura (BARUCH et al., 2011). A Figura 43 mostra a distribuição média dos tempos de atraso das ondas $\Delta \mathrm{t}_{0,1}$ (Figura 43(a)) e $\Delta \mathrm{t}_{0,2}$ (Figura 43(b)) de 20 pulsos consecutivos para 42 voluntários de ambos os sexos.

O tempo de atraso, $\Delta t_{0,1}$, é a diferença entre o tempo no pico da primeira onda, interpretado como a onda de ejeção primária e a primeira onda de reflexão (BARUCH et al., 2011). Para essa variável, é esperado o tempo de atraso entre 70 e 140 milissegundos. No ajuste realizado pela função gaussiana, o valor médio foi igual a $122 \pm 46 \mathrm{~ms}$ com mínima igual a 82 ms e máxima 223 ms. Para o ajuste pela função secante hiperbólica, o valor médio foi igual 101 $\pm 26 \mathrm{~ms}$, com mínima igual a $84 \mathrm{~ms}$ e máxima $235 \mathrm{~ms}$. O tempo $\left(\Delta \mathrm{t}_{0,2}\right)$ necessário, para que a segunda onda de reflexão dirija-se até a ponta do dedo é entre 180 e 400 milissegundo (BARUCH et al., 2011). Para o ajuste com a função gaussiana, o valor médio foi de $343 \pm 81$ ms com mínimo $153 \mathrm{~ms}$ e máxima $554 \mathrm{~ms}$, para o ajuste da função secante hiperbólica apresentou valor médio de $297 \pm 25$ ms, com mínima de 251 ms e máxima 351 ms. 

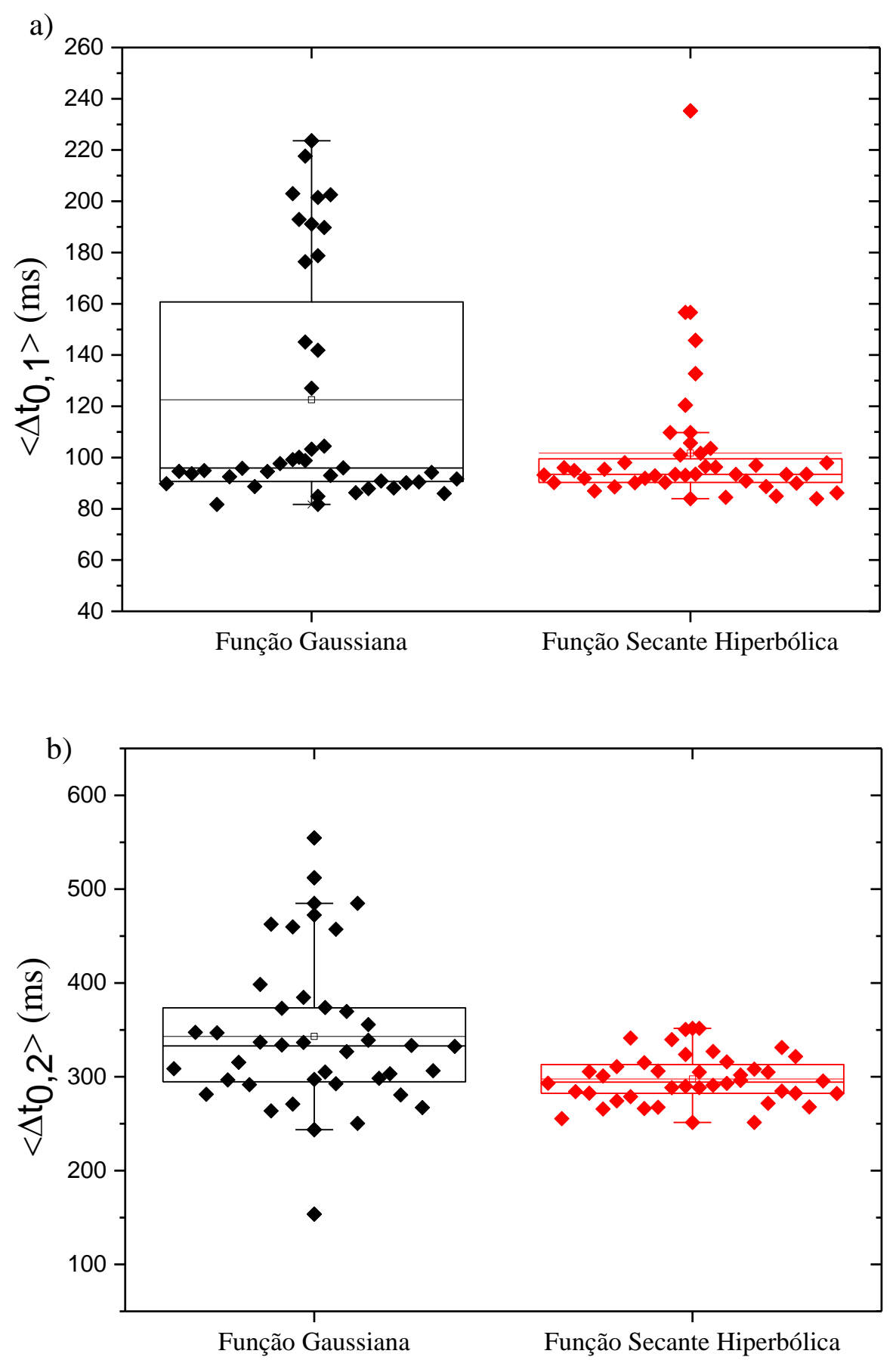

Figura 43. Média dos tempos de atrasos $\Delta t_{0,1}$ e $\Delta t_{0,2}$ de vinte pulsos subsequentes para 42 participantes. Valores obtidos por dois ajustes, secante hiperbólico e gaussiano. a) $\Delta t_{0,1}$ b) $\Delta t_{0,2}$.

A partir desses resultados não é possível dizer qual modelo de PDA é o mais adequado, com decomposição em gaussianas ou em secantes hiperbólicas. Ambas as decomposições 
concordam entre si. Na próxima Seção realizamos um teste para determinar a função mais adequada entre as duas.

\subsubsection{Variabilidade das medidas dos tempos de atraso.}

A PDA é um método interessante pois o resultado do tempo de atraso pode inferir em informações fisiológicas do sistema circulatório. Esperamos que a variabilidade dos valores de $\Delta \mathrm{t}_{0,1}$ e $\Delta \mathrm{t}_{0,2}$ entre dois pulsos cardíacos consecutivos permaneçam estáveis, uma vez os voluntários permaneceram em repouso. Nesta seção, estudamos a variabilidade dos tempos de atraso $\left(\delta \Delta \mathrm{t}_{0,1}\right.$ e $\left.\delta \Delta \mathrm{t}_{0,2}\right)$ entre pulsos consecutivos, para comparar o PDA com as funções, gaussiana e secante hiperbólica.

A Figura 44 mostra a distribuição dos resultados obtidos, dos valores $\delta \Delta t_{0,1}$ (Figura 44(a)) e $\delta \Delta t_{0,2}$ (Figura 44(b)) da média dos 20 pulsos consecutivos para 40 voluntários de ambos os sexos. Utilizamos o módulo da diferença entre os valores $\Delta \mathrm{t}_{0,1}$ e $\Delta \mathrm{t}_{0,2}$ de cada pulso ajustado. Assim, é esperado que os valores de $\delta \Delta \mathrm{t}_{0,1}$ e $\delta \Delta \mathrm{t}_{0,2}$ mantenham o menor possível.

Os resultados obtidos da variabilidade do tempo $\Delta \mathrm{t}_{0,1}$ com o ajuste com da função gaussiana, mostram que $34 \%$ dos participantes apresentaram diferença maior que $20 \mathrm{~ms}$ entre um pulso e outro, enquanto que para o ajuste utilizando a função secante hiperbólica somente $13 \%$ dos participantes apresentaram diferença maior que $20 \mathrm{~ms}$, esse resultado também foi semelhante para o tempo $\Delta \mathrm{t}_{0,2}$, sendo que $17 \%$ dos participantes apresentaram valores maiores que $20 \mathrm{~ms}$ para o ajuste secante hiperbólico enquanto que para o ajuste gaussiano, $80 \%$ dos participantes apresentaram valores maiores que $20 \mathrm{~ms}$ entre um pulso e o subsequente.

A Tabela 9 apresenta os resultados da variabilidade para os tempos de atraso $\Delta \mathrm{t}_{0,1} \mathrm{e}$ $\Delta \mathrm{t}_{0,2}$ para ambos os ajustes. Esses resultados mostram que a função gaussiana possui variabilidade instável enquanto a função secante hiperbólica apresenta resultados mais estáveis. 

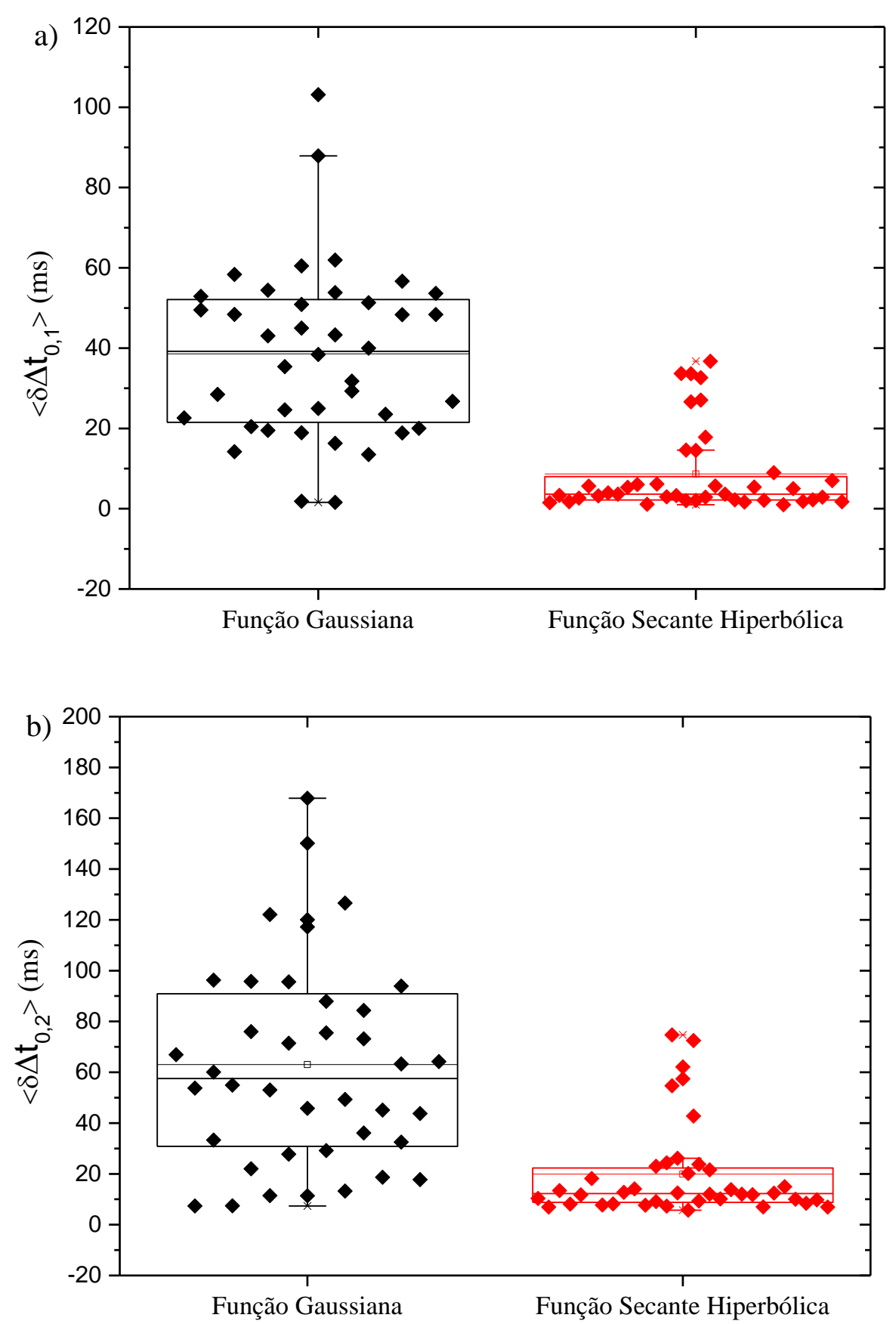

Figura 44. Variabilidade entre os tempos: a) $\Delta t_{0,1}$ e b) $\Delta t_{0,2}$. Cada ponto simboliza a média dos 20 valores da diferença entre cada tempo de atraso de 42 participantes. 
Tabela 9. Valores médios da variabilidade $\delta \Delta \mathrm{t}_{0, \mathrm{i}}$ onde $\mathrm{i}=1,2$. Medidos em 40 participantes. ${ }^{1} \mathrm{SE}$ : erro padrão

\begin{tabular}{lcccccc}
\hline & \multicolumn{3}{c}{ função gaussiana } & \multicolumn{2}{c}{ função secante hiperbólica } \\
& $<\delta \Delta \mathrm{t}_{0, \mathrm{i}}>(\mathrm{ms})$ & $\mathrm{SE}^{1}$ & $<\delta \Delta \mathrm{t}_{0, \mathrm{i}}>(\mathrm{ms})$ & $\mathrm{SE}^{1}$ \\
\hline$\delta \Delta \mathrm{t}_{0,1}(\mathrm{~ms})$ & 39 & \pm & 3 & 9 & \pm & 2 \\
$\delta \Delta \mathrm{t}_{0,2}(\mathrm{~ms})$ & 63 & \pm & 6 & 20 & \pm & 3 \\
\hline
\end{tabular}

A menor variação nos parâmetros obtidos, em média, entre as pulsações subsequentes faz da função secante hiperbólica o melhor ajuste. Entretanto, é esperado baixa alteração entre um pulso e outro em caso de mudanças drásticas no domínio simpático do sistema nervoso central (SNC), entretanto, esperamos que, em média, os pulsos subsequentes reflitam a constância dos parâmetros fisiológicos em tempos abaixo de 2 segundos. Esse é o principal resultado deste capítulo e uma contribuição para a literatura da área.

\subsubsection{Análise do tempo de atraso $\left(\Delta t_{0,2}\right)$ com a idade}

Estudos relatam que o aumento da idade leva a rigidez arterial. Componentes como: diminuição na complacência; o aumento da impedância e da velocidade da onda de pulso (VASAN, 2008), mudam com a idade. Sendo assim, a rigidez arterial é um indicador de aumento de risco de doenças cardiovasculares. Dentre os métodos para detectar a rigidez arterial, a análise do pulso de PPG pode gerar resposta mais rápida (MILLASSEAU et al., 2000).

O comportamento do sinal de PPG de três mulheres com diferentes idades (Figura 45), indica que o segundo pico do sinal é menos expressivo em mulheres acima de 50 anos. Esse resultado colabora com alguns estudos (MILLASSEAU et al., 2000; BARUCH et al., 2011; ELGENDI, 2012). O resultado obtido mostra a existência de uma relação entre o envelhecimento e a redução do tempo de atraso $\Delta \mathrm{t}_{0,2}$. 
a)

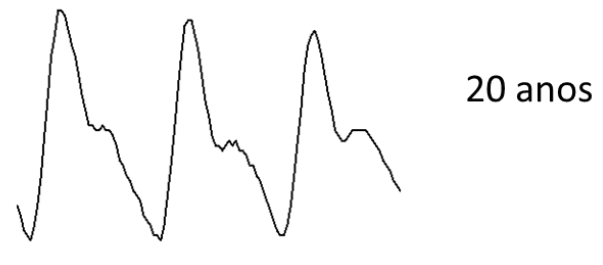

b)

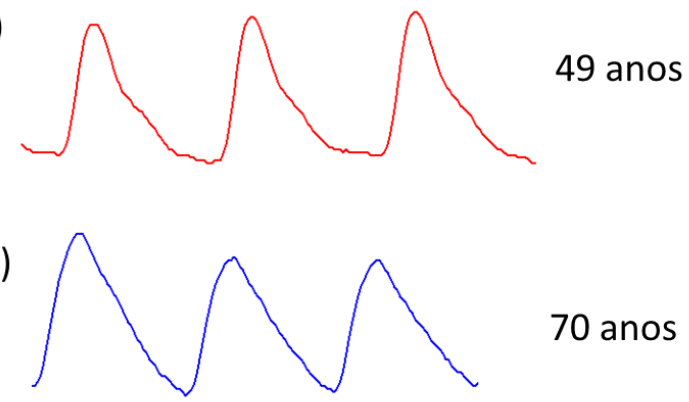

Figura 45. Curvas de PPG para três participantes do sexo feminino, com aspectos típicos para as idades mostradas.

a)

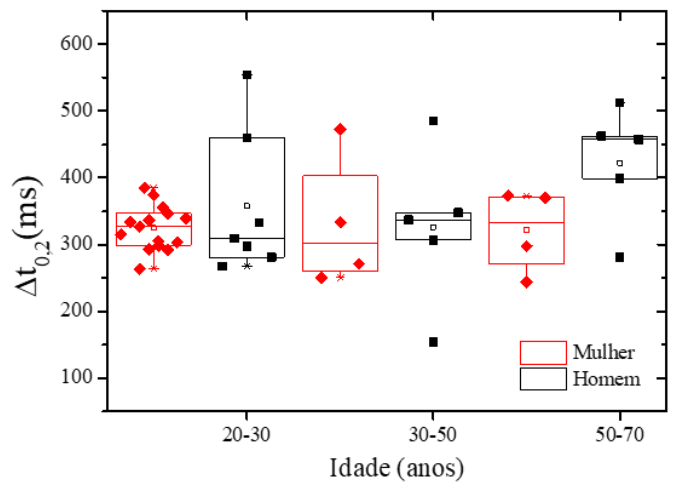

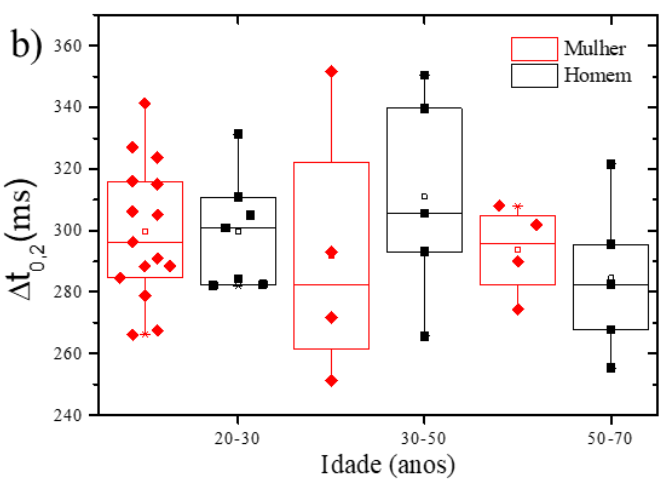

Figura 46. Distribuição dos valores do tempo de atraso $\left(\Delta \mathrm{t}_{0,2}\right)$ com a idade, obtidos pelas funções: a) gaussiana e b) secante hiperbólica de 42 participantes do sexo feminino (diamante vermelho) e masculino (quadrado em preto) distribuídos em diferentes faixas etárias: 20 a 30 , 30 a 50 e 50 a 70 anos. Cada ponto representa a média do tempo de atraso $\Delta \mathrm{t}_{0,2}$ de 20 pulsos subsequentes.

Como é esperado, em pessoas idosas, o tempo de atraso $\left(\Delta t_{0,2}\right)$ deve apresentar valores menores, dado a aumento da velocidade da propagação da onda de pressão. O envelhecimento leva ao enrijecimento das grandes artérias o que contribui para o aumento da velocidade das ondas de pressão que se propagam pela árvore arterial e cria pontos de reflexão precoce 
próximos ao coração (MILLASSEAU et al., 2000). Entretanto, como é possível observar na Figura 46(a), os valores $\Delta \mathrm{t}_{0,2}$ obtidos pelo ajuste com a função gaussiana ocorre o contrário, levando a um aumento significativo nos valores temporais para os homens. Já nos resultados obtidos pelo ajuste da função secante hiperbólica (Figura 46(b)) em média os valores de $\Delta \mathrm{t}_{0,2}$ diminuiu com o aumento da idade, conforme esperado.

Em vista dos bons resultados adquiridos pela função secante hiperbólica mostrados nesse capítulo, em testes futuros sugerimos a investigação do uso de ondas do tipo secante hiperbólica quadrática para analises PDA. As funções secantes hiperbólicas quadráticas são soluções para a equação de Moens-Korteweg para um sóliton de pressão propagante em tubos elásticos (ZHANG; ZHANG, 2010).

\subsection{Conclusão}

Esse trabalho mostrou uma nova contribuição para a análise de decomposição de pulso. O uso de novas funções para o PDA que garantam melhor estabilidade nas medidas dos tempos de atrasos das ondas do PPG geram a possibilidade de uso dessa métrica para identificar rapidamente a existência de uma dada alteração, em pacientes cardiopatas. Essas alterações podem ser percebidas a partir do teste da variabilidade dos tempos de atraso. Se a função é estável, então a alteração percebida por esta será proveniente da disfunção no formato do pulso e não de algum artefato causado durante a aquisição dos dados.

Entre as funções encontradas na literatura para uso do PDA, a função gaussiana é a proposta mais aceita até o momento, entretanto, como mostrado nesse trabalho, o ajuste com a função secante hiperbólica apresentou melhor resultado quando comparada com a função gaussiana. Portanto, vale, salientar que a análise de PDA utilizado nesse trabalho necessita de mais pesquisas para compreensão do significado fisiológico e a faixa normal de valores para cada um dos parâmetros estudados.

Este trabalho sugere que a partir da metodologia proposta e dos dados obtidos, é possível associar as mudanças instantâneas na curva do PPG com a pressão arterial. Possibilitando a criação de um modelo que utilize curvas do sinal de PPG a fim de minimizar a incerteza associada à medida da pressão arterial e identificá-la de maneira contínua sem o uso de métodos invasivos ou por contato. 


\section{CAPÍTULO 4}

Esse estudo tem como objetivo, desenvolver uma metodologia capaz de correlacionar as mudanças do rCRT com alterações da ativação simpática e parassimpática do sistema autonômico através da análise da variabilidade do pulso, (PRV do inglês pulse rate variability) utilizando indicadores no domínio do tempo. Neste Capítulo estudamos a relação entre PRV e rCRT.

\section{Sistema Nervoso Autonômico}

O sistema nervoso autônomo (SNA) possui alta influência sobre o funcionamento dos órgãos, aparelhos e sistemas que compõem o organismo humano. Este é essencial para a preservação das condições do equilíbrio fisiológico interno, permitindo que o mesmo exerça, adequadamente, sua interação com o meio ambiente circundante (PASCHOAL et al., 2006).

Fatores que causem desequilíbrio, modificam as respostas do SNA que têm por finalidade reverter o processo em andamento e restabelecer o equilíbrio funcional, chamadas de respostas autonômicas, e são desempenhadas pelo SNA através de subdivisões anatomofuncionais (PASCHOAL et al., 2006):

i) Sistema nervoso simpático (SNS)

ii) Sistema nervoso parassimpático (SNP).

Praticamente, todos os órgãos são dotados desses dois ramos do SNA e são, dessa forma, controlados em rede, para que todo o organismo trabalhe harmoniosamente. No coração, apesar de a inervação ser intrínseca, algumas funções são moduladas pelo SNA, como: capacidade de regulação e contração do ritmo, promoção e condução dos estímulos intracardíacos. Assim, o SNS atua sobre o miocárdio, enquanto o SNP possui atuação sobre o nodo sinoatrial (S-A), miocárdio atrial e o nodo atrioventricular $(\mathrm{A}-\mathrm{V})$. Durante o ritmo sinusal normal, a influência dinâmica de vários mecanismos fisiológicos regula, pulso a pulso, a frequência cardíaca (HR) (PASCHOAL et al., 2006). 


\subsection{Variabilidade da Frequência Cardíaca}

Uma ferramenta muito utilizada na avaliação da regulação do sistema cardiovascular pelo SNA é a variabilidade da frequência cardíaca (HRV do inglês Heart-rate variability). Esta é uma técnica não invasiva empregada na investigação da modulação autonômica cardíaca, e quantifica as mudanças nos períodos entre ciclos cardíacos consecutivos (PINHEIRO et al., 2016).

Em princípio, qualquer registro contínuo que forneça intervalos precisos de batimentos cardíacos pode ser utilizado no HRV (TREVIZANI; BENCHIMOL-BARBOSA; NADAL, 2012; PINHEIRO et al., 2016; VAN DEN BERG et al., 2018). Entretanto, as diretrizes da HRV recomendam medições do intervalos R-R obtidos no eletrocardiograma (ECG) de 5 minutos ou 24 horas (VAN DEN BERG et al., 2018).

A HRV pode ser analisada a partir de dois métodos lineares: no domínio do tempo e no domínio da frequência. A análise no domínio do tempo, realiza o cálculo dos índices da HRV baseado em operações estatísticas dos intervalos R-R normais. Os índices no domínio do tempo são (SCHÄFER; VAGEDES, 2013):

i. $\quad$ SDNN (Standard Deviation of the Normal-to-Normal (NN) Index): desvio padrão (DP) de todos os intervalos R-R gravados no intervalo de tempo, expresso em milissegundos (ms).

ii. SDANN (Standard Deviation of the Average NN Intervals): representa o desvio padrão das médias dos intervalos R-R normais, a cada 5 minutos, em um intervalo de tempo, expresso em ms;

iii. $\quad$ RMSSD (Root Mean Square of Successive NN Differences): raiz quadrada da média do quadrado das diferenças entre intervalos R-R normais adjacentes, em um intervalo de tempo, expresso em ms;

iv. pNN50 (Percent of $N N$ intervals whose difference exceeds $50 \mathrm{~ms}$ ): representa a porcentagem dos intervalos R-R adjacentes com diferenças de duração maiores que 50 ms.

Os indicadores SDNN e SDANN são obtidos mediante a análise de intervalos R-R individuais portanto, representam as atividades simpático e parassimpático. Como a variância é matematicamente igual à potência total na análise espectral, o índice SDNN reflete todos os 
componentes oscilatórios fundamentais responsáveis pela HRV. O índice RMSSD reflete o tônus vagal e não tem influências respiratórias. E é um indicador correlacionado com a HRV de alta frequência (LABORDE; MOSLEY; THAYER, 2017).

A análise pelo domínio da frequência considera que os intervalos $R-R$ possuem comportamento periódico oscilatório no tempo. A Transformada Rápida de Fourier é utilizada para obter a densidade de potência espectral. Assim, é possível decompor a HRV em componentes oscilatórios fundamentais. Os principais componentes são (SCHÄFER; VAGEDES, 2013):

i. LF (Baixa Frequência): faixa entre 0,04 a 0,15 Hz. Reflete a ação conjunta dos componentes parassimpático e simpático, com predominância do componente simpático.

ii. HF (Alta Frequência): faixa entre 0,15 e 0,4 Hz. Reflete a atividade parassimpática e é chamada de banda respiratória, pois corresponde as variações da frequência cardíaca ocasionadas pelo ciclo respiratório.

A razão HF/LF estabelece a relação entre o SNS e SNP, indicando o balanço entre os componentes: simpático/parassimpático sobre o coração. Entretanto, a resposta do HRV em longos períodos (24h) não é viável, assim, para superar esse problema, Van Den Berg et al. constataram a possibilidade de usar somente $10 \mathrm{~s}$ de aquisição do ECG para se fazer a HRV. Embora não seja possível determinar as medidas no domínio da frequência em um sinal menor que $60 \mathrm{~s}$ (ESCO; FLATT, 2014) é possível obter as duas medidas no domínio do tempo mais comumente usadas: o SDNN e a RMSSD (VAN DEN BERG et al., 2018).

Alguns autores sugerem a realização da HRV utilizando o sinal da fotopletismografia (PPG) ao invés do ECG. O PPG é uma ferramenta muito versátil em uma ampla gama de aplicações, e tem despertado alto interesse pela análise do HRV pelo PPG ao invés do ECG. A técnica é chamada de variabilidade da taxa de pulso, (PRV do inglês Pulse Rate Variability) pois se baseia na duração variável dos ciclos de pulso, ao invés de ciclos cardíacos. Pinheiro et al. mostraram que a técnica fornece resultados semelhantes em comparação com uma análise de HRV (SCHÄFER; VAGEDES, 2013; PINHEIRO et al., 2016).

Para a investigação da mudança da cor da pele causada durante o teste do Tempo de Enchimento Capilar (Capítulo 2) em resposta a mudanças do sistema nervoso, calculamos o PRV. O PRV foi extraído utilizando um algoritmo especializado escrito em MATLAB (VOLLMER, 2015), a partir do sinal do PPG (Capítulo 3) adquirido durante o teste de rCRT. 
O tempo de observação do PPG foi cerca de 1 minuto para cada voluntário. Por ser um teste de rápida execução, extraímos dois indicadores no domínio do tempo: SDNN e o RMSSD. O objetivo da nossa investigação é uma relação funcional entre rCRT e as métricas de HRV (SDNN e RMSSD).

Não é do nosso conhecimento, relatos na literatura sobre a influência do valor do teste de CRT em resposta com os indicadores da HRV ou PRV. Testamos a correção do rCRT com os parâmetros: diferença de pressão (sistólica e diastólica), idade e IMC, entretanto, esses não melhoram a relação funcional. Somente a frequência cardíaca (HR) pareceu ser um fator modificador. Para esse teste, não consideramos o ritmo respiratório. Sendo assim, corrigimos o rCRT pela (HR) de forma que:

$$
r C R T_{c}=C R T^{\alpha} \mathrm{e}^{H R \cdot \beta}
$$

A Figura 47 mostra a relação do RMSSD com o rCRT corrigido pelo HR dado pela equação 4.1. Os parâmetros $\alpha$ e $\beta$ obtidos para garantir melhor ajuste de correlação $r=-0.721$ foi $\alpha=0.3$ e $\beta=0.059$.

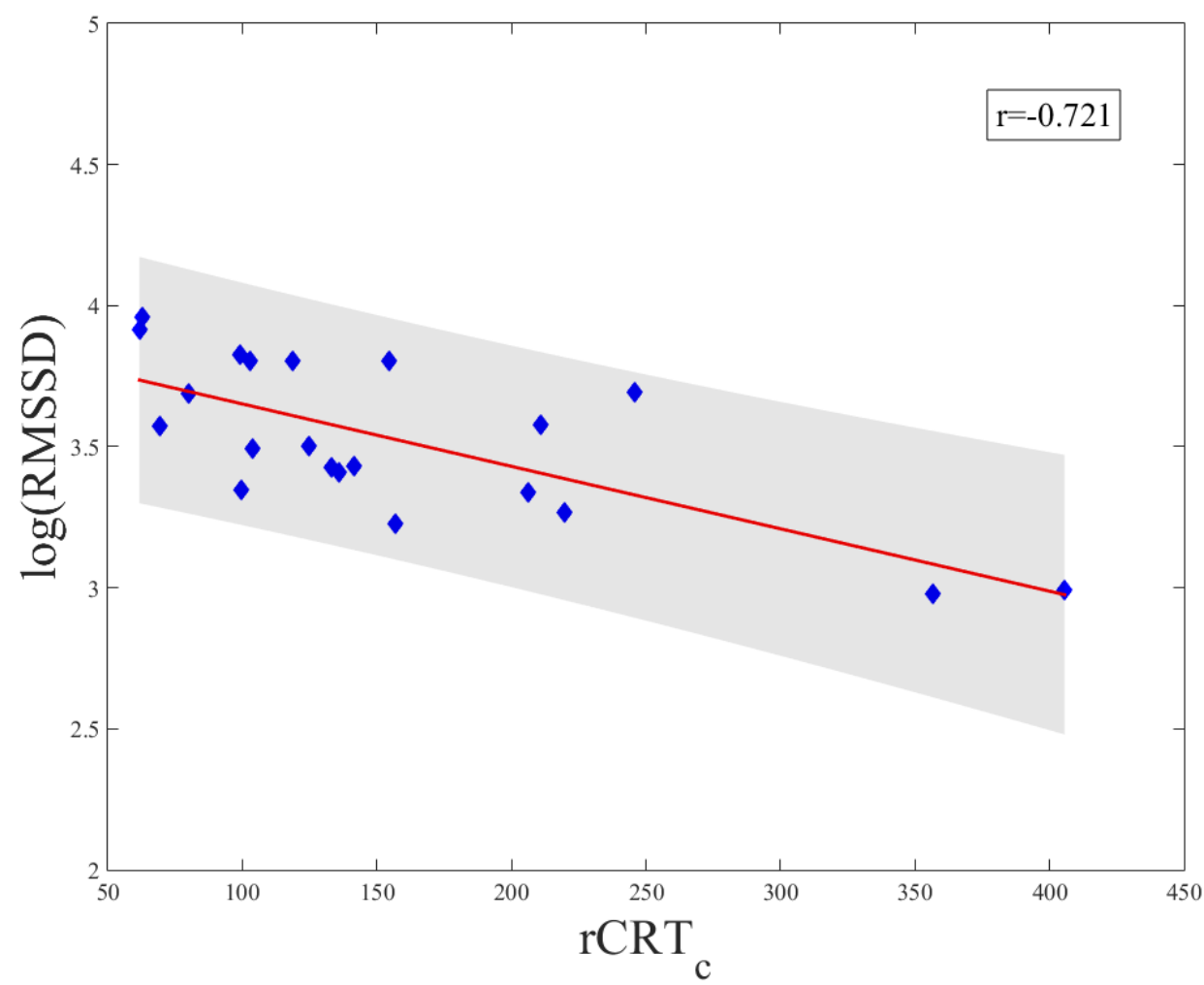

Figura 47. Ajuste linear da relação funcional do RMSSD com rCRT corrigido pelo HR (Eq.4.1). Resposta para 22 voluntários. 
Para o indicador SDNN (Figura 48) a correção com o rCRT corrigido pela Eq. 4.1 foi de $\mathrm{r}=-0.6806$ e os parâmetros foram iguais a $\alpha=0.51$ e $\beta=0.038$.

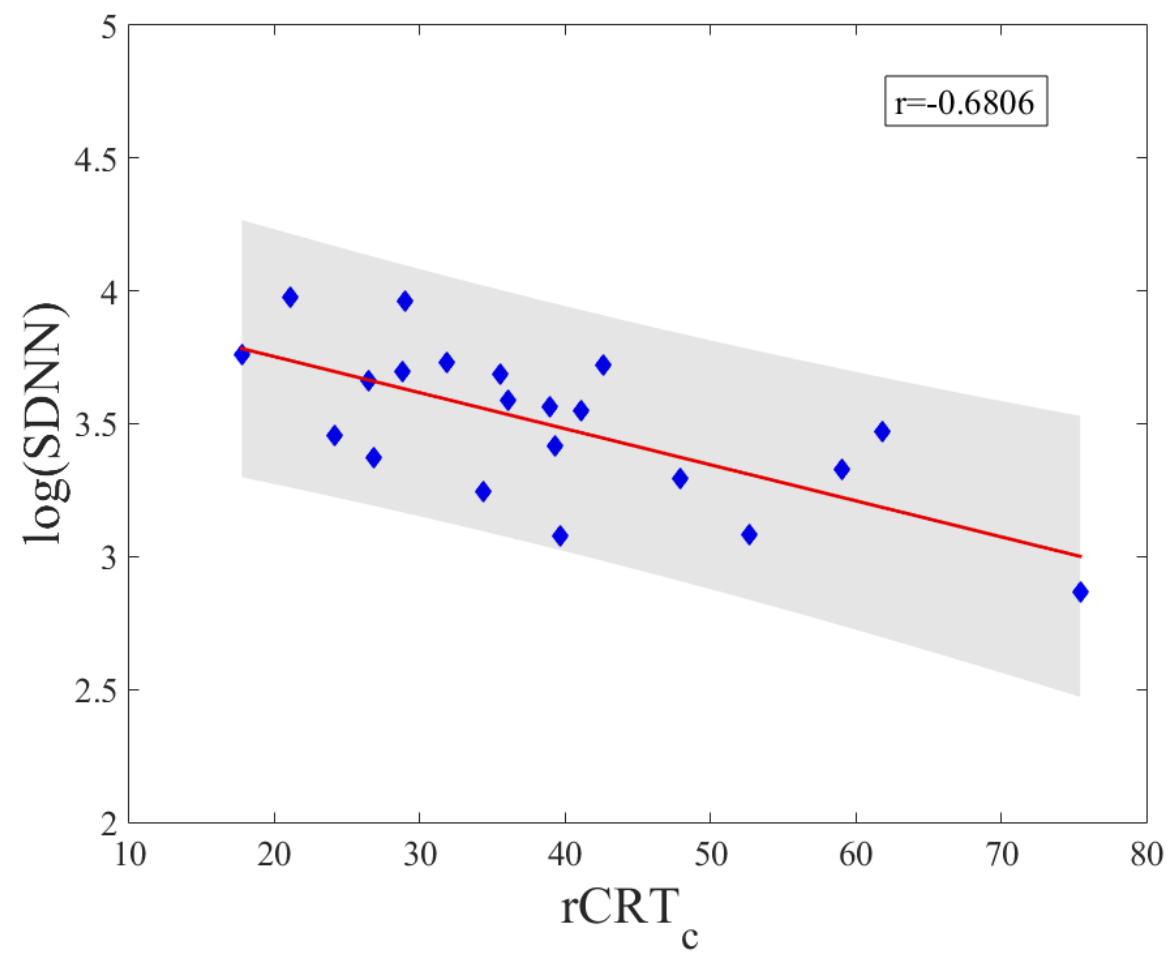

Figura 48. Ajuste linear da relação funcional do SDNN com rCRT corrigido pelo HR (Eq.4.1).

Estes resultados mostram alta correlação entre mudanças na cor da pele em reposta com os indicadores RMSSD e SDNN. Segundo Shaffer e Ginsberg os indicadores RMSSD e SDNN, refletem na resposta parassimpática (SHAFFER; GINSBERG, 2017). Testes posteriores podem testar melhor essa relação, verificando se em um estado de medo (atividade parassimpática diminuída) altera a resposta de rCRT. 


\section{Conclusões}

Nosso estudo do tempo de enchimento capilar (CRT) mostrou que o canal verde de uma câmera indica a dinâmica do sangue oxigenado após o procedimento de compressão da técnica CRT. A metodologia desenvolvida apresenta incerteza menor que $20 \%$ na determinação do rCRT em $78 \%$ dos casos. Chamamos rCRT para distinguir da técnica convencional de CRT. A reprodutibilidade do rCRT é um grande avanço em relação ao estado da arte, principalmente quando se leva em conta que o rCRT permite a avaliação precisa até mesmo em pele negra. A qualidade dos resultados se deu, devido ao uso de luz polarizada na configuração de polarizadores cruzados, aliada ao uso de uma câmera. Além disso, foi possível obter os bons resultados de rCRT com uso de apenas uma leve compressão (7 $\mathrm{kPa}$ ) na superfície da pele. Constatamos que compressões maiores, como as apresentadas na literatura, induzem a um aumento da variabilidade nas medidas e dificuldade na determinação do CRT. Sugerimos uma análise posterior para investigar o limite inferior de compressão aplicada que permita bons resultados.

$\mathrm{Na}$ análise de decomposição de pulsos (PDA), a função gaussiana é a proposta mais aceita na literatura até o momento. Neste trabalho propomos pela primeira vez o uso da função secante hiperbólica em PDA, que apresentou melhor resultado quando comparada com a função gaussiana. A PDA utilizando a decomposição em secante hiperbólica apresentou melhor variabilidade em pulsos de PPG sucessivos. Essa melhor reprodutibilidade usando a PDA em secante hiperbólica poderá ser explorada no futuro em estudos de determinação de pressão arterial através do uso do sinal do PPG. Em trabalhos futuros, propomos o uso de secantes hiperbólicas para PDA em pesquisas da pressão arterial.

Finalmente, outro achado importante neste trabalho foi a correlação entre rCRT e parâmetros que indicam a atividade do sistema nervoso parassimpático através da variabilidade do ritmo cardíaco (HRV ou PRV). É esperado da literatura que CRT em pacientes em estado de choque seja prolongado; também é esperado que um aumento da atividade simpática diminua perfusão periférica. Neste trabalho observamos pela primeira vez uma relação funcional entre CRT e atividade HRV. À medida que a atividade parassimpática aumenta, o rCRT diminui, o que verifica o que é intuitivamente esperado. Mais pesquisas nessa direção são necessárias para determinar se é possível estabelecer o estado do sistema nervoso autonômico com um teste rápido, de cerca de 5 segundos, atualmente, pelo menos 60 s são necessários para essa avaliação usando técnicas de HRV. 


\section{Referências}

ALIAN, A. A.; SHELlEY, K. H. PhotoplethysmographyBest Practice and Research: Clinical AnaesthesiologyBailliere Tindall Ltd, , 2014. .

ALLEN, J. Photoplethysmography and its application in clinical physiological measurement. Physiological measurement, v. 28, n. 3, p. R1-39, 2007.

ANDERSON, B. et al. Impact of patient and environmental factors on capillary refill time in adults. American Journal of Emergency Medicine, v. 26, n. 1, p. 62-65, jan. 2008a.

ANDERSON, B. et al. Capillary refill time in adults has poor inter-observer agreement. Hong Kong Journal of Emergency Medicine, v. 15, n. 2, p. 71-74, 11 abr. 2008b.

ANDERSON, R. R.; PARRISH, J. A. The Optics of Human Skin. Journal of Investigative Dermatology, v. 77, n. 1, p. 13-19, 1 jul. 1981.

ANGELOPOUlOU, E. The Reflectance Spectrum of Human Skin. (Technical Report MSCIS-99-29), p. 1-14, 1999.

BARANOSKI, G. V. G.; KRISHNASWAMY, A. Light \& Skin Interactions: Simulations for Computer Graphics Applications. Light \& Skin Interactions: Simulations for Computer Graphics Applications, 2010.

BARUCH, M. C. et al. Pulse Decomposition Analysis of the digital arterial pulse during hemorrhage simulation. Nonlinear Biomedical Physics, v. 5, n. 1, p. 1, dez. 2011.

BARUCH, M. C. et al. Validation of the pulse decomposition analysis algorithm using central arterial blood pressure. Biomedical engineering online, v. 13, p. 96, 8 jul. 2014.

BOIGNARD, A. et al. Local hyperemia to heating is impaired in secondary Raynaud's phenomenon. Arthritis research \& therapy, v. 7, n. 5, 2005

BOURCIER, S. et al. Diagnosis of non-occlusive acute mesenteric ischemia in the intensive care unit. Annals of Intensive Care, v. 6, n. 1, p. 112, 17 dez. 2016.

BRANDT, K. G.; DE CASTRO ANTUNES, M. M.; DA SILVA, G. A. P. Diarreia aguda: manejo baseado em evidênciasJornal de PediatriaElsevier Editora Ltda, , 1 dez. 2015. . 
BRASIL. MINISTÉRIO DA SAÚDE. Dengue: diagnóstico e manejo clínico adulto e criança. .2007, p. 28.

BROWN, L. H.; PRASAD, N. H.; WHITLEY, T. W. Adverse lighting condition effects on the assessment of capillary refill. American Journal of Emergency Medicine, v. 12, n. 1, p. 4647, 1994.

CHAMPION, H. R. et al. Assessment of injury severity: the triage index. Critical care medicine, v. 8, n. 4, p. 201-208, 1980.

CHARKOUDIAN, N. Mechanisms and modifiers of reflex induced cutaneous vasodilation and vasoconstriction in humansJournal of Applied Physiology, out. 2010. .

CHO, D. S. et al. Physiological characterization of skin lesion using non-linear random forest regression model. In: 2014 36th Annual International Conference of the IEEE Engineering in Medicine and Biology Society, EMBC 2014, Anais...Institute of Electrical and Electronics Engineers Inc., 2 nov. 2014.

CLOUGH, G. R. Role of nitric oxide in the regulation of microvascular perfusion in human skin in vivo. Journal of Physiology, v. 516, n. 2, p. 549-557, 1999.

COUCEIRO, R. et al. Assessment of cardiovascular function from multi-Gaussian fitting of a finger photoplethysmogram. Physiological Measurement, v. 36, n. 9, p. 1801-1825, set. 2015.

ELGENDI, M. On the Analysis of Fingertip Photoplethysmogram Signals. Current Cardiology Reviews, v. 8, n. 1, p. 14-25, 26 jun. 2012.

ESCO, M. R.; FLATT, A. A. Ultra-short-term heart rate variability indexes at rest and postexercise in athletes: Evaluating the agreement with accepted recommendations. Journal of Sports Science and Medicine, v. 13, n. 3, p. 535-541, 2014.

EVERETT, J. S.; BUDESCU, M.; SOMMERS, M. S. Making Sense of Skin Color in Clinical Care. Clinical Nursing Research, v. 21, n. 4, p. 495-516, nov. 2012.

FLEMING, S. et al. Validity and reliability of measurement of capillary refill time in children: A systematic reviewArchives of Disease in Childhood, 2015. .

FLEMING, S. et al. Capillary refill time in sick children: A clinical guide for general practiceBritish Journal of General PracticeRoyal College of General Practitioners, , 1 nov. 
2016. .

GONG, H.; DESVIGNES, M. Hemoglobin and melanin quantification on skin images. In: Lecture Notes in Computer Science (including subseries Lecture Notes in Artificial Intelligence and Lecture Notes in Bioinformatics), PART 2, Anais...Springer, Berlin, Heidelberg, 2012.

GORELICK, M. et al. Effect of ambient temperature on capillary refill in healthy children. Am Acad Pediatrics, 1993.

GOSWAMI, D.; CHAUDHURI, K.; MUKHERJEE, J. A New Two-Pulse Synthesis Model for Digital Volume Pulse Signal Analysis. Cardiovascular Engineering, v. 10, n. 3, p. 109-117, set. 2010 .

GRONER, W. et al. Orthogonal polarization spectral imaging: A new method for study of the microcirculation. Nature Medicine, v. 5, n. 10, p. 1209-1212, 1 out. 1999.

HALL, J. E.; GUYTON, A. C. Guyton and Hall Physiology Review. [s.l: s.n.]

HAND, D. J. Measurements and their Uncertainties: A Practical Guide to Modern Error Analysis by Ifan G. Hughes, Thomas P. A. Hase. International Statistical Review, v. 79, n. 2, p. $280-280,2011$.

HARIRI, G. et al. Narrative review: clinical assessment of peripheral tissue perfusion in septic shockAnnals of Intensive Care, 2019.

HECHT, E. Optics. 4th. ed. [s.1.] Addison-Wesley, 2002.

HERTZMAN, A. B.; SPEALMAN, C. R. Observations on the finger volume pulse recorded photoelectrically. American Journal of Physiology, v. 119, p. 334-335, 1937.

HICKEY, M.; PHILLIPS, J. P.; KYRIACOU, P. A. Investigation of peripheral photoplethysmographic morphology changes induced during a hand-elevation study. Journal of Clinical Monitoring and Computing, v. 30, n. 5, p. 727-736, 2016.

HOLOWATZ, L. A.; THOMPSON-TORGERSON, C. S.; KENNEY, W. L. The human cutaneous circulation as a model of generalized microvascular functionJournal of Applied Physiology, jul. 2008. .

IGARASHI, T.; NISHINO, K.; NAYAR, S. K. The appearance of human skin: A surveyFoundations and Trends in Computer Graphics and Vision, 2007. 
JACQUET-LAGRÈZE, M. et al. Capillary refill time variation induced by passive leg raising predicts capillary refill time response to volume expansion. Critical Care, v. 23, n. 1, p. 281, 16 dez. 2019.

JOHANSSON, A. Neural network for photoplethysmographic respiratory rate monitoring. Medical and Biological Engineering and Computing, v. 41, n. 3, p. 242-248, maio 2003.

JOHNSON, J. M.; MINSON, C. T.; KELlOGG, D. L. Cutaneous Vasodilator and Vasoconstrictor Mechanisms in Temperature Regulation. In: Comprehensive Physiology. Hoboken, NJ, USA: John Wiley \& Sons, Inc., 2014. p. 33-89.

KAMSHILIN, A. A.; MARGARYANTS, N. B. Origin of Photoplethysmographic Waveform at Green Light. Physics Procedia, v. 86, n. June 2015, p. 72-80, 2017.

KHAN, Y. et al. A flexible organic reflectance oximeter array. Proceedings of the National Academy of Sciences of the United States of America, v. 115, n. 47, p. E11015-E11024, 2018.

KIM, B. E. et al. Ganong's Review of Medical Physiology. In: Nursing Standard. [s.1.] RCN Publishing Ltd., 2010. 23p. 727.

KOLLIAS, N.; STAMATAS, G. N. Optical Non-Invasive Approaches to Diagnosis of Skin Diseases. Journal of Investigative Dermatology Symposium Proceedings, v. 7, n. 1, p. 6475, 1 dez. 2002.

KŘIIŽ, J.; ŠEBA, P. Force plate monitoring of human hemodynamics. Nonlinear Biomedical Physics, v. 2, 2008.

LABORDE, S.; MOSLEY, E.; THAYER, J. F. Heart rate variability and cardiac vagal tone in psychophysiological research - Recommendations for experiment planning, data analysis, and data reportingFrontiers in PsychologyFrontiers Research Foundation, , 20 fev. 2017. .

LANTING, S. M. et al. Post-occlusive reactive hyperaemia of skin microvasculature and foot complications in type 2 diabetes. Journal of Diabetes and its Complications, v. 31, n. 8, p. 1305-1310, 1 ago. 2017.

LATHAM, R. D. et al. Regional wave travel and reflections along the human aorta: A study with six simultaneous micromanometric pressures. Circulation, v. 72, n. 6, p. 1257-1269, 
1985.

LAZARO, J. et al. Respiratory Rate Derived from Pulse Photoplethysmographic Signal by Pulse Decomposition Analysis. In: Proceedings of the Annual International Conference of the IEEE Engineering in Medicine and Biology Society, EMBS, Anais...IEEE, jul. 2018.

LIMA, A. et al. The prognostic value of the subjective assessment of peripheral perfusion in critically ill patients. Critical Care Medicine, v. 37, n. 3, p. 934-938, 1 mar. 2009.

LIMA, A.; BAKKER, J. Noninvasive monitoring of peripheral perfusion. In: Applied Physiology in Intensive Care Medicine 2: Physiological Reviews and Editorials. [s.l: s.n.]p. $39-49$.

LIU, C. et al. Modeling carotid and radial artery pulse pressure waveforms by curve fitting with Gaussian functions. Biomedical Signal Processing and Control, v. 8, n. 5, p. 449-454, 1 set. 2013.

LIU, C. et al. Gaussian fitting for carotid and radial artery pressure waveforms: Comparison between normal subjects and heart failure patients. In: Bio-Medical Materials and Engineering, 1, Anais...IOS Press, 1 jan. 2014.

MARIA, V. et al. Proposta de escala para avaliar o turgor da pele de idosos. revistaeletronicafunvic.org, v. 1, n. 1, p. 1-7, 2016.

MARTIN BLAND, J.; ALTMAN, D. G. Statistical methods for assessing agreement between two methods of clinical measurement. The Lancet, v. 327, n. 8476, p. 307-310, 1986.

MATAS, A. et al. Eliminating the issue of skin color in assessment of the blanch response. Advances in skin \& wound care, v. 14, n. 4, p. 180-188, 2001.

MILLASSEAU, S. C. et al. Noninvasive assessment of the digital volume pulse: Comparison with the peripheral pressure pulse. Hypertension, v. 36, n. 6, p. 952-956, 2000.

MILLASSEAU, S. C. et al. Determination of age-related increases in large artery stiffness by digital pulse contour analysis. Clinical Science, v. 103, n. 4, p. 371-377, 2002.

MOÇO, A. V.; STUIJK, S.; DE HAAN, G. Motion robust PPG-imaging through color channel mapping. Biomedical Optics Express, v. 7, n. 5, p. 1737, 1 maio 2016.

MOYLE, J. T. B. Pulse Oximetry. [s.1.] BMJ Books, 2002. 
NAKANO, K. et al. Visualization of venous compliance of superficial veins using non-contact plethysmography based on digital red-green-blue images. Sensors (Switzerland), v. 16, n. 12, 2016.

NAKANO, K. et al. Noncontact sphygmomanometer based on pulse-wave transit time between the face and hand. (G. L. Coté, Ed.) In: Optical Diagnostics and Sensing XVIII: Toward Pointof-Care Diagnostics, Anais...SPIE, 20 fev. 2018.

NICHOLS, W. W. et al. McDonald's blood flow in arteries theoretical, experimental and clinical principles. Echocardiography, v. 8, n. 3, p. 405-406, 2007.

NICKEL, A. et al. Impact of Skin Color on Accuracy of Capillary Refill Time Measurement by Pulse Oximeter. CIRCULATION, v. 138, n. A276, 2018.

NOVAIS, E. G. Determinação da rigidez arterial em pacientes portadores de insuficiência renal crônica através da velocidade de onda de pulso e da fotopletismografia digital. 2006. Universidade Federal do Espírito Santo, Centro Biomédico., 2006.

PASCHOAL, M. et al. Variabilidade da freqüência cardíaca em diferentes faixas etárias. Revista Brasileira de Fisioterapia, v. 10, n. 4, p. 413-419, 2006.

PATHAK, M. A. In memory of Thomas Bernhard Fitzpatrick. The Journal of investigative dermatology, v. 122, n. 2, 2004.

PICKARD, A.; KARLEN, W.; ANSERMINO, J. M. Capillary refill time: Is it still a useful clinical sign? Anesthesia and Analgesia, v. 113, n. 1, p. 120-123, 2011.

PINHEIRO, N. et al. Can PPG be used for HRV analysis? In: Proceedings of the Annual International Conference of the IEEE Engineering in Medicine and Biology Society, EMBS, Anais...Institute of Electrical and Electronics Engineers Inc., out. 2016.

PINSKY, M. R. et al. Applied physiology in intensive care medicine. [s.l.] Springer Berlin Heidelberg, 2006.

POSTELNICU, R.; EVANS, L. Monitoring of the physical exam in sepsisCurrent Opinion in Critical CareLippincott Williams and Wilkins, , 2017. .

PRAHL'S S. Tabulated Molar Extinction Coefficient for Hemoglobin in Water. Water, p. 17, 2011. 
RADY, M. Y.; RIVERS, E. P.; NOWAK, R. M. Resuscitation of the critically ill in the ED: Responses of blood pressure, heart rate, shock index, central venous oxygen saturation, and lactateAmerican Journal of Emergency MedicineW.B. Saunders, , 1 mar. 1996. .

RÉA-NETO, Á. et al. Consenso brasileiro de monitorização e suporte hemodinâmico - Parte IV: monitorização da perfusão tecidual. Revista Brasileira de Terapia Intensiva, v. 18, n. 2, p. 154-160, jun. 2006.

RUBINS, U. Finger and ear photoplethysmogram waveform analysis by fitting with Gaussians. Medical and Biological Engineering and Computing, v. 46, n. 12, p. 1271-1276, 2008.

RYLANDER, C. G. et al. Mechanical tissue optical clearing devices: Enhancement of light penetration in ex vivo porcine skin and adipose tissue. Lasers in Surgery and Medicine, v. 40, n. 10, p. 688-694, dez. 2008.

RYLANDER, C. G. et al. Effect of localized mechanical indentation on skin water content evaluated using OCT. International Journal of Biomedical Imaging, v. 2011, 2011.

SAAVEDRA, J. M. et al. Capillary Refilling (Skin Turgor) in the Assessment of Dehydration. American Journal of Diseases of Children, v. 145, n. 3, p. 296-298, 1991.

SACHDEVA, S. Fitzpatrick skin typing: Applications in dermatologyIndian Journal of Dermatology, Venereology and Leprology, 2009. .

SANSONE, C. M. et al. Relationship between Capillary Refill Time at Triage and Abnormal Clinical Condition: A Prospective Study. The Open Nursing Journal, v. 11, n. 1, p. 84-90, 2017.

SANTOS, D. M. dos et al. Association between peripheral perfusion, microcirculation and mortality in sepsis: a systematic reviewBrazilian Journal of Anesthesiology, 2019. .

SCANLON, V. C.; SANDERS, T. Essentials of Anatomy and Physiology. Fifth Edit ed. [s.l: s.n.]

SCHÄFER, A.; VAGEDES, J. How accurate is pulse rate variability as an estimate of heart rate variability?: A review on studies comparing photoplethysmographic technology with an electrocardiogramInternational Journal of CardiologyElsevier, , jun. 2013. .

SCHRIGER, D. L.; BARAFF, L. Defining normal capillary refill: Variation with age, sex, and 
temperature. Annals of Emergency Medicine, v. 17, n. 9, p. 932-935, 1988.

SHAFFER, F.; GINSBERG, J. P. An Overview of Heart Rate Variability Metrics and Norms. Frontiers in Public Health, v. 5, 28 set. 2017.

SHELLEY, K. H. Photoplethysmography: Beyond the calculation of arterial oxygen saturation and heart rate. Anesthesia and Analgesia, v. 105, n. SUPPL. 6, 2007.

SHINOZAKI, K. et al. Does training level affect the accuracy of visual assessment of capillary refill time?Critical CareBioMed Central, , 2019a. .

SHINOZAKI, K. et al. Low temperature increases capillary blood refill time following mechanical fingertip compression of healthy volunteers: prospective cohort study. Journal of Clinical Monitoring and Computing, v. 33, n. 2, p. 259-267, 30 abr. 2019 b.

SHINOZAKI, K. et al. Evaluation of accuracy of capillary refill index with pneumatic fingertip compression. Journal of Clinical Monitoring and Computing, 2020.

SIGEL, G. H. Optical Absorption of Glasses. In: [s.l: s.n.]p. 5-89.

SOKOLNICKI, L. A. et al. Contribution of nitric oxide to cutaneous microvascular dilation in individuals with type 2 diabetes mellitus. American Journal of Physiology - Endocrinology and Metabolism, v. 292, n. 1, jan. 2007.

SORELLI, M.; PERRELLA, A.; BOCCHI, L. Detecting Vascular Age Using the Analysis of Peripheral Pulse. IEEE Transactions on Biomedical Engineering, v. 65, n. 12, p. 2742-2750, 1 dez. 2018.

SPIGULIS, J. et al. Smartphone snapshot mapping of skin chromophores under triplewavelength laser illumination. Journal of Biomedical Optics, v. 22, n. 9, p. 091508, 2 mar. 2017.

STAMATAS, G. N. et al. Non-invasive measurements of skin pigmentation in situPigment Cell ResearchJohn Wiley \& Sons, Ltd (10.1111), , 1 dez. 2004. .

STAMATAS, G. N.; KOLLIAS, N. Blood stasis contributions to the perception of skin pigmentation. Journal of Biomedical Optics, v. 9, n. 2, p. 315, 2004.

STEWART, J. et al. Noninvasive interrogation of microvasculature for signs of endothelial dysfunction in patients with chronic renal failure. American Journal of Physiology - Heart 
and Circulatory Physiology, v. 287, n. 6 56-6, dez. 2004.

STROZIK, K. S.; PIEPER, C. H.; ROLLER, J. Capillary refilling time in newborn babies: Normal values. Archives of Disease in Childhood: Fetal and Neonatal Edition, v. 76, n. 3, 1997.

TAMURA, T. et al. Wearable photoplethysmographic sensors - past and present. Electronics , v. 3, n. 2, p. 282-302, 2014.

THODY, A. J. et al. Pheomelanin as well as eumelanin is present in human epidermis. Journal of Investigative Dermatology, v. 97, n. 2, p. 340-344, 1991.

TIBBY, S. M.; HATHERILL, M.; MURDOCH, I. A. Capillary refill and core-peripheral temperature gap as indicators of haemodynamic status in paediatric intensive care patients. Archives of Disease in Childhood, v. 80, n. 2, p. 163-166, 1999.

TIGGES, T. et al. Model selection for the Pulse Decomposition Analysis of fingertip photoplethysmograms. In: Proceedings of the Annual International Conference of the IEEE Engineering in Medicine and Biology Society, EMBS, Anais...2017.

TORTORA, G. J.; DERRICKSON, B. Principles of anatomy \& physiology. 14. ed. United States of America: John Wiley and Sons, Inc., 2014.

TOYODA, K. Digital still cameras at a glance. In: Image Sensors and Signal Processing for Digital Still Cameras. [s.1: s.n.]p. 1-20.

TREVIZANI, G. A.; BENCHIMOL-BARBOSA, P. R.; NADAL, J. Efeitos da idade e da aptidão aeróbica na recuperação da frequência cardíaca em homens adultos. Arquivos Brasileiros de Cardiologia, v. 99, n. 3, p. 802-810, 2012.

TSUMURA, N.; HANEISHI, H.; MIYAKE, Y. Independent component analysis of skin color image. In: Final Program and Proceedings - IS and T/SID Color Imaging Conference, Anais...1998.

TUCHIN, V. V. Optical clearing of tissues and blood. [s.1.] SPIE, 2005.

VALENZUELA ESPINOZA, E. D.; WELSH, S.; DUBIN, A. Lack of agreement between different observers and methods in the measurement of capillary refill time in healthy volunteers: An observational study. Revista Brasileira de Terapia Intensiva, v. 26, n. 3, p. 
269-276, 2014a.

VALENZUELA ESPINOZA, E. D.; WELSH, S.; DUBIN, A. Lack of agreement between different observers and methods in the measurement of capillary refill time in healthy volunteers: An observational study. Revista Brasileira de Terapia Intensiva, 2014b.

VAN DEN BERG, M. E. et al. Normal values of corrected heart-rate variability in 10 -second electrocardiograms for all ages. Frontiers in Physiology, v. 9, n. APR, p. 424, 27 abr. 2018.

VAN GENDEREN, M. E.; VAN BOMMEL, J.; LIMA, A. Monitoring peripheral perfusion in critically ill patients at the bedsideCurrent Opinion in Critical CareCurr Opin Crit Care, , jun. 2012. .

VASAN, R. S. Pathogenesis of elevated peripheral pulse pressure: Some reflections and thinking forwardHypertension, jan. 2008. .

VOLLMER, M. A robust, simple and reliable measure of heart rate variability using relative RR intervals. Computing in Cardiology, v. 42, n. 6, p. 609-612, 2015.

WEBSTER, J. G. Design of Pulse Oximeters. 23 out. 1997.

WEI, C. et al. Study on conditioning and feature extraction algorithm of photoplethysmography signal for physiological parameters detection. In: Proceedings - 4th International Congress on Image and Signal Processing, CISP 2011, Anais...2011.

WELLER, R. B.; HUNTER, H. J. A.; MANN, M. W. Clinical dermatology: Fifth edition. [s.l.] Wiley Blackwell, 2015.

YAMAMOTO, T. et al. Derivation and clinical application of special imaging by means of digital cameras and Image $\mathbf{J}$ freeware for quantification of erythema and pigmentation. Skin Research and Technology, v. 14, n. 1, p. 26-34, 2008.

YOON, G. et al. Development and application of three-dimensional light distribution model for laser irradiated tissueIEEE Journal of Quantum Electronics, 1987. .

ZHANG, S. Y.; ZHANG, T. Nonlinear waves in a fluid-filled thin viscoelastic tube. Chinese Physics B, v. 19, n. 11, p. 1-7, 2010. 


\section{Apêndice A - Caracterização dos Equipamentos}

\subsection{Metodologia para caracterização da Fonte de iluminação}

Analisamos o comportamento do espectro luz que atinge a superfície da pele durante os experimentos descritos no Capítulo 2. Para isso, foi medido o espectro da lâmpada LED (Taschibra TKL 90) nas duas configurações: sem e com o polarizador circular acoplado na saída da luz. Analisou-se o efeito da polarização na intensidade de luz. Para esse procedimento foi utilizado o espectrômetro Ocean Optics, modelo USB-4000.

Verificamos a precisão do espectrômetro utilizando uma fonte calibrada de Mercúrio/Argônio Ocean Optics. A Figura 49(a) apresenta o espectro da fonte calibrada e Figura 49(b) seus valores de referência. A comparação dos picos de emissão apresentaram desvio de $+2 \mathrm{~nm}$ deslocados para a direita do gráfico (Figura 49(a)). Os próximos resultados, foram corrigidos por essa incerteza.

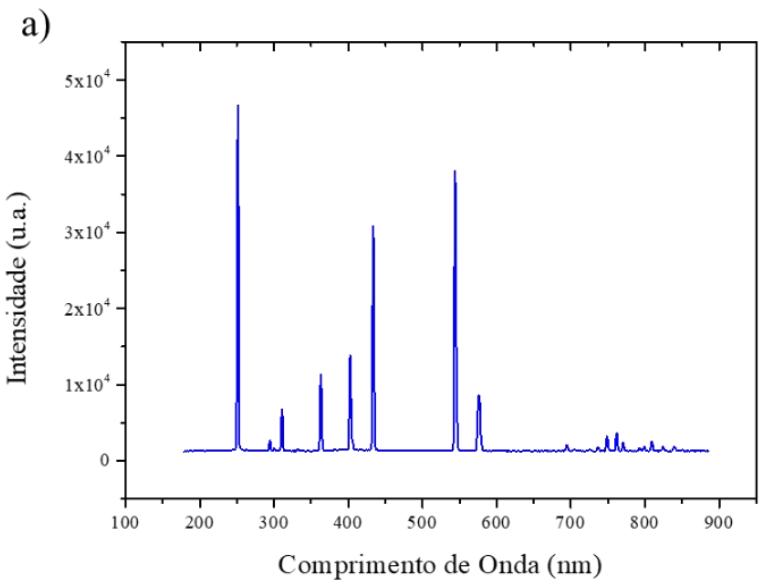

b)

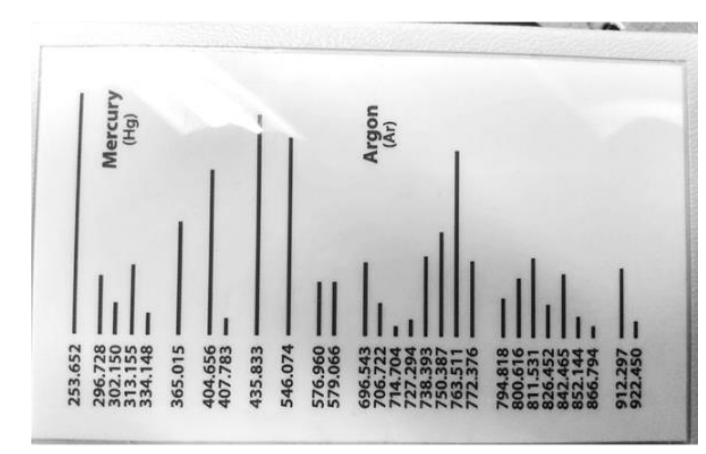

Figura 49. a) Imagem da especificação da fonte calibrada Mercúrio/Argônio Ocean Optics com raias entre 253-922 nm. b) Espectro.

Para a obtenção das imagens, foi utilizado polarizadores (descrito na próxima Seção) na acoplados na saída do feixe de luz. A Figura 50, mostra o espectro da lâmpada LED sem (linha contínua) e com (linha pontilhada) polarizador. É possível verificar que o polarizador, reduziu a intensidade de luz que atinge o espectrômetro. Entretanto, o uso do polarizador não interferiu no formato do espectro da lâmpada (LED). Também é possível verificar a transmissão da luz polarizada que incide a superfície da pele. Para isso usamos a razão da intensidade de luz 
polarizada e não polarizada. Como pode ser observado (Figura 51), na banda de 400-480 nm o uso do polarizador tem alta absorção e diminui a passagem da luz. Entretanto, após $500 \mathrm{~nm}$ a variação na intensidade de luz é baixa (apresentando um platô). Ao passo que, o uso do polarizador circular não modifica o espectro de reflexão na faixa do comprimento de onda de interesse (500-550 nm faixa da alta concentração da hemoglobina oxigenada e desoxigenada), isto é, o polarizador não afeta a transmissão da luz.

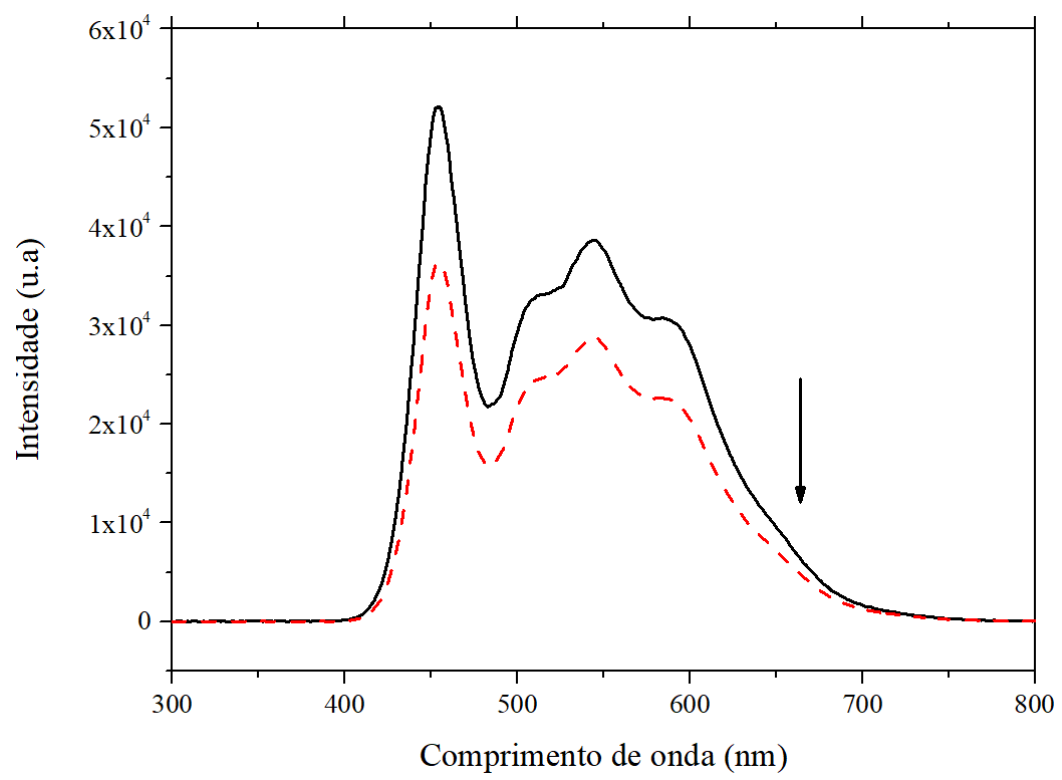

Figura 50. Espectro da lâmpada LED sem (linha contínua) e com (linha pontilhada) polarizador circular.

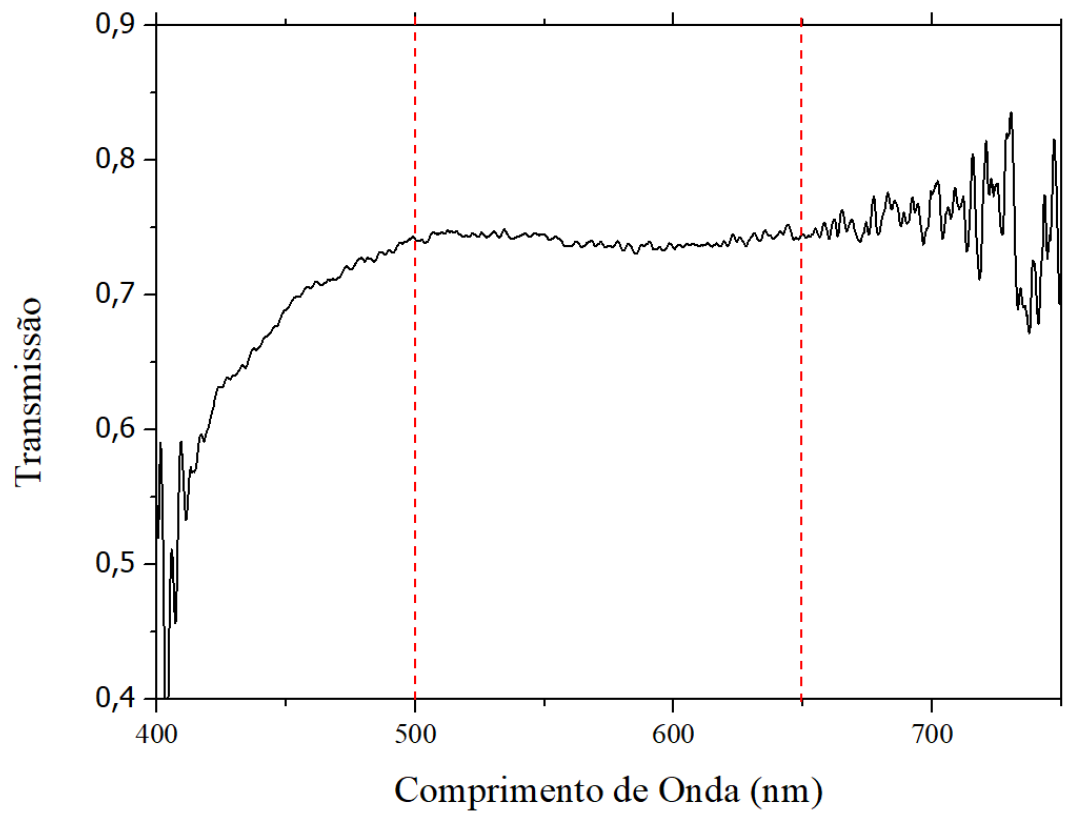

Figura 51. Transmissão da luz na configuração do polarizador circular. 


\subsection{Caracterização dos polarizadores}

Para a aquisição dos vídeos desse trabalho, foram usados dois polarizadores circulares, um na saída da fonte de luz (P1) e outro acoplado na frente da lente da câmera (P2). O correto posicionamento dos polarizadores garante a diminuição da componente de reflexão especular causada pela interface ar-pele e pela oleosidade da pele. Os polarizadores usados no experimento possuem especificações conforme dados do fornecedor (Tabela 10).

Como mostra a Figura 52, o polarizador circular possui duas faces. A Face 1, é um polarizador linear de amplo espectro. A Face 2 é, uma placa de onda $\lambda / 4$ (placa de quarto de onda), que introduz um atraso de $\pi / 2$, em um dos eixos em relação ao eixo perpendicular (HECHT, 2002). Para os polarizadores utilizados, $\lambda / 4=125 \mathrm{~nm}$, assim, a polarização é perfeitamente circular na faixa de $500 \mathrm{~nm}$, para o restante do espectro visível é elíptico.

Tabela 10. Especificações conforme fornecedor do polarizador.

\begin{tabular}{ll}
\hline Especificação Polarizador \\
\hline Transmissão & Simples (42\%) Paralelo (35\%); Cruzado (0.5\%) \\
Eficiência & $99.98 \%$ \\
Filme retardador & $125 \mathrm{~nm}$ \\
Espessura & $0.28 \mathrm{~mm}$ \\
Durabilidade & 500 Horas a $60{ }^{\circ} \mathrm{C}$ \\
Aplicações & Óculos 3D, Câmera, LCD, OELD
\end{tabular}

Fonte: https://3dlens.com/circular-polarizer-film-100x100mm.php

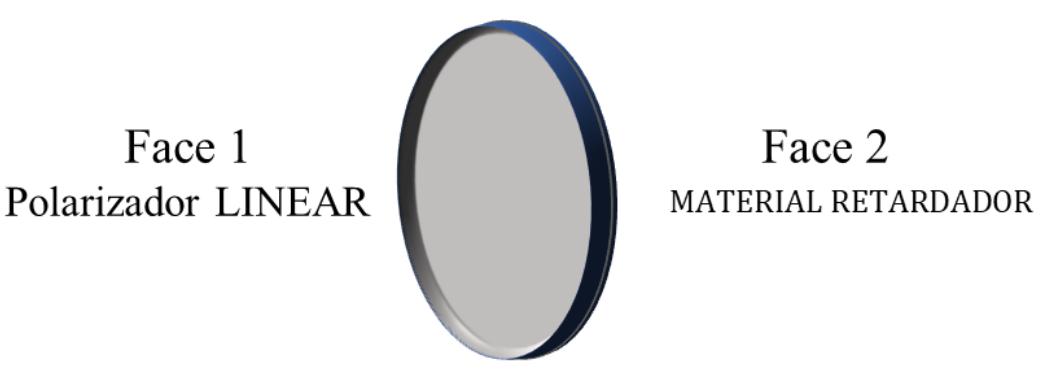

Figura 52. Esquema do polarizador circular utilizado nos experimentos. Em uma das faces possui polarização linear e na outra face um material retardador de quarto de onda. Essa configuração visa transformar a luz polarizada linearmente em luz polarizada circularmente e vice-versa. 
Para obter melhor posicionamento dos polarizadores foi observado o comportamento do espectro da luz transmitido em duas configurações: Modo de Transmissão e Modo de Reflexão, com as montagens experimentais como mostrado nas Figuras 53 e 54 respectivamente. Para essa investigação, cada polarizador foi acoplado em um goniômetro com incerteza $\pm 2^{\circ}$. Sendo assim, o posicionamento angular relativo dos polarizadores (P2 em relação ao polarizador P1), podia ser alterado em passos de $4^{\circ}$. Para cada posição relativa entre os ângulos de giro de $\mathrm{P} 1 \mathrm{e}$ P2, um espectro de luz transmitida por P2 era adquirido com espectrômetro de fibra acoplada (Ocean Optics, modelo USB-4000).

$\mathrm{Na}$ configuração do modo de reflexão, foram usados dois polarizadores do tipo horário (R) (Figura 54). Na saída da fonte de luz, foi acoplado um polarizador com a face linear para a fonte de luz e a face $\lambda / 4$ para o espelho, configuração semelhante ao segundo polarizador. Na saída do primeiro polarizador foi acoplado um material espalhador (phantom branco). Variando o ângulo do polarizador P2 em intervalos de $4^{\circ}$ analisamos o comportamento do espectro em ambos os sentidos (horário e anti-horário).

a)

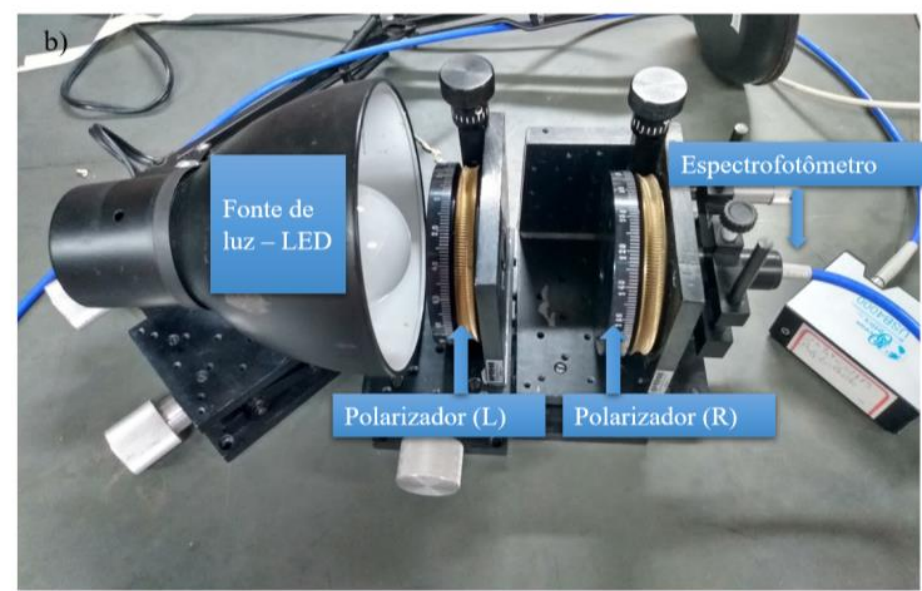

Figura 53. Montagem Experimental para verificar posicionamento dos polarizadores. Teste de modo de transmissão. a) Esquema do posicionamento dos polarizadores b) Imagem do experimento. 
a)

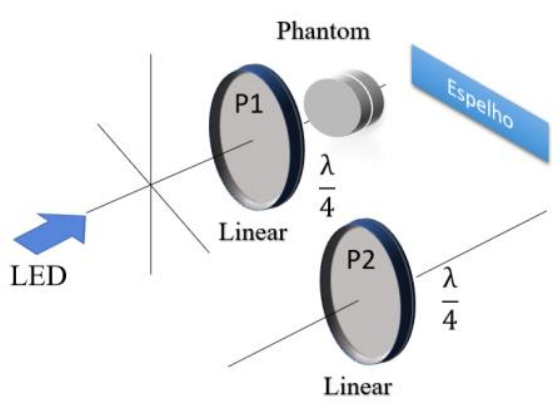

b)

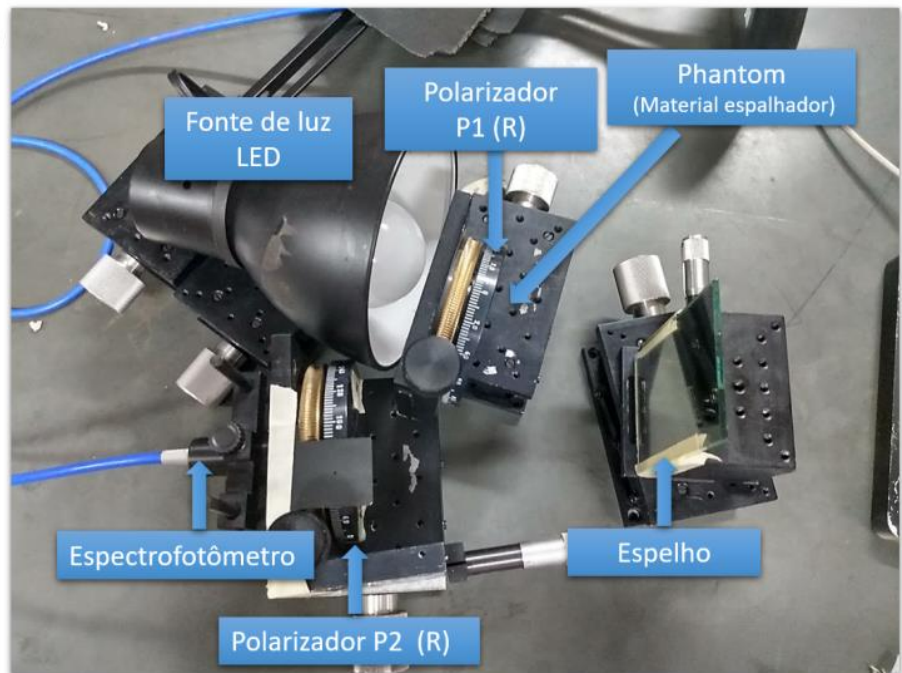

Figura 54. Montagem experimental para verificar o posicionamento dos polarizadores, posicionamento modo de reflexão. a) Esquema do posicionamento dos polarizadores b) Imagem do experimento.

\subsubsection{Resultados e Discussões}

Analisamos o comportamento do espectro de transmissão, para rotação angular relativa de $0^{\circ}, 30^{\circ}$ e $60^{\circ}$ (Figura 55 e 56). Zero graus de rotação representa a posição onde os polarizadores lineares de P1 e P2 estão alinhados. Os espectros apresentados não estão normalizados pelo espectro da fonte de luz (Figura 50). No caso de rotações relativas de $30^{\circ} \mathrm{e}$ $60^{\circ}$ (Figura 55), a intensidade da luz transmitida diminuiu consideravelmente, e na região de 500 - 700 nm do espectro começou a apresentar distorções. Já para rotação relativa de ângulos menores $\left(16^{\circ}\right)$ (Figura 56) pouca mudança se teve no perfil espectral, nos três espectros do perfil obtidos para rotações relativas para o sentido horário $\left(16^{\circ}\right)$, e no sentido anti-horário $\left(-16^{\circ}\right)$, em ambos os sentidos, na faixa de 500 a $700 \mathrm{~nm}$ não ocorreram mudanças significativas no perfil espectral. Esses resultados apontam que o uso de polarizadores circulares apresentam vantagens em relação a movimentação, garantindo que pequenas variações angulares causadas pelo movimento durante o posicionamento, gerem baixa modificação no perfil espectral. 


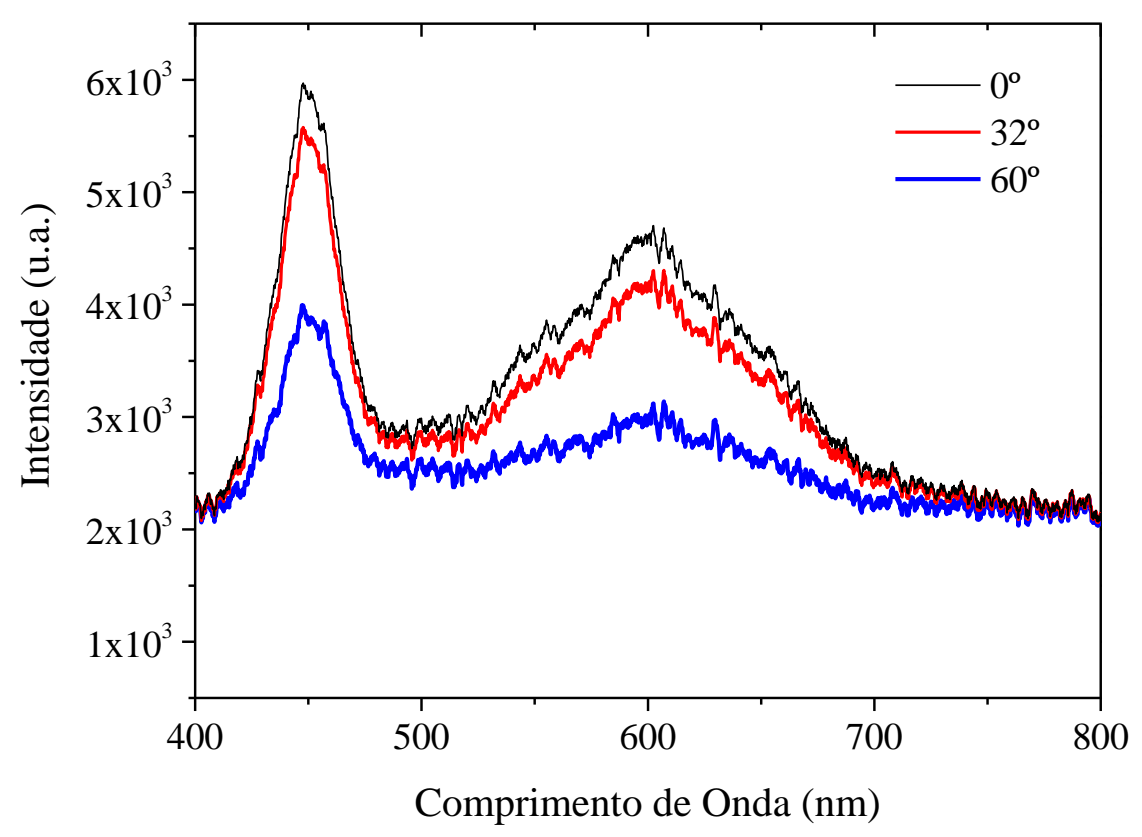

Figura 55. Espectro da lâmpada LED obtido pelo espectrômetro, realizando montagem do teste do modo de transmissão.

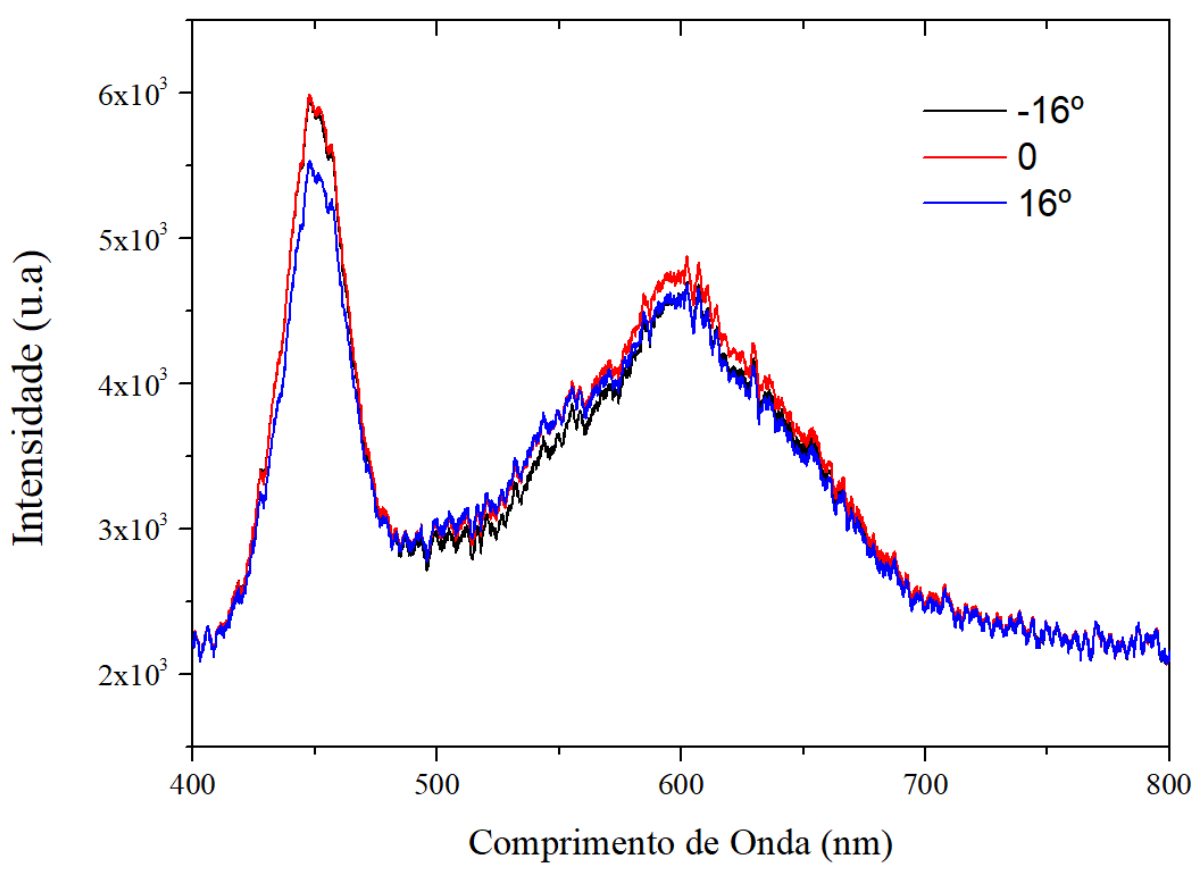

Figura 56. Espectro da lâmpada LED obtido pelo espectrômetro, realizando a montagem do teste do modo de transmissão variação de ângulos pequenos. 


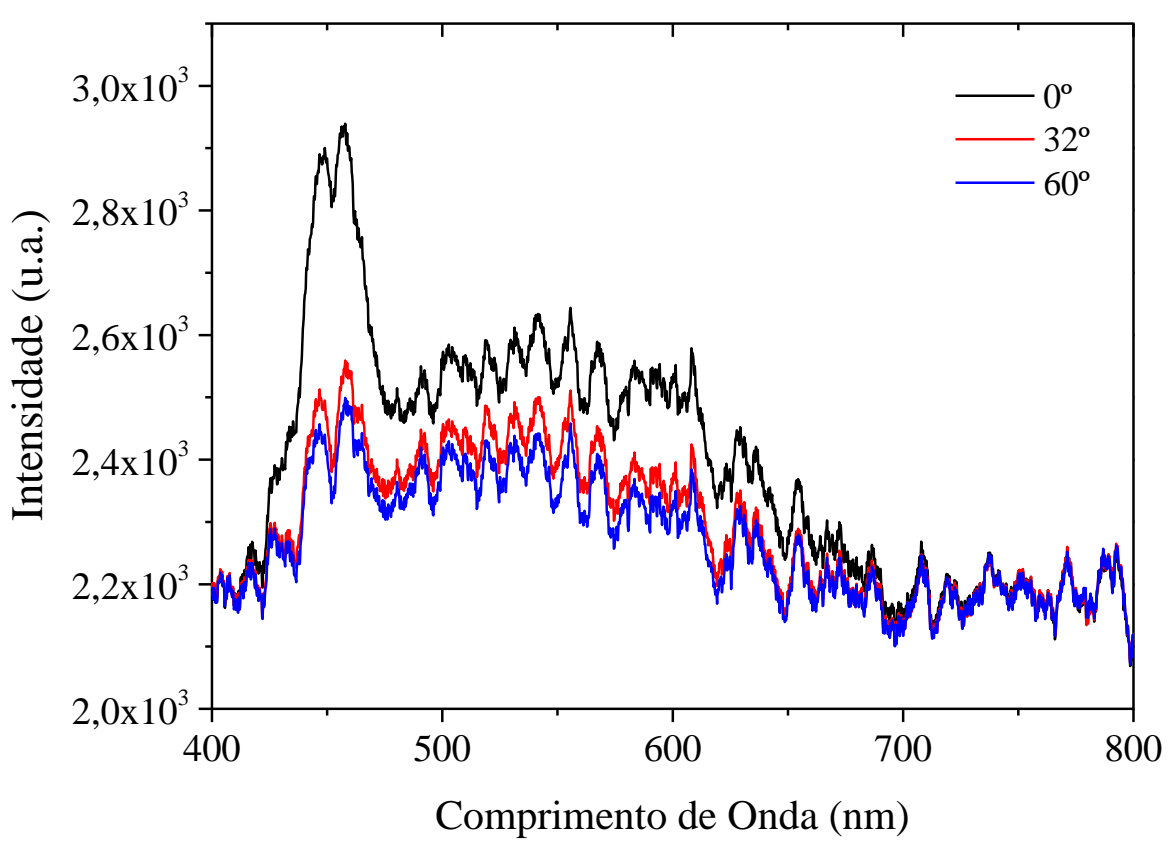

Figura 57. Espectro da lâmpada LED obtido pelo espectrômetro, realizando o experimento do teste de modo de reflexão.

A Figura 57 mostra a intensidade de luz que atinge o espectrômetro pelo modo de reflexão. Esse posicionamento é o mais próximo da nossa aplicação. A luz foi espalhada por um phantom acoplado no sistema (Figura 54). Variações maiores que $30^{\circ}$ na rotação relativa entre o polarizador P2 (acoplado ao espectrômetro) em relação ao polarizador de referência (P1, acoplado com a fonte de luz) causa diminuição na intensidade de luz refletida especularmente no pico de $\approx 460 \mathrm{~nm}$. Consequentemente nessa configuração, obtemos um espectro ruidoso devido ao uso do phantom com o intuito de simular o espalhamento causado na pele. Entretanto, nessa configuração, a rotação relativa entre os polarizadores causa baixa alteração na intensidade de luz transmitida na faixa de 500 a $700 \mathrm{~nm}$. Isso garante que no posicionamento realizado nos experimentos relatados no Capítulo 2, o uso de polarizadores lineares gerem baixo ruído nas imagens adquiridas.

\subsection{Metodologia para determinação da Curva de Sensibilidade da Câmera}

Para investigar a curva de sensibilidade da câmera (WebCam modelo Logitech HD ProC910) foi utilizado um monocromador Oriel Instruments (Modelo: MS257 - 77782). Este possui duas portas (entrada e saída da luz), ambas foram abertas com grade de $80 \mathrm{~mm}$. Na porta 
de entrada, foi acoplado uma fonte de Xenônio (Figura 58), com potência regulável ajustada em 500 W e na saída foi posicionado a câmera, configurada para obter as imagens com exposição máxima e fora de foco a fim de eliminar regiões de saturação.

O monocromador foi ajustado para realizar a variação do comprimento de onda em passos de $1 \mathrm{~nm}$ por segundo, no intervalo de 300 a $900 \mathrm{~nm}$. Com a câmera foi adquirido um vídeo da imagem da mudança dos comprimentos de onda e processadas em MATLAB (ANEXO 3).

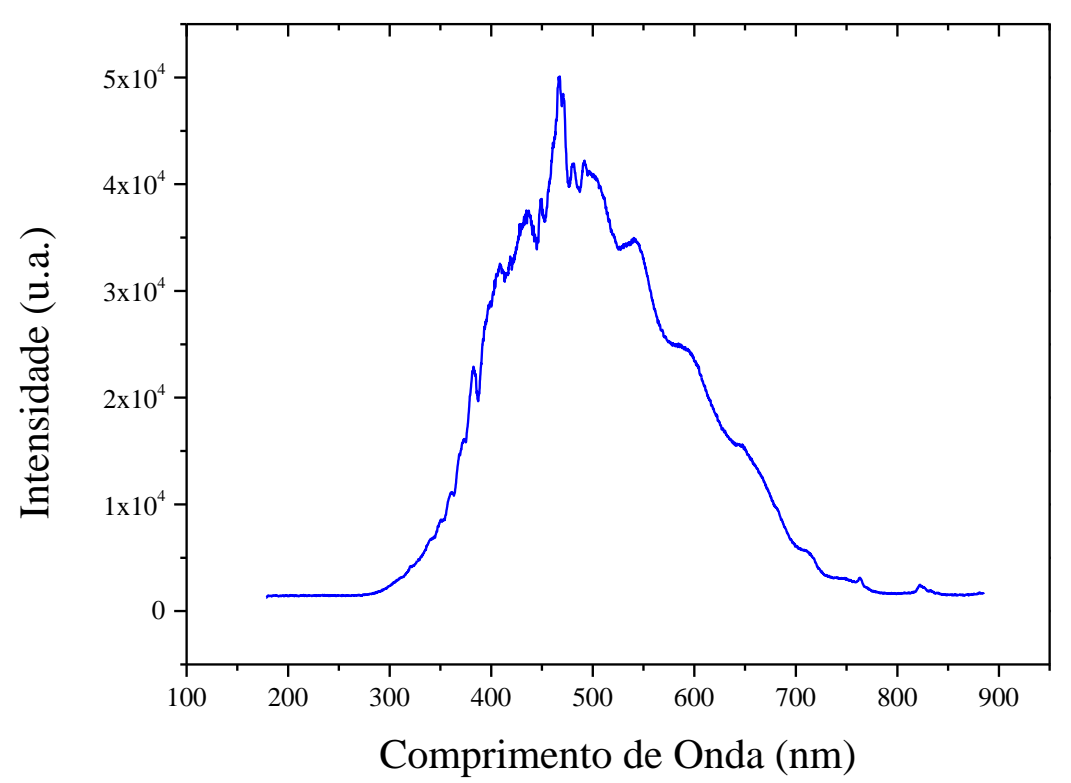

Figura 58. Espectro da lâmpada de xenônio utilizada na entrada do monocromador neste é possível observar um pico característico de alta intensidade na faixa de 450-550 nm. 


\section{Apêndice B -Resultado da Correlação}

A Tabela 11 mostra o mapa de correlação com os valores de $\Delta \mathrm{t}_{0,1} \mathrm{e} \Delta \mathrm{t}_{0,2}$, pressão arterial sistólica (SBP) e diastólica (DBP), Peso, Frequência (HR), Altura, Idade, Índice de Massa Corpórea (IMC) e rCRT de 22 participantes correspondentes aos experimentos descritos nos Capítulos 2 e 3.

Tabela 11. Mapa de correlação dos valores adquiridos no experimento. Dados de 22 participantes.

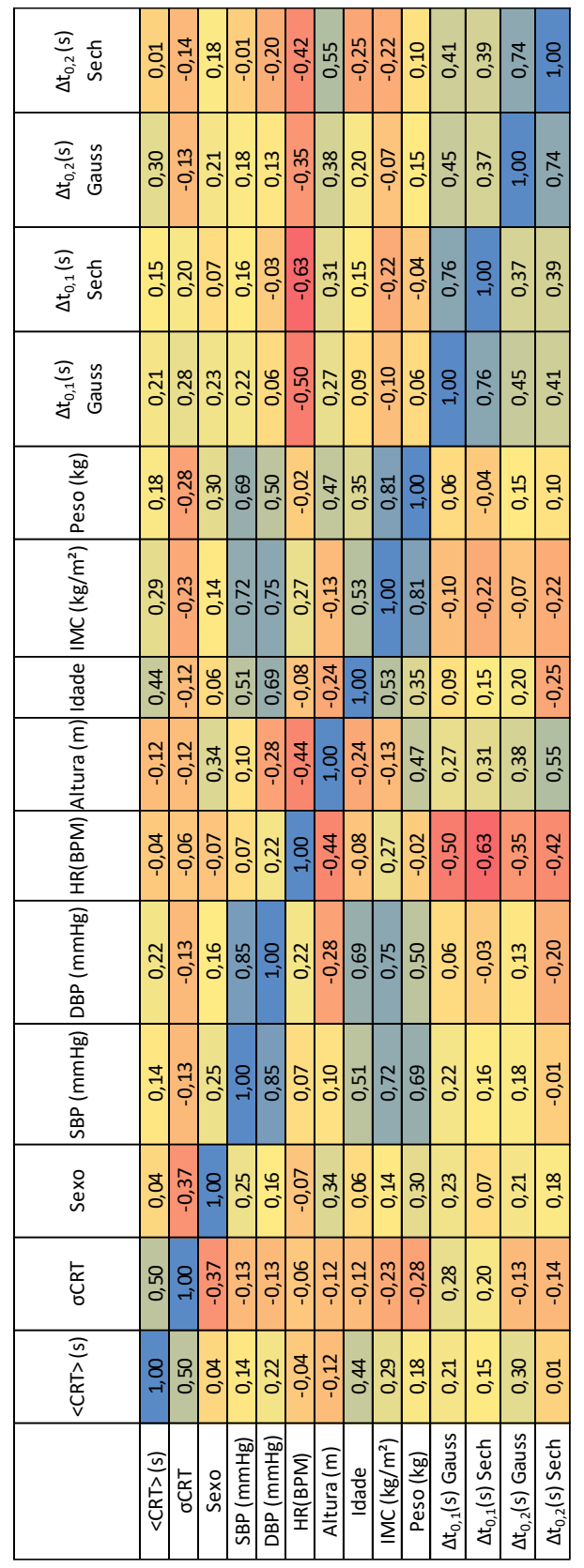




\section{ANEXO 1- Termo de Consentimento}

\section{TERMO DE CONSENTIMENTO LIVRE E ESCLARECIDO}

Você está sendo convidado (a) a participar, como voluntário (a), da pesquisa intitulada "Medidas Ópticas não Invasivas de Tempo de Resposta da Perfusão Sanguínea", conduzida pela pesquisadora do programa de pósgraduação em Física Aplicada à Medicina e Biologia (FAMB) da Universidade de São Paulo, Raquel Pantojo de Souza, e pelo pesquisador, professor doutor do Departamento de Física da Faculdade de Filosofia, Ciências e Letras da Universidade de São Paulo, George Cunha Cardoso.

Este estudo tem por objetivo analisar a rapidez na recuperação da cor da pele após uma leve pressão aplicada. Essas observações serão feitas em participantes de diferentes idades e fototipos de pele.

Você foi selecionado (a) por se encaixar no critério de seleção para a pesquisa, que consiste em ter no mínimo 20 anos. Caso aceite participar, você permanecerá sentado (a) por 15 minutos após a chegada à sala onde será realizado o experimento, durante todo o experimento, você não poderá utilizar aparelhos eletrônicos (celular etc.) e seu batimento cardíaco será monitorado. Será realizada a medição da altura e da pressão arterial. Assim que estabilizar o ritmo cardíaco, serão exercidas pressões, nas áreas previamente escolhidas, com pesos variando de $50 \mathrm{~g}$ a $1 \mathrm{~kg}$ durante cerca de $10 \mathrm{~s}$ e serão capturados vídeos de cerca de $30 \mathrm{~s}$ dessa região. Uma parte da sua testa e pé também poderá ser filmada (sem o uso dos pesos). Em alguns casos, o experimento será repetido, mas desta vez não será utilizado a câmera para a captação das imagens e sim um aparelho que emite luz para fazer uma imagem da região da pele. É previsto o tempo total de experimento de $45 \mathrm{~min}$. A obtenção das imagens será feita no Laboratório de Ensino de Óptica do Departamento de Física em uma única sessão, exceto em casos eventuais será repetido.

Sua participação é voluntária, não há risco previsível. A qualquer momento poderá desistir de participar e retirar o seu consentimento. Em caso de recusa, desistência ou retirada de consentimento não acarretará prejuízo a você. Também a qualquer momento poderá esclarecer dúvidas a respeito desta pesquisa. Nenhum procedimento invasivo será realizado e a sua identidade será preservada na divulgação dos resultados desta pesquisa. Em caso de se sentir constrangido ao ser filmado, garantimos que apenas o pesquisador responsável por este trabalho será o fotógrafo e o foco da câmera estará apenas na região escolhida. A sua participação nesta pesquisa contribuirá no desenvolvimento na área de métodos de monitoração cardiovascular. Não são previstos gastos com sua participação, mas caso haja despesas você terá direito de ressarcimento.

Caso concorde em participar desta pesquisa, assine ao final deste documento, que possui duas vias, sendo uma delas sua, e a outra, do pesquisador responsável. responsáveis:

Você poderá tirar suas dúvidas sobre o projeto agora ou a qualquer hora, pelo contato dos pesquisadores

Raquel Pantojo de Souza. Telefone: (15) 98178-3660

Email: raquel.pantojo.souza@usp.br

Prof. Dr. George Cunha Cardoso. Telefone: (16) 99402-5515

Email: gcc@usp.br

Dúvidas sobre questões éticas a respeito deste projeto entre em contato com o Comitê de Ética em Pesquisa - CEP.

Comitê de Ética em Pesquisa da Faculdade de Filosofia, Ciências e Letras de Ribeirão Preto - USP

Avenida Bandeirantes, 3900 - Bloco 01 - Prédio da Administração-SALA O7- 14040-901 - Ribeirão Preto - SP Brasil Fone: (16) 3315-4811 E-mail: coetp@ffclrp.usp.br

Nome do Participante (impresso ou letra de forma)

Nome da Pesquisadora (impresso ou letra de forma)

Nome do Orientador (impresso ou letra de forma)

Ribeirão Preto, de de Hora: 


\section{ANEXO 2}

Questionário utilizado como complemento para base de dados da pesquisa - via Google forms

- Nome

- Idade

- Altura (cm)

- Peso $(\mathrm{Kg})$

- O peso que você colocou na resposta anterior pode apresentar incerteza de $2 \mathrm{Kg}$ ?

- Você ingeriu café ou energético hoje?

- Você faz exercícios físicos? Quantas vezes na semana?

- Qual a Pressão Arterial (mmHg) normalmente?

Perguntas somente para mulheres:

- Faz uso de anticoncepcional?

- Quantos dias desde a última menstruação?

https://docs.google.com/forms/d/e/1FAIpQLScbEBvmtmfcRCGxYuNMPbNlKv_1OHRIX4 wG9pZjgbQp3AYmpA/viewform 


\section{ANEXO 3}

Link para acesso dos programas escritos em MATLAB

https://github.com/raquelpantojo/rCRT-CappillaryRefillTime-.git

i. Determinação de rCRT

ii. Determinação de $\mathrm{CHbO} 2, \mathrm{CHbr}$, Melanina

iii. PDA com função gaussiana e secante hiperbólica 